\title{
Behavior that Hurts: Theoretical Orientation, Terminology, and Diagnosis of Self-injury
}

Susannah C. Rowan Flamm

West Virginia University

Follow this and additional works at: https://researchrepository.wvu.edu/etd

\section{Recommended Citation}

Flamm, Susannah C. Rowan, "Behavior that Hurts: Theoretical Orientation, Terminology, and Diagnosis of Self-injury" (2011). Graduate Theses, Dissertations, and Problem Reports. 3477.

https://researchrepository.wvu.edu/etd/3477

This Dissertation is protected by copyright and/or related rights. It has been brought to you by the The Research Repository @ WVU with permission from the rights-holder(s). You are free to use this Dissertation in any way that is permitted by the copyright and related rights legislation that applies to your use. For other uses you must obtain permission from the rights-holder(s) directly, unless additional rights are indicated by a Creative Commons license in the record and/ or on the work itself. This Dissertation has been accepted for inclusion in WVU Graduate Theses, Dissertations, and Problem Reports collection by an authorized administrator of The Research Repository @ WVU.

For more information, please contact researchrepository@mail.wvu.edu. 
Behavior that Hurts:

Theoretical Orientation, Terminology, and Diagnosis of Self-injury

Susannah C. Rowan Flamm

Dissertation submitted to the College of Human Resources and Education

at West Virginia University in partial fulfillment of the requirements

for the degree of

\title{
Doctor of Philosophy \\ in \\ Counseling Psychology
}

\author{
James Bartee, Ph.D., Chair \\ Jeffrey Daniels, Ph.D. \\ Margaret Glenn, Ed.D. \\ D.J. Hendricks, Ed.D. \\ Ian Kellems, Ph.D.
}

\section{Morgantown, West Virginia \\ 2011}

Keywords: theoretical orientation, diagnosis, terminology, self-injury 


\section{ABSTRACT \\ Behavior that hurts: Theoretical orientation, terminology, and diagnosis of self-injury}

\section{Susannah C. Rowan Flamm}

Self-injurious behavior prevalence continues to rise in both adolescent and adult nonclinical populations and within adolescent and adult clinical populations. Despite a large volume of literature regarding the antecedents and functions of self-injury, exploration of clinician factors in regard to these clients is sparse. This study examined the associations among 346 doctoral level clinicians' theoretical orientations, preferred terminology to describe self-injurious behaviors, and preferred diagnoses for clients who engage in selfinjury. Therapist variables such as age, years in practice, and gender were examined for their association with terminology and diagnostic preferences. Chi-square analyses were conducted for the two-way interactions and a multi-way frequency analysis using loglinear modeling was used to examine the possible interaction of three categorical variables. Significant associations were found between theoretical orientation and preferred diagnosis, preferred terminology and preferred diagnosis, and theoretical orientation, preferred terminology, and preferred diagnosis together. Additionally, age, years in practice, and gender were significantly associated with preferred terminology, but not with preferred diagnosis. Clinical implications and limitations are discussed as well as suggestions for future research. 


\section{Acknowledgements}

I would like to take the opportunity to thank several people who provided valuable support and guidance throughout the process of completing my doctoral training and dissertation. Foremost, I would like to express sincere thanks to my chair, Dr. James Bartee who never lost faith in my abilities and who always had the right mix of encouragement and support. I also extend my gratitude to the other dissertation committee members, Dr. Jeffrey Daniels, Dr. Margaret Glenn, Dr. D.J. Henricks, and Dr. Ian Kellems for their time, valuable feedback, and patience while this project matured. Special thanks goes to Dr. D.J. Hendricks for all the extra time she put in to help me sift through the study data as well as the time spent in the classroom as my statistics professor. I finally understand the multitude of available statistical analyses and what they all mean.

Additionally, I would like to thank my friends who kept encouraging me to finish despite several major roadblocks and side-tracks. Specifically, I thank Sarah Lyle and Sam Schwarz for shared dinners, breaks at the dog park, and most importantly, the opening of their home to me and my beloved animals without question or concern for how long the stay might be. Furthermore, I would like to take this opportunity to thank a number of women who have become good friends despite long distances. Many have become chosen family members: Jean "Baba" Forant, Samantha Vinke, Astrid Grove, Cherie Ackerson, Alisa Starkweather, Becky Schupbach, and Lushanya Echeverria. Thanks for the long talks and singing in the dark of the night. Finally, to good friend Deb Campbell, for her support, girl talk, and hot chocolate at Starbucks.

Most importantly, I would like to thank Dr. Maxine Kane who has been my mentor throughout my graduate studies. I am exceedingly grateful for the tremendous amount of time and energy she expended in helping me reach my goal of becoming a psychologist. She was my sounding board for every imaginable topic and the kick in the rear when I stalled out. Additionally, she constantly reminded me that if getting a Ph.D. was easy, everyone would have one. There are countless ways she has changed my life, far too many to count; she not only helped shaped the professional I have become but also the woman I have grown to be. I will be forever grateful and feel very blessed to have her in my life. Thanks Max. 
Table of Contents

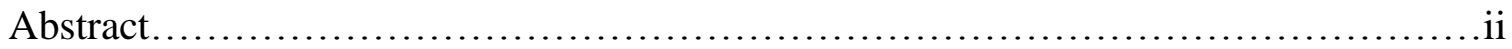

Acknowledgements.........................................................

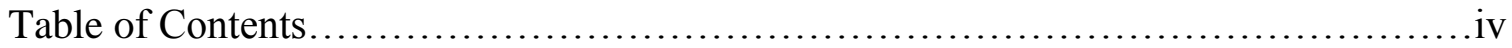

List Figure/Tables......................................................................viii

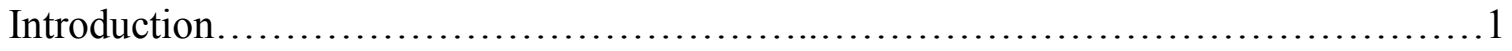

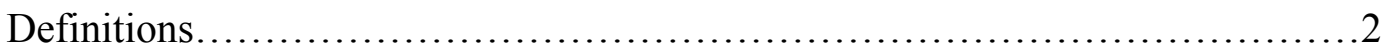

Diagnostic Choice..................................................4

Clinician Factors....................................................... 5

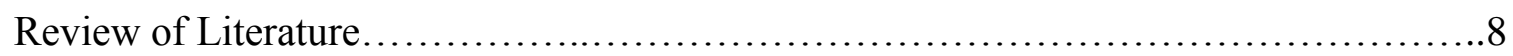

Definition Difficulty...............................................8

Prevalence Rates of Self-Injury.....................................17

General Population Non-Clinical................................ 18

College Age Non-Clinical........................................19

Adult Clinical..................................................21

Adolescent Non-Clinical..........................................21

Adolescent Clinical.............................................. 22

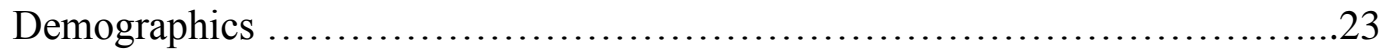

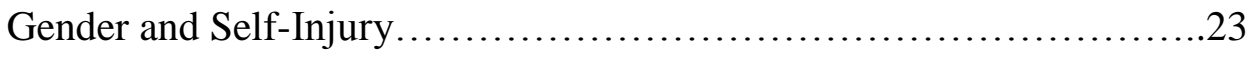

Ethnicity and Self-Injury..................................... 25

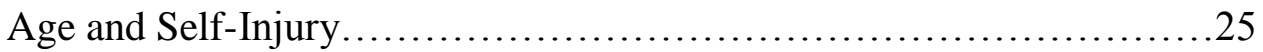

Sexual Orientation and Self-Injury..............................26 
Co-Morbidity with Self-Injury........................................27

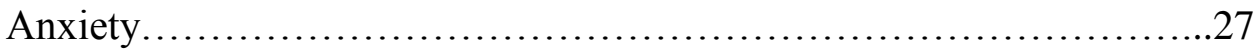

Borderline Personality Disorder................................28

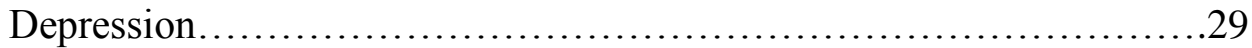

Dissociative Identity Disorder.................................... 30

Post-Traumatic Stress Disorder.................................. 31

Explanatory Models for Self-Injury...................................... 35

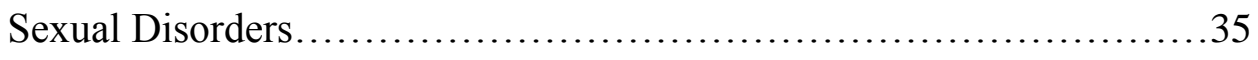

Suicide/Anti-Suicide............................................. 36

Punishment.................................................. 37

Behavioral/Environmental......................................38

Physiological/Biological...................................... 38

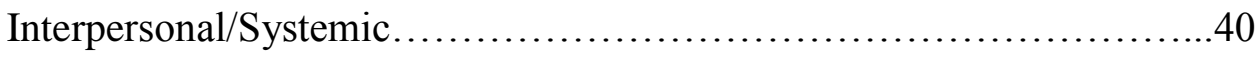

Anti-Dissociation/Depersonalization.............................41

Affect Regulation............................................42

Theoretical Formulation and the Treatment of Self-Injury....................44

Psychodynamic..............................................45

Cognitive-Behavioral...........................................48

Dialectical-Behavioral.......................................50

Feminist................................................51

Multi-Modal....................................................53

Therapist Factors.................................................56

Research Hypotheses.............................................58 
Methods.

Sample .61

Procedure .62

Data Analysis. .63

Results. .67

Terminology Preference.............................................68

Theoretical Orientation and Terminology ...............................69

Theoretical Orientation and Diagnosis.................................. 72

Terminology and Diagnosis......................................... 73

Theoretical Orientation, Terminology, and Diagnosis $\ldots \ldots \ldots \ldots \ldots \ldots \ldots \ldots \ldots . . . \ldots 4$

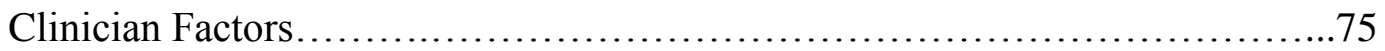

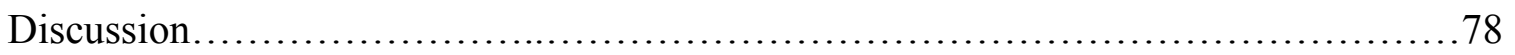

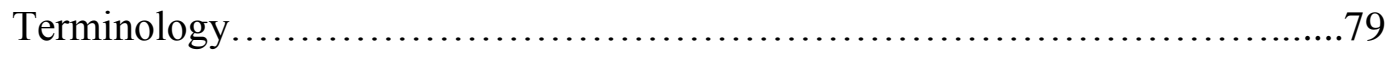

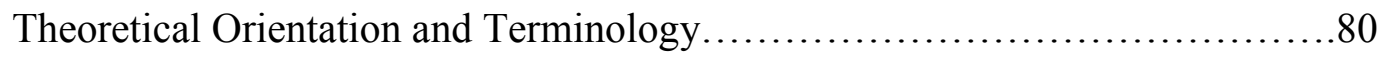

Theoretical Orientation and Diagnosis................................. 80

Terminology and Diagnosis......................................... 82

Theoretical Orientation, Terminology, and Diagnosis $\ldots \ldots \ldots \ldots \ldots \ldots \ldots \ldots \ldots . \ldots 3$

Clinician Characteristics..............................................84

Limitations.................................................... 87

Directions for Future Research.....................................90

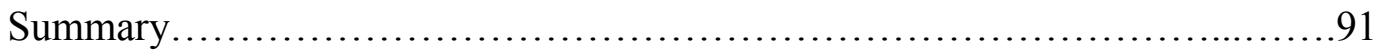

References.............................................................94

Appendix A: IRB Consent.................................................134 
Appendix B: Participant Invitation........................................ 137

Appendix C: Survey......................................................... 138

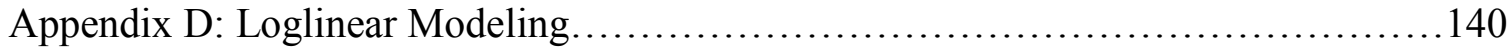

Appendix E: Additional Statistical Tables.........................................143 


\section{List of Figure/Tables}

Figure 1. Flow Chart for Self-Injury Determination..........................13

Table 1. Frequency Distribution: Terminology $\quad$..........................68

Table 2. Frequency Distribution: Theoretical Orientation......................70

Table 3. Frequency Distribution: Theoretical Orientation x Terminology.........71

Table 4. Chi-Square: Feminism x Respondent Age.......................... 71

Table 5. Frequency Distribution: Diagnosis.............................. 72

Table 6. Frequency Distribution: Theoretical Orientation x Diagnosis.............73

Table 7. Frequency Distribution: Diagnosis x Terminology...................74

Table 8. Frequency Distribution: Terminology x Age $\quad$....................... 77

Table 9. Frequency Distribution: Terminology x Years in Practice................77

Table 10. Frequency Distribution: Terminology x Gender..................... 77

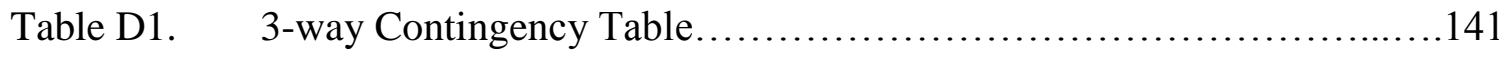

Table E1. Crosstabulation: Theoretical Orientation x Terminology................143

Table E2. Frequency Distribution: Feminist Theoretical Orientation...............143

Table E3. Crosstabulation: Theoretical Orientation x Diagnosis................. 144

Table E4. Crosstabulation: Terminology x Diagnosis......................... 144

Table E5. Chi-Square: Gender x Terminology $\quad$............................ 145

Table E6. Chi-Square: Gender x Diagnosis............................. 145

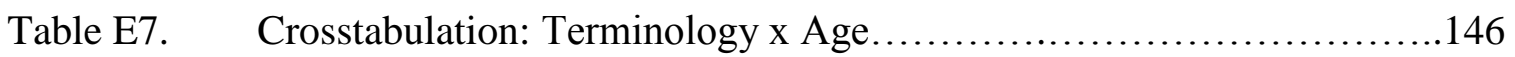

Table E8. Chi-Square: Terminology x Age.................................. 146

Table E9. Crosstabulation: Diagnosis x Age.............................. 147

Table E10. Chi-Square: Diagnosis x Age................................... 147 
Table E11. Crosstabulation: Terminology x Years in Practice.....................148

Table E12. Chi-Square: Terminology x Years in Practice.........................148

Table E13. Chi-Square: Diagnosis x Years in Practice...........................149 


\section{Behavior that Hurts:}

\section{Theoretical Orientation, Terminology, and Diagnosis for Self-Injury}

Self-injury has a long history dating back centuries. The behavior appears in classical and contemporary literature from Oedipus Rex in 500 b.c.e. to the poetry of Silvia Plath and the popular Harry Potter series (Rowling, 1999). In western culture, the prevalence of self-injury has shown a steady rise among high school and college age populations with reported incidences of self-injury ranging from a rate of 400 per 100,000 in the 1980 's to 1000 per 100,000 in the late 1990 's (Favazza, 1998; Pattison \& Kahan, 1983; Walsh, 2006). More specifically, rates of adolescent self-injury in nonclinical samples vary from 4\% - $15 \%$ (Galley, 2003; Whitlock, Eckenrode, \& Silverman, 2006), while young adult/college student samples rates of self-injury range from $12 \%$ to 17\% (Favazza, 1992; Favazza, DeRosear, \& Conterio, 1989; Whitlock, Powers, \& Eckenrode, 2006) to a staggering $38 \%$ (Gratz, Sheree, \& Roemer, 2002).

In clinical populations, the prevalence rates are even higher. Adolescent clinical populations show prevalence rates of self-injury between 30\% to $60 \%$ (Darche, 1990; DiClemente, Ponton, \& Hartley, 1991; Nock \& Prinstein, 2005; Pattison \& Kahan, 1983), while adult studies have found rates ranging from a low of $20 \%$ (Briere \& Gil, 1998) to 35\% in mixed clinical samples (Claes et al., 2010; Zlotnick, Mattia, \& Zimmerman, 1999) to highs of $70 \%$ (Gunderson, 1991) and even $90 \%$ for an inpatient population diagnosed with borderline personality disorder (Zanarini et al., 2008).

These high prevalence rates make it likely that practicing clinicians will encounter this growing phenomenon throughout their career. Self-injury itself may be seen as challenging to clinicians for a variety of reasons. First is the widespread belief that self- 
injury is long-standing, complex, and difficult to treat (Favazza, 1996; Hoffman \& Kress, 2010; Klonsky \& Muehlenkamp, 2007; Matsumoto, Azekawa, Yamaguchi, Asami, \& Iseki, 2004; Muehlenkamp, 2006). Second, evidence in the literature suggests that many of those who self-injure do not report the behavior or are reticent to reveal the behavior to anyone which frequently results in their going under-treated or untreated altogether (Adler \& Adler, 2007; Conterio \& Lader, 1998; Favazza \& Conterio, 1988; Hawton, Rodham, Evans, \& Weatherall, 2002; Hoffman \& Kress, 2010). Third, clients who self injure often evoke negative countertransference from treatment providers (Connors, 2000; Deiter \& Pearlman, 1998; Gallop, Lancee, \& Garfinkel, 1989; McIntyre \& Schwartz, 1998; Perseius, Kaver, Eckahl, Asberg, \& Samuelsson, 2007). Fourth, those clients who engage in self-injury often are heavy users of the mental health system, both as outpatients and inpatients straining already limited resources (Favazza \& Conterio, 1988; Commons-Treloar \& Lewis, 2008; Zanarini, Frankenburg, Khera, \& Bleichmar, 2001). Last and perhaps most important is the strong evidentiary link between self-injury and other behaviors such as suicide and the frequent existence of co-morbidly occurring disorders (Becker, 2000; Dyer et al., 2009; Hawton et al., 2009; Heath, Baxter, Toste, \& McLouth, 2010; Herman, 1992a, 1992b; Hodges, 2003; Lang et al., 2003; Tuisku et al., 2009; Wachter, Murphy, Kennerley, \& Wachter, 2009; Yates, 2004).

\section{Definitions}

In spite of the high prevalence rates of self-injury, its discussion in the professional literature is fraught with inconsistencies further complicating the clinician's treatment of the self-injuring client. These varying and sometimes contradictory perspectives range from the terminology used to label the behavior to recommended 
diagnosis and treatment. Experts in the field differ in the way they frame the behavior and the importance they place on it when diagnosing a client's condition and determining the extent and manner of treatment (Adler \& Adler, 2007; Andover, Pepper, \& Gibb, 2007; Brown and Bryan, 2007; Chapman, Gratz, \& Brown, 2006; Connors, 2000; Gratz, 2007; Herman, Perry, \& van der Kolk, 1989; Linehan, 1993; Mazelis, 1992; Nock, 2009a; Trepal, 2010; Walsh, 2006).

The term professionals use to label a concept is a basic building block for forming a common understanding of the behavior. Within the exigent literature, self-injury (Connors, 1996a,1996b; Walsh, 2006) has been referred to as non-suicidal self-injury (Brown, Comtois, \& Linehan, 2002; Glassman, Weierich, Hooley, Deliberto \& Nock, 2004; Heath, Toste, Nedecheva, \& Charlebois, 2008), self-mutilation (Conn \& Lion, 1983; Favazza, 1989; Suyemoto, 1998; Walsh \& Rosen, 1988; Zila \& Kiselica, 2001), self-cutting (Suyemoto \& MacDonald, 1995), self-inflicted violence (Alderman 1997; Blessing, 1990; Mazelis, 1990), self-abuse (Davies \& Frawley, 1994), self-destructive behavior (Figueroa, 1988), self-damaging behavior (Courtois, 1988), self-injurious behavior (Muehlenkamp \& Gutierrez, 2004), self-harm (Green, 2008; Lloyd-Richardson, 2008; Nicholson, 2004), and deliberate self-harm (Pattison \& Kahan, 1983; Gratz, 2001; Hurry 2000). More importantly, these varying terms frequently describe different behaviors with wider or narrower ranges of focus. There is much controversy regarding which behaviors should be included or excluded from the definition. For example, deliberate self-harm, the term most frequently used in the United Kingdom, includes such acts as self-poisoning which may be more accurately labeled as a suicide attempt (Johnston, Cooper, Webb, \& Kapur, 2006; Joyce, Light, Rowe, Cloninger, \& Kennedy, 
2010; Skeeg, 2005; Welch, Sylvers, Linehan, Chittams, \& Rizvi, 2008). Other behaviors have also been included, which have questionable self-injury intent such as pill abuse and eating disorders (Laye-Gindhu \& Schonert-Reichel, 2005).

Using interchangeable terms often leads to widely varying prevalence rates. In addition, the inconsistency can limit validity and reliability in research measures, can prevent useful comparisons among studies, and can cause considerable confusion in the clinical research especially for treating clinicians (Claes \& Vandereycken, 2007; DeLeo $\&$ Heller, 2004). In addition, the behaviors that are included or excluded in defining the particular term used could change the way a clinician conceptualizes self-injury in the pursuit of a proper diagnosis.

\section{Diagnostic Choice}

Experts in the field have been divided over the appropriate diagnosis for clients who engage in self-injury. The most frequently used and studied diagnosis for clients who engage in self-injury is Borderline Personality Disorder (BPD)(Brodsky, Cloitre, \& Dulit, 1995; Brown et al., 2002; Favazza, 1998; Gratz \& Gunderson, 2006; Hulbert \& Thomas, 2010; Lieb, Zanarini, Schmahl, Linehan, \& Bohus, 2004; Commons-Treloar \& Lewis, 2008; Zanarini, Frankenburg, Hennen, Reich, \& Silk, 2006; Zanarini et al., 2008). Other experts in the field have suggested alternative diagnoses that do not have selfinjury explicit in the criteria but where self-injury often occurs including depression and other mood disorders (Dyer et al., 2009; Haw, Houston, Townsend, \& Hawton, 2002; O’Connor, Rasmussen, \& Hawton, 2010; Tuisku et al., 2009; Yates, 2004). Even more prevalent has been the shift toward a diagnosis of post-traumatic stress disorder (PTSD) for those clients who self-injure and also have a history of trauma (Herman et al., 1989; 
Miller, 1996; Trippany, Helm, \& Simpson, 2006). Some experts have gone so far as to suggest a separate clinical syndrome (Herman, 1992a, 1992b; Herman, Perry, \& van der Kolk, 1989; Kahan \& Pattison, 1984; Klonsky, 2007b; Muehlenkamp, 2005; van der Kolk, 1989; Wilkerson \& Goodyer, 2011). As a result, non-suicidal self-injury is now being considered for inclusion in the upcoming DSM-V within the child and adolescent disorders section (http://www.dsm5.org/ProposedRevisions/Pages/proposedrevision.aspx?rid=443).

Other experts believe that the conceptualization of self injury has been too dichotomous particularly in terms of borderline personality disorder versus posttraumatic stress disorder and have focused on the overlap of these disorders or the cooccurrence of multiple disorders on both axis I and II. They suggest that if clinicians look deeper than the self-injury behavior and consider how symptoms may be operating at different levels and serving different functions, multiple diagnoses may be appropriate (Becker, 2000; Gunderson \& Sabo, 1993; Harned, Jackson, Comtois, \& Linehan, 2010; Hodges, 2003; Murray, 1993; Ochberg, 1991).

\section{Clinician Factors}

Given the varied and sometimes conflicting information and research regarding self-injury and its diagnosis, clinicians have developed multiple approaches to treating clients who self-injure. Included among these are dialectical behavioral therapy (DBT), specific cognitive behavioral approaches, psychodynamic approaches, and multi-modal approaches (Aviram, Hellerstein, Gerson, \& Stanley, 2004; Chiesa, Sharp, \& Fonagy, 2011; Gratz, 2007; Gratz \& Gunderson, 2006; Herman, 1992b; Linehan, 1993; Muehlenkamp, 2005, 2006; Nock, 2009a; van der Kolk, 1989; Walsh \& Rosen, 1988). 
While it is evident that the literature is replete with information regarding selfinjury, including who self injures and why and suggested terminology and diagnoses, little information exists about clinician factors that may contribute to a professional's choice of terminology and diagnosis when treating a client who self injures. For example, when confronted with varying information, does the clinician's age, gender, years of practice, or theoretical orientation affect his or her labeling of self injurious behavior and the diagnosis he or she most frequently ascribes to clients who engage in self injurious behavior?

This study used survey methodology to answer some of these questions. More specifically, it examined the effect of the theoretical orientation of the clinician on his or her preferred terminology to describe self-injurious behavior. Secondarily, the study examined the effect of the theoretical orientation of the clinician on his or her preferred diagnosis assigned to clients who self-injure. Thirdly, this study examined the possible effect of terminology on diagnosis and the possible interaction effect of theoretical orientation of the clinician, preferred terminology, and preferred diagnosis. Fourth and finally, the characteristics of the therapist such as age, gender, and years in practice were examined for their effect on theoretical orientation, preferred terminology, and preferred diagnosis.

The results of this study added to the growing evidence regarding the need for a single, unified, reliable and well-defined term to describe self-injurious behaviors. The study has laid the groundwork for future research into what factors influence choice of terminology and possibly diagnosis, particularly in regard to clinician factors. Additionally, this study added further evidence of the multiple diagnoses that clinicians 
assign to those who self-injure varying across axis I and axis II. As these issues are resolved, a distillation of therapeutic approaches may emerge and training of future clinicians may be more focused and thorough. 


\section{Chapter 2}

\section{Review of the Literature}

Self-injury has a long history and continues to create controversy in the search for appropriate definitions, diagnosis, and treatment. While the literature is filled with information regarding who self-injures and why they do so (Selby, Anestis, \& Joiner, 2008; van der Kolk, Perry, \& Herman, 1991; Walsh, 2006; Wedig \& Nock, 2007; White, Trepal-Wollenzier, \& Nolan, 2002; Winchel \& Stanley, 1991; Wise, 1990; Woods, 1988; Yates, 2004; Zanarini, 1993), the factors that influence terminology and diagnosis have been sparse. There is evidence of a growing number of people who engage in selfinjurious behavior, increasing the likelihood that counseling psychologists will encounter these clients in various treatment settings. A common language regarding self-injury is needed to assist in professional communication, research, and proper diagnosis and treatment.

\section{Definitional Difficulty}

Self-injury is associated with many terms and definitions: para-suicidal behavior, self-mutilation, self-destructive behavior, self-damaging behavior, deliberate self-harm, self-inflicted violence, self-injurious behavior, self-wounding, para-suicide and self-abuse (Connors, 1996b; Favazza, 1989; Huband \& Tantam, 1999; Nock \& Prinstein, 2004;

Ogundipe, 1999; Tantam \& Whittaker, 1992). These terms have all been used at different times by different researchers, for different purposes, and continue to confound and complicate research in this area.

One of the earliest references to self-injury is from the 5th century b.c.e. in Book Six of History where Herodotus described the story of a "deranged, probably psychotic" 
Spartan leader who sliced his flesh into strips, working upwards on his body starting with the shins (as cited in Favazza, 1998). The Christian bible in the gospel of Mark described a man who was believed to be possessed and would cut himself deliberately with stones (as cited in Velez, 2007). Later, Bergmann (1846) published the first medical article on a case report of a 48 year-old woman who removed one eye and during hospitalization, asked doctors to remove her legs and feet (as cited in Favazza, 1996). Boston Corbett, the man who shot John Wilkes Booth, Abraham Lincoln's assassin, was known to engage in self-castration (Swanson, 2006). In 1969, Pao explored the syndrome of "delicate selfcutting" where he discussed "delicate" and "coarse" self-cutting within a psychiatric population. Almost a decade later, Simpson (1976) explored a group of "wrist-slashers" in a psychiatric population.

The term self-mutilation was first used extensively by Ross and McKay (1979) and was then adopted as the terminology of choice by Favazza and used in his subsequent works (Favazza \& Conterio, 1988; Favazza, 1989). The term self-mutilation is used most often within the literature, regardless of time frame (Andover et al., 2007; Bennum \& Phil, 1983; Brain, Haines, \& Williams, 1998; Conn \& Lion, 1983; Connors, 1996a; Derouin \& Bravender, 2004; Favazza, 1989; Gratz, 2001; Nock \& Prinstein; 2005; Ray, 2007; Simpson \& Porter, 1981; Suyemoto, 1998; Turell \& Armsworth, 2000). Favazza’s (1998) definition of self-mutilation is most widely accepted: the deliberate, direct destruction or alteration of body tissue without conscious suicidal intent. Further, in Favazza's research he excluded acts of body modification that are culturally or socially sanctioned, i.e. tattooing or piercing (1996). Favazza identified three categories of selfmutilation: major, which entails drastic acts of self-injury including self-castration, 
amputation or removal of an eye; stereotypic, which includes head banging, biting and repetitive skin scratching; and moderate/superficial, which is the use a variety of sharp instruments to make controlled and relatively shallow cuts to the skin many of which break the skin versus repetitive scratching which does not.

Walsh and Rosen (1988) developed a different definition of self-mutilation but also included a statement about social acceptability. Walsh and Rosen's (1988) definition of self-mutilation is "behavior that is deliberate, non-life-threatening, selfeffected bodily harm or disfigurement of a socially unacceptable nature" (p.10). However, as Connors (2000) pointed out, self-mutilation is often not an accurate descriptor, because some behaviors do not include mutilation per se, such as headbanging, punching, and ingesting objects. Further, self-mutilation may imply that a person has purposefully and severely altered his or her body. For instance, under selfmutilation in the online Merriam-Webster Medical Dictionary, the definition of mutilation is to "deprive of a limb or other essential part, making imperfect by removing or irreparably damaging parts" (www.merriam-webster.com/dictionary/selfmutilation).

This severe level of behavior is not always the case. Using the term selfmutilation may cause a clinician to envision hideous disfigurement such as selfamputation or self-castration while these types of behavior are in fact extremely rare (Alderman, 1997; Connors, 2000). Similarly, the term "self-destructive behavior" (SDB) does not adequately describe a behavior that may not be damaging and rarely occurs with the intent of destruction (Connors, 2000). Other researchers have chosen different terminology in order to reflect cultural differences, to include/exclude different 
behaviors, and to be more or less descriptive (Connors, 2000; Lloyd-Richardson, 2008; Walsh, 2006).

In the United Kingdom (U.K.), most research is conducted on behavior that is termed deliberate self-harm (DSH) (Owens, Horrocks, \& House, 2002; Rodham, Hawton, \& Evans, 2004; Taiminen, Kallio-Soukainen, Nokso-Koivisto, Kaljonen, \& Helenius, 1998; Taylor, Hawton, Fortune, \& Kapur, 2010; Tuisku et al., 2009; Webb, 2002; Zahl \& Hawton, 2004). The accepted definition of DSH includes self-poisoning and even suicide attempts (Comtois, 2002; Goddard, Subotsky, \& Fombonne, 1996; Milnes, Owens, \& Blenkiron, 2002; Romans, Martin, Anderson, Herbison, \& Mullen, 1995; Skeeg, NadaRaja, Dickson, Paul, \& Williams, 2003). This definition combines self-injurious behaviors such as cutting or burning with behaviors that may more accurately be defined as suicidal, i.e. self-poisoning, overdosing, or ingesting extremely sharp objects (Brittlebank et al., 1990; Chapman \& Dixon-Gordon, 2007; Commons-Treloar \& Lewis, 2008). To add to the confusion, the WHO/Euro Multicentre Study on Suicidal Behavior defined deliberate self-harm as acts of self-poisoning and self-injury but excluded repetitive self-cutting (Platt et al., 1992).

The wide variety of ways in which deliberate self-harm is defined makes it difficult to compare several significant studies. For example, Harriss, Hawton, and Zahl (2005) examined 4,415 patients over the age of 15 who presented at emergency departments of general hospitals in the U.K. The authors utilized the definition of deliberate self-harm that did not address the possible intent of the behavior. By including self-poisoning, the results are difficult to interpret within a framework of a more restrictive definition of self-injury. Likewise, Evans (2000), in discussing interventions to 
reduce the repetition of self-harm, attempted to fit interventions to both non-suicidal selfharm and self-injury with suicidal intent, e.g., self-poisoning, thereby mixing the sample and reducing generalizability. Hurry (2000) attempted to examine deliberate self-harm in adolescents in the U.K. and included the following in her introduction: deliberate selfharm "does not necessarily include the wish to kill oneself" (p.31). However, she quoted other research stating "around $90 \%$ of young people who go to the hospital following deliberate self-harm will have taken an overdose and the remaining $10 \%$ will cut themselves" which strongly links the definition of deliberate self-harm to suicide attempts (p.31). Further, Hurry (2000) interchangeably used the term para-suicidal to describe deliberate self-harm behaviors that served to link the concept of self-injury to suicidality.

This terminological and definitional link to suicide is in direct contradiction to the intent of self-injury (Connors, 2000). Figure 1 depicts a flow chart developed by Magnall and Yurkovich (2008) which determines if a behavior specifically qualifies as deliberate self-harm based on their review of the literature. 
Figure 1. Deliberate Self-Harm Decision Tree

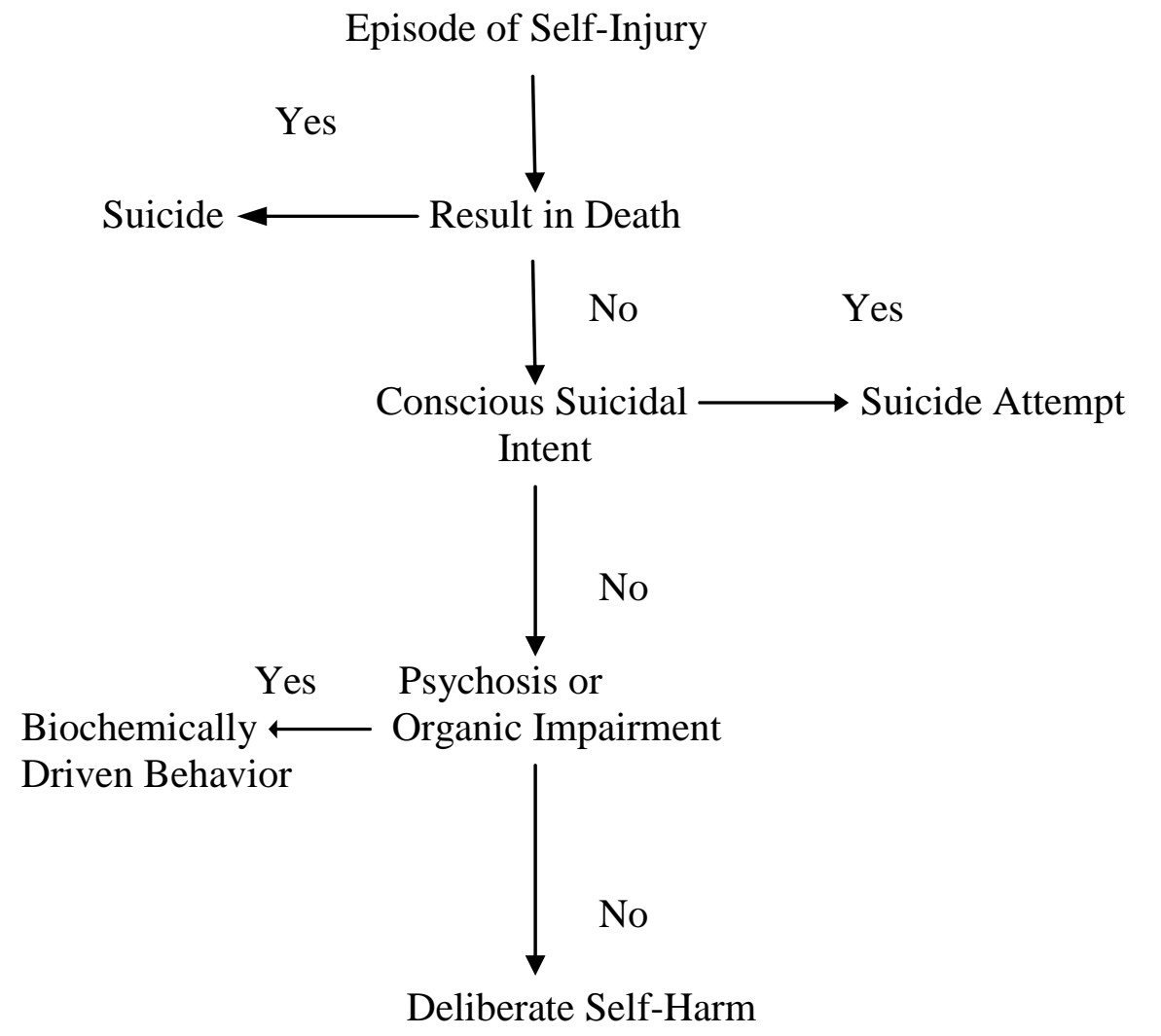

Figure 1. Flow chart determining if injury is deliberate self-harm based upon literature review by Magnall and Yurkovich (2008).

Gratz (2001) also used the term deliberate self-harm, however her definition was quite different. She defined deliberate self-harm as the" deliberate, direct destruction or alteration of body tissue without conscious suicidal intent but resulting in injury severe enough for tissue damage to occur" (Gratz, 2001, p.255). Although this definition is more specific than the U.K. definition of DSH and self-mutilation, it does not address cultural acceptance nor does it mention which behaviors are excluded from the definition. 
Connors (2000) defined self-injury as deliberate violence toward one's body that has a purpose other than suicide. In addition, her definition of self-injury placed behavior on a broad continuum. She discussed the following categories of self-injury:

1. Body alterations: direct, self-chosen changes to the body, often to conform to cultural or group norms. Body alterations may or may not involve pain, and sometimes entail the use of anesthesia. The intent behind these common, socially sanctioned (at least by a subgroup if not by the dominant culture) actions is generally beautification or symbolic marking to indicate belonging. These include cosmetic surgery, tattoos, ear/body piercing, eyebrow plucking and ceremonial or initiation scarring or marking.

2. Indirect self-harm: behaviors that can indirectly cause harm to the person's body and psychological wellbeing even though the apparent or conscious intent is not to harm the self. Substance abuse, overeating, dieting, purging, smoking, staying in a damaging relationship, unnecessary surgeries, and excessive exercise are all forms of indirect self-harm.

3. Failure to care for self: an inadequate ability to provide self-care or protect self. Significant mental health problems, inadequate economic resources, and lack of information may contribute to or exaggerate these forms of self-harm including excessive risk-taking, accident proneness, not getting necessary medical care, and poor nutrition.

4. Self-injury: direct actions that injure the body that do not appear to fit in the category of body alterations noted above; e.g., cutting, burning, and headbanging. (pp.12-13)

It is important to note that definitions of self-injury are also influenced by social norms. Many cultures engage in ritualized body injury, such as cutting, branding and tattooing, both self inflicted and inflicted by others. Even more extreme forms of violence to the body are culturally accepted and promoted as part of religious rituals among some peoples and ethnic groups (B. Little Thunder, 2003). The Sun Dance of the Plains Indians is a clear example of this type of behavior. This ceremony continues to the present day largely unchanged. Young braves, traditionally men, have wooden skewers placed under the skin of their chests and/or backs. These skewers are then attached to a 
central pole. In the heat of the day, with other tribe members chanting and sounding encouragement, the braves pull against the ropes until the skewers rip through their flesh and they are freed (B. Little Thunder, personal communication, July 10, 2003). This culturally specific tradition causes severe pain and permanent scarring, however it is not considered to be self-injury due to the high level of cultural support.

Connors (2000) pointed out that current culture dictates that ear piercing, smoking, excessive exercising, dieting, drinking alcohol, overeating, and elective cosmetic surgery to meet perceived beauty standards are not usually considered selfinjurious behaviors. However, she places such behaviors in the category of indirect selfinjury, because even though the behaviors are not intended to cause self-harm, they frequently do. Strong (1998) pointed out that tattooing and piercing were once only accepted in subcultures but have now crossed over into other aspects of society. Many people have tattoos and piercings, from students to homemakers to corporate executives. The issue of intent is the major divider between what is considered self-injury and what may be considered body modification.

Levenkron (1998) excluded tattooing and piercing, even in the extreme, from a definition of self-mutilation because he believed that when a person receives a tattoo or piercing he/she does so for body modification and dislikes the associated pain. Pain is an unavoidable but generally unwanted part of the package of body modification. In contrast, someone who self-injures does so for the experience of physical pain and is far less concerned with the resulting skin changes (Bohus et al., 2000; Michelman, Eicher, \& Michelman, 1991; Stanley, Gameroff, Michalsen, \& Mann, 2001; Stirn \& Hinz, 2008; Zlotnick, Mattia, \& Zimmerman, 2001). Others argue that this is the rationale utilized by 
the mutilation industry that terms their practices as 'body decoration', 'body art' or 'body modification while essentially being self-injurious (Jeffreys, 2000).

Cutting and burning are the more common forms of self-injury that many therapists and researchers recognize (Conn \& Lion, 1983; Favazza, 1989; Suyemoto \& MacDonald, 1995; Webb, 2002; Yip, 2006). However, other, lesser known behaviors such as picking, scratching, or scraping the skin, tearing at cuticles, biting nails to the quick, using an eraser or steel wool to "burn" or tear the skin, taking scalding showers or baths, and interfering with the healing of wounds also may be considered self-injury (Connors, 2000). Connors (2000) suggested that these lesser-known behaviors take four variations within her self-injury category. The first variation involves the "use of force against the body" including punching oneself or walls, head-banging, breaking bones, hitting oneself with objects or choking oneself. The second variation involves "poking or inserting"; stabbing, gouging skin and tissue, biting parts of the body, using harmful or painful enemas and douches, ingesting sharp objects, such as razor blades, staples, needles, nails, and pins, and inserting large or sharp objects into the vagina or rectum. The third variation involves "swallowing toxic substances" which includes deliberate overdoses that are not intended to kill. Finally, the fourth variation involves "removal of parts of the body" including digging into the gums, cutting off a body part, hair pulling or plucking usually on the head or pubic area, and pulling out eyelashes or teeth (Connors, 2000, pp.20-21).

There are other practices that have not traditionally been considered self-injurious that may, in fact, have self-injury as their goal. Connors (1996b) pointed out that some self-injury may be conducted in the guise of gender role games, e.g. "I'm tougher than 
you are because I can take more cigarette burns than you can," or in socially sanctioned events such as street fights and high contact sports. Taylor (2003) suggested that men engage in public and violent self-harm such as punching themselves or walls and breaking bones.

All these types of behaviors, which may or may not be considered self-injury, make it difficult to measure the actual prevalence of such behaviors in contemporary society (Nock, 2009b). Synthesizing the work of Connors (2000), Gratz (2001, 2003, 2007), and Walsh and Rosen (1988), the author of this research defines self-injury as:

deliberate violence against one's body that results in tissue damage, is socially unacceptable, is not intended to cause death, is not the result of cognitive deficits such as autism or mental retardation and is not part of an accepted cultural or spiritual practice.

This definition combines the leading researchers' differing definitions (Connors, 2000; Favazza, 1989; Gratz, 2001, 2007; Walsh \& Rosen, 1988) and provides a concise conceptualization of the behaviors that characterize self-injury. It also takes into consideration the behavior itself, the intent of the behavior, and the cultural acceptability of the behavior. Common behaviors such as cutting and burning are included while tattooing and piercing are excluded because of their cultural acceptability and lack of injurious intent.

\section{Prevalence Rates of Self-Injury}

A lack of consensus regarding terminology and definition of self-injury has not dampened the measurement of prevalence rates in varied populations. These populations most frequently include the general population, college-age non-clinical population, adult clinical population, adolescent non-clinical population, and adolescent clinical population (Akyuz, Sar, Kugu, \& Dogan, 2005; Andover et al., 2007; Briere \& Gil, 1998; Cloutier, 
Martin, Kennedy, Nixon, \& Muehlenkamp, 2010; DeLeo \& Heller, 2004; Dellinger-Ness \& Handler, 2007; Hankin \& Abela, 2011; Hasking, Momeni, Swannell, \& Chia, 2008; Nixon, Cloutier, \& Jansson, 2008; Vajani, Annest, Crosby, Alexander, \& Millet, 2007; Yates, Luthar, \& Tracy, 2008; You, Leung, Fu, \& Lai, 2011).

General population non-clinical. Prevalence rates for self-injury published by different researchers are quite difficult to compare for at least three reasons. One is the lack of a common definition for the phenomenon. Secondly, the majority of research regarding self-injury is primarily focused on women resulting in the possible underreporting of its existence in the male population, and thirdly, studies often include suicidal behaviors (Crouch \& Wright, 2004; Douglas et al., 2004; Gladstone et al., 2004; Harriss et al., 2005). As recently as 2010, self-injury was “...seldom examined separately from suicide attempts" (Joyce et al., 2010, p.250). Another possible contributing factor affecting accurate data collection is the secrecy and shame surrounding self-injury and its possible underreporting as a result of not acknowledging the behavior to others (Babiker \& Arnold, 1997; Brown, Linehan, Comtois, Murray, \& Chapman, 2009; Evans, Hawton, \& Rodham, 2004, 2005; Heath, Ross, Toste, Charlebois, \& Nedecheva, 2009; Hooley, 2008; Nehls, 1999). Regardless of these difficulties research studies addressing prevalence rates continue to be conducted. Favazza and Conterio (1988) who sampled 250 college students, 96\% of whom were female, estimated prevalence of self-mutilation in the general population to range from 750 per 100,000 up to 1800 per 100,000 in people aged 15 to 35 . Walsh and Rosen (1988) in their book, Self-mutilation: Theory, research and treatment, reviewed available 
incidence data and noted that rates of self-mutilation are on the rise with a prevalence of 14 to 600 per 100,000 people.

Conversely, Briere and Gil (1998) in their study of 927 people from the general population found a prevalence rate for self-injury of four percent. Other prevalence studies looked at different, non-clinical populations. For example, Klonsky, Oltmann, and Turkheimer (2003) conducted a study using male and female military recruits, $64 \%$ of whom were male, and found that four percent of the sample reported a history of deliberate self-harm.

When examining the percentages above, the estimates may seem low and/or insignificant. To put these behaviors in perspective however, if the U.S. population is approximately 260 million, then between 36,400 and 1.5 million people engage in selfinjury.

College age non-clinical. Favazza and Conterio (1988) further analyzed their original study of 500 college students to reveal that $12 \%$ admitted to engaging in selfinjury that the authors defined as cutting, burning, or carving. A replication of this study by the same authors in 1989 showed a two percent increase to $14 \%$ in a sample of 254 college students who had engaged in self-harm at least once. Boudewyn and Liem (1995) surveyed 438 undergraduate college students, $61 \%$ of whom were female, and found that $16 \%$ of men and $24 \%$ of women were identified as having histories of childhood sexual abuse. Further, of those who were identified as having a trauma history, $30 \%$ of women and $9 \%$ of men self-injured more than once. This is compared to $6 \%$ for women and $5 \%$ of men who self-injured more than once but did not have a history of childhood sexual abuse (Boudewyn and Liem, 1995). A significantly higher 
percentage of subjects who self injured were found in a study by Wiederman, Sansone and Sansone (1999) who explored self-injury as part of a larger study of 147 women who visited their primary care doctor. These women had a lifetime self-injury rate of $22 \%$. Finally, a more recent study of 2,875 college students, $53 \%$ of which were female, found that $17 \%$ engaged in self-injury within their lifetime (Whitlock, Eckenrode et al., 2006).

These statistics are much lower than found by Gratz (2001), who reported that $35 \%$ of 150 undergraduate college age participants in his study endorsed a history of selfharm. More specifically, of the 53 participants who reported engaging in self-harm, 15\% reported harming themselves more than 10 times, and $9 \%$ reported harming themselves more than 100 times (Gratz, 2001). It is unclear whether this high percentage could have resulted through self-selection of participants. The study advertised that it was looking for individuals who self-injured, thereby resulting in a sample with higher than average participants who engage in this behavior (Gratz, 2001). Another study of college students that inquired about students' coping mechanisms including self-injury reported a much lower rate of $17 \%$ who engaged in self-injury. It is notable that $75 \%$ of those $17 \%$ who did self-injure endorsed doing so on more than one occasion (Whitlock, Eckenrode et al., 2006). In a sample of 2,843 college students, $48 \%$ of whom were female, Gollust, Eisenberg, and Golberstein (2008) reported that seven percent had self-injured in the past four weeks. It is unknown what that rate would have been if the single survey question had asked about the previous three months, previous year, or lifetime occurrence. Finally, a study examining self-injury in 211 Australians, aged 18-30, 78\% of whom were female, was pooled from a large university, doctor's offices, private practices, and other businesses and found that $44 \%$ of the sample had engaged in self-injurious behavior at 
least once, a prevalence rate that is consistent with the levels found by Gratz (Hasking et al., 2008).

Adult clinical. As one would expect, samples of adults drawn from psychiatric populations demonstrate higher prevalence rates of self-injury than do non-clinical samples. According to Zlotnick et al., (1999) 33.2\% of a sample of 500 psychiatric patients, $57.8 \%$ of whom were female, engaged in self-injurious behavior. Similarly, Briere and Gil (1998) found that 20\% of a sample of 390 psychiatric patients, $50 \%$ of whom were female, engaged in self-injurious behavior. Gunderson, in his classic book, Borderline Personality Disorder: A Clinical Guide (2001) stated that as many as $70 \%$ to $75 \%$ of individuals with borderline personality disorder engage in self-harm. This high rate of self-injury was supported in a study by Zanarini et al., (2008), who reported that in a sample of 290 inpatient clients diagnosed with borderline personality disorder, $77 \%$ of which were female, $90 \%$ had engaged in multiple self-injury episodes and multiple types of self-injury. In comparison, a second group of 72 non-borderline personality, axis II disorder patients had a relatively low rate of 35\% who self-injured (Zanarini et al., 2008). The most recent study of adult psychiatric patients was conducted in Belgium. In a group of 128 patients with a mean age of 35 years-old, $75 \%$ of whom were female, $37 \%$ had engaged in at least one type of self-injury (Claes et al., 2010).

Adolescent non-clinical. An exploration of the literature finds that the most striking aspect about self-injury in the non-clinical adolescent population is the consistent rise in its prevalence. Diekstra (1993) reviewed studies with adolescent samples published up to 1990 and discovered consistent rates of between $2 \%-11 \%$ of adolescents engaged in deliberate self-harm. Subsequently, Hawton et al., (2002) interviewed 6020 
high-school students, aged 15-16 and found that $6.9 \%$ had engaged in deliberate selfharm in the previous year. Ross and Heath (2002) found $14 \%$ of their 122 participants, $64 \%$ of whom were female, had self-injured at least one time. Similarly, Muehlenkamp and Gutierrez (2004) in a sample of 390 high school students, 55\% of whom were female, found that $15.9 \%$ of students surveyed engaged in self-injury. Additionally, $17 \%$ of a group of 568 adolescents, aged 14-21, 54\% of whom were female, had self-injured during their lifetimes (Nixon et al., 2008). Another study by Laye-Gindhu and SchonertReichl (2005) surveyed 424 high school students, 55\% of whom were female, and reported that $15 \%$ of students engaged in self-harm behavior. By contrast, a more recent study by Lloyd-Richardson et al. (2007) showed a dramatic jump to a self-injury rate of $46 \%$ in a sample of 293 ninth and tenth graders, $57 \%$ of whom were female. These adolescents endorsed at least one self-injurious behavior in the past year, including $14 \%$ who cut or carved their skin and 12\% who burned their skin (Lloyd-Richardson et al., 2007).

Adolescent clinical. As one might predict, adolescent inpatient rates of selfinjury are higher than those of outpatient or non-clinical samples. In general, self-injury rates for adolescent inpatients vary between 30-60\% (Darche, 1990; DiClemente et al., 1991; Nock \& Prinstein, 2004). In a 1983 review of 56 published case reports, Pattison and Kahan reported that $40 \%$ of "violent and antisocial youth in institutional settings" self-injured (p. 867). DiClemente et al., (1991) recorded the highest prevalence rate for institutionalized adolescents. They found that $61 \%$ of 76 inpatient adolescents, $53 \%$ of whom were female, had a history of cutting. Penn, Esposito, Schaeffer, Fritz, and Spirito, (2003) found that $30 \%$ of a sample of 78 clinically referred male juveniles self- 
injured while incarcerated. Moreover, a more recent study of 441 adolescents, $71 \%$ of whom were female, showed that $14 \%$ had engaged in self-injury alone while $19 \%$ had engaged in self-injury and a suicide attempt, creating an overall percentage of $33 \%$ who had engaged in self-injury (Muehlencamp, Ertelt, Miller, \& Claes, 2011).

\section{Demographics of Those who Self-Injure}

Many studies of self-injury have focused on specific gender populations. Much less is known about prevalence rates or motivations for self-injury in different racial groups. Even fewer studies have examined self-injury in populations with different sexual orientations.

Gender and self-injury. The vast majority of research examining why clients self-injure has been done solely on female adolescent clinical populations resulting in the common belief that self-injury is limited to female, upper-middle class adolescents/young adults who cut on their arms or wrists (Favazza \& Conterio, 1989; Suyemoto \& MacDonald, 1995; Zila \& Kiselica, 2001). This in large part was due to the work of Favazza and Conterio (1989) whose initial study sample was 96\% female and thus may have created a sub-group mindset. By contrast, more recent studies have proven that this view is far too limiting in regard to understanding those who engage in self-injurious behavior (Andover et al., 2007; Armey \& Crowther, 2008; Croyle \& Waltz, 2007; Gratz \& Chapman, 2007).

One possible explanation for the bias toward women and girls is that females who self-injure are more likely to enter mental health treatment while men who self-injure are more likely to end up in jail (Alderman, 1997; Busfield, 1996). Taylor (2003), in concurrence, stated that while men are as likely to engage in self-injury as women, many 
of them do not have access to support and feel marginalized because of their self-injury. The belief that self-injury is predominately a female problem has lowered the likelihood that men will be routinely assessed and treated for self-injury.

In the last decade, this gender-biased belief has been repeatedly disproven (Andover, Primack, Gibb, \& Pepper, 2010; Claes, Vandereycken, \& Vertommen, 2007; Taylor, 2003; Warm, Murray, \& Fox, 2003). Current studies have shown that both women and men engage in self-injury at roughly the same rates (Briere \& Gil, 1998; Connors, 2000; Gratz, 2001; Marchetto, 2006). Gratz (2007) surveyed 97 college-age men and found that $44 \%$ engaged in deliberate self-harm, with $84 \%$ of those who report self-injury doing so more than once. Connors (2000) suggested that women and men are likely to self-injure in different ways with men harming themselves in the context of a group or in competitive ways such as gender role games and high-contact sports. Men appeared more likely to burn or hit themselves rather than engage in cutting behaviors, the most common form of self-injury for women (Claes et al., 2007; Laye-Gindhu \& Schonert-Reichl, 2005). Additionally, men tend to self-injure by punching themselves or a wall, purposefully breaking bones, and smashing things with their bodies (Andover et al., 2010; Claes, et al., 2007; Taylor, 2003). Further, men are more likely to injure themselves more severely, are less concerned about possible scarring, and less likely to seek medical attention (Hawton, Fagg, Simkin, Bale, \& Bond, 2000). This difference in behavioral patterns may lead to underestimates of male self-injury, lack of clinical research, and lack of gender specific treatment approaches. More recent self-injury measures have included a wider range of behaviors in order to capture more typical male behaviors (Andover et al., 2010; Claes et al., 2007; Gratz, 2001, 2003; Gratz \& Chapman, 
2007 Kleespies et al., 2011; Santa-Mina et al., 2006; Taylor, 2003; Wilkerson \& Goodyer, 2011).

Ethnicity and self-injury. In studies where race is a variable, the connection between race and self-injury is conflicting. One study found no difference in deliberate self-harm rates between Caucasian and Asian female adolescents (Goddard et al., 1996). By contrast, other studies have found a significant difference between ethnicities, with Caucasians within the United States having the highest prevalence rates (Favazza, 1996, Ross \& Heath, 2002).

Because of the varying definitions of self-injury, it is especially difficult to compare U.S. prevalence rates with individuals outside of the U.S. However, a search of non-U.S., non-U.K. studies revealed that self-injury was studied in Austria (Wolfradt, Veith, Jany, \& Frank, 2002), China (Wong, Steward, Ho, \& Lam, 2007), Colombia (Rodriguez \& Martiza, 2007), Finland (Rissanen, Kylma, \& Laukkanen, 2008), Hungary (Csorba, Ferencz, Solymossy, Vados, \& Pali; 2007), Japan (Matsumoto, Imamura, Chiba, Katsumata, Kitani, \& Masahiko, 2008), Pakistan (Zakiullah et al., 2008), Slovakia (Kocourkova \& Koutek, 2005) and Turkey (Zoroglu et al., 2003). This suggests that the phenomenon is not solely a U.S. or mainly Caucasian issue.

Age and self-injury. With respect to age, there is common agreement that selfinjurious behavior begins in adolescence (Austin \& Kortum, 2004; Best, 2005; Boxer, 2010; Cavanaugh, 2002; Cloutier et al., 2010; Crouch \& Wright, 2004; Dorer, 1998; Favazza, 1996; Hankin \& Abela, 2011; Jacobson, Muehlenkamp, Miller, \& Turner, 2008; Lundh, Karim, \& Quilisch, 2007; Messer \& Winokur, 1981; Miller \& Smith, 2008; Nixon et al., 2008; Oliver, Hall, \& Murphy, 2005). Favazza and Conterio (1989) studied 
a group of 254 people who engaged in self-mutilation and found that the average age for the first self-injurious act was 14 years old. Alderman (1997) suggested that self-inflicted violence first appears in adolescence, peaks in the early to mid-twenties and declines thereafter with most individuals stopping their self-injurious behaviors in their midthirties.

By contrast, Adler and Adler (2007) interviewed 80 self-identified self-injurers who frequented online chat rooms and support groups and found that people continued to self-injure well into adulthood. They stated that "two-thirds of the 'regulars' we encountered on the Internet were older than twenty-five, and half were older than thirtyfive" (Adler \& Adler, 2007, p.547). In addition, another study of 59 inpatients showed the range of onset to vary from a four year-old to a 47 year old (Dubo, Zanarini, Lewis, and Williams, 1997).

Sexual orientation and self-injury. Relatively few self-injury studies included sexual orientation as a variable for comparison. The first, by Skeeg et al., (2003) examined self-harm in 176 homosexual and bisexual men and women as part of a larger longitudinal study of 946 participants in New Zealand. All were surveyed when they were 26 years old. This study, however, used the term self-harm which included in its definition suicide attempts of all kinds. Despite this limitation, the authors stated that participants with same-sex attraction had higher risks of engaging in self-harm. Further, "one quarter of deliberate self-harm in men, and one-sixth among women was potentially attributable to same-sex attraction" (Skeeg et al., 2003, p.541). The second study by Gratz (2006) who surveyed 249 college-age women found that self-harm rates were significantly higher for lesbian or bisexual women, $65 \%$ of whom engaged in self-injury, 
as compared to the $17 \%$ of heterosexual women who engaged in self-injury. Finally, a study by Alexander and Clare (2004) of 16 lesbian or bisexual women found that social and cultural factors associated with their sexual identity heightened the risk for selfinjury.

\section{Co-Morbidity with Self-Injury}

While the review of the self-injury literature indicates that there are conflicting results regarding self-injury and ethnicity, gender, and age, there is strong support for the existence of co-morbid disorders in clients who self-injure. The vast majority of research literature on self-injury has utilized clinical populations who have been diagnosed with borderline personality disorder (Andover, Pepper, Ryabchenko, Orrico, \& Gibb, 2005; Aviram et al., 2004; Bohus et al., 2000; Brown et al., 2002; Darche, 1990; Kemperman, Russ, \& Shearin, 1997; Leibenluft, Gardner, \& Cowdry, 1987). Additionally, many studies examining self-injury in clients diagnosed with mood disorders have been conducted on populations who evidenced co-morbid Axis II diagnoses. This makes generalizing results to clients without Axis II features difficult (Joyce et al., 2010; McIntyre \& Schwartz, 1998; Soloff, Lynch, Kelly, Malone \& Mann, 2000; Wurr \& Partridge, 1996; Zlotnick et al., 2001). Nevertheless, a review of the professional literature yields a broad range of diagnoses associated with self-injury.

Anxiety. Klonsky et al. (2003) stated that anxiety could be more strongly linked with self-injury than depression in light of the high levels of emotional arousal and emotional pressure that often precede self-injurious behaviors. Despite this assertion, both the empirical and anecdotal literature on the connections between anxiety and self- 
injury is scant. Few if any studies include this connection without the influence of BPD in the diagnostic formulation.

Borderline personality disorder. Borderline Personality Disorder (BPD) is only one of three psychological diagnoses that specifically include self-injury among its diagnostic criteria. The others are Trichotillomania, the behavior of pulling out one's own hair, or Sexual Masochism which often involves self directed behaviors that may be injurious. Self-injury has been seen as a telltale symptom of BPD, a disorder characterized by a pervasive pattern of instability in interpersonal relationships, selfimage, affects, and marked impulsivity (APA, 2000). It is by far the diagnosis most commonly associated with self-injury within the professional literature (Andover et al., 2005; Brown et al., 2009; Brown et al., 2002; Coid, Allolio, \& Rees, 1993; Dulit, Fryer, Leon, Brodsky, \& Frances, 1994; Kemperman et al., 1997; Linehan, 1993; Russ, Roth, Kakuma, Harrison, \& Hull, 1994; Tantam \& Whittaker, 1992). Connors (1996b) pointed out that for some people self-injury is an impulsive act performed in immediate response to intense affect. Both impulsivity and intense affect are major criteria of BPD. Research studies have placed the rates of self-injury within a population diagnosed with BPD between 48\% and 79\% (Brodsky et al., 1995; Bryer, Nelson, Miller \& Krol, 1987; Clarkin, Widiger, Frances, Hurt, \& Gilmore,1983; Dubo et al., 1997; Dulit et al., 1994; Grove \& Tellegen, 1991; Linehan, 1993; Stone, 1993; Zanarini, Gunderson, Frankenburg, \& Chauncey, 1990; Zweig-Frank, Paris \& Guzder, 1994).

While many researchers and clinicians have been reluctant to diagnose a personality disorder in a young adult or adolescent whose personality is still evolving, some researchers are calling for a re-examination of this reluctance (Miller, 
Muehlenkamp, \& Jacobson, 2008, p.970). There is growing evidence that the symptoms of BPD can be accurately and reliably identified in adolescents (Becker, McGlashan, \& Grilo, 2006; Bondurant, Greenfield, \& Tse, 2004; Grilo et al., 1996; Ludolph et al., 1990). Miller et al., (2008) pointed out that there is not a prohibition in the DSM-IV regarding diagnosing an adolescent with a personality disorder. Moreover, the DSM-IVTR states that while diagnosis of a personality disorder for a child or adolescent would be unusual, there are individuals whose particular maladaptive personality traits appear to be so pervasive and persistent as to be unlikely to be limited to a particular developmental stage or an episode of an Axis I disorder (APA, 2000). It has been shown that specific symptoms and traits of BPD such as affective instability, impulsivity, and self-injury are sometimes detectable at an early age and frequently are predictive of receiving a diagnosis of BPD as an adult (as cited in Miller et al., 2008). Assessing Axis II disorders, especially BPD, enhances the possibility for "psychological interventions to be implemented before maladaptive behavior patterns become crystallized and refractory to treatment in later life" (Miller et al., 2008, p.970).

Other researchers, however, report that symptoms of BPD are exceptionally difficult to differentiate from normal adolescent stress and development. They note that the diagnosis itself fails to demonstrate diagnostic stability and is therefore useless as a clinical disorder for consideration (Bernstein et al., 1993; Bondurant et al., 2004; Meijer, Goedhart, \& Treffers, 1998).

Depression. Professional literature regarding self-injury and depression has shown a significant connection between these two variables (Andover et al., 2005; Bennum \& Phil, 1983; Klonsky et al., 2003; Harrington, 2001; Ross \& Heath, 2002). In 
a study of 105 individuals, both in psychiatric treatment and not, 30.4\% of the sample engaged in self-injury and fit the criteria for Major Depression (Castille et al., 2007). Moreover, in a study of 42 individuals who were diagnosed BPD, 74\% also met the criteria for depressive disorder (Welch et al., 2008).

One possible explanation is that depressed individuals, particularly in adolescence, often struggle with appropriate emotional expression. This in turn may lead to the use of self-injury to communicate distress (Andover et al., 2005; Gratz \& Roemer, 2004; Harrington, 2001). In addition, individuals may seek to avoid thoughts and feelings associated with their depressive symptomology, a concept termed experiential avoidance, and use self-injury as an avoidance behavior (Chapman et al., 2006; Gratz, 2003; Hulbert \& Thomas, 2010; Linehan, 1993).

Dissociative identity disorder. Dissociative Identity Disorders are characterized by the disruption in the usually integrated functions of consciousness, memory, identity, or perception of the environment (APA, 2000). Self-injury has a unique connection with Dissociative Identity Disorder (DID) because the behavior can serve to moderate dissociative states (Brodsky et al., 1995; Herman, 1992a; Saxe, Chawla, \& van der Kolk, 2002; Strong, 1998; Zlotnick et al., 1996; Zweig-Frank et al., 1994). Brodsky et al. (1995) found that $50 \%$ of women who had a diagnosis of BPD and engaged in self-injury also had clinically significant dissociative experiences. Blessing (1990) found that women often describe their self-injurious behavior in the context of dissociation; for example "It doesn't hurt when I do it. When I cut them, those aren't my arms" (p.6). Connors (1996b) concurred describing the dual purpose of self-injury in relation to dissociation in the following way: 
It may keep someone from dissociating or switching, or it may facilitate a switch; some survivors describe both experiences. They sometimes injure themselves so that the pain can serve as an anchor to the present and allow them to avoid switching or 'going away.' Other times, or for other survivors, self-injury either causes or coincides with a switch to an altered state, helping the person to disconnect from current distress. (p.204).

Post traumatic stress disorder. Post Traumatic Stress Disorder (PTSD) is an alternative diagnosis for clients with a history of trauma who also engage in self-injury. Several authors advocate for PTSD as the diagnosis of choice for these individuals instead of Borderline Personality Disorder or Dissociative Identity Disorder (Connors, 2000; Herman, 1992b; Strong, 1998; van der Kolk, 1994). PTSD is characterized by exposure to an extreme traumatic stressor involving direct experience of a threat of death, witness of actual death, or personal injury (APA, 2000). Many of those who self-injure describe having histories of severe trauma (Herman, 1992b) especially histories of childhood physical and/or sexual abuse (Akyuz et al., 2005; Alexander, 1999; Banyard, Williams, \& Siegel, 2000; Baral, Kora, Yuksel, \& Sezgin, 1998; Boudewyn \& Liem, 1995; Bryer et al., 1987; Cavanaugh, 2002; Connors, 1996b; Glassman et al., 2007; Miller, 1994, 1996). It is within this trauma context that self-injury may be understood. In a study by Deiter, Nicholls, and Pearlman, (2000) of 233 inpatients and outpatients, $75 \%$ of whom were female, 109 participants or $47 \%$ reported a history of childhood abuse and endorsed engaging in self-injury.

Noll, Horowitz, Bonanno, Trickett, and Putnam (2003) suggested that those who self-injure "may be reenacting the abuse perpetrated on them" (p.1467). Connors (2000) concurred and stated "reenactments are attempts to master a previously unmanageable situation" (p.48). McLane added further clarification in the following statement: "Self- 
directed violence preempts, or tries to preempt, injuries from others. It is initiated, defined, and ended by the mutilator herself..." (as cited in Connors, 2000, p.114). Favazza (1989) found that in a sample of 250 college students who engaged in self-injury, $96 \%$ of whom were women, $50 \%$ reported a history of childhood sexual abuse. Abused children often discover that unpleasant emotional states can be terminated by causing a jolt to the body, namely through deliberate self-injury (Herman, 1992b). Among 147 women surveyed at their primary physician's office, $22.4 \%$ engaged in regular self-injury. The results indicated that sexual abuse, physical abuse, and witnessing domestic violence were all uniquely related to a higher likelihood of self-injury (Wiederman et al., 1999). In a study of 34 adult inpatient men, Sansone, Gaither, and Songer (2001) found that $26.5 \%$ who were sexually abused reported significantly more self-harm behaviors than non-abused men on the Self-Harm Inventory. Similarly, a study of 438 college students, $60 \%$ of whom were female, revealed that of the $16 \%$ of men and $24 \%$ of women who reported a history of childhood sexual abuse, $29 \%$ engaged in selfharm behavior (Boudewyn \& Liem, 1995). This study found that in both men and women with a history of childhood sexual abuse, self-harm along with depression, chronic self-destructiveness, self-harm ideation, suicidal ideation and suicide attempts could be accurately predicted (Boudewyn \& Liem, 1995). Moreover, van der Kolk (1994) stated that not only childhood sexual abuse, but also, differing forms of childhood trauma, neglect and insecure attachment form the foundation for self-injury. Yates (2004) postulated that childhood maltreatment undermines the formation of positive adaptations to stress. These childhood vulnerabilities necessitate the adoption of alternative regulatory and relational strategies for coping (Yates, 2004). Overall, 
researchers have concluded that childhood sexual abuse is a significant factor in the later development of self-injurious behavior (Baral et al., 1998; van der Kolk, McFarlane, \& Weisaeth, 1996; Zlotnick et al., 1996).

Childhood sexual abuse is not the only type of trauma associated with self-injury. In 1990, a short article by Pitman was the first to present a military veteran diagnosed with combat-related PTSD who also engaged in self-injury. Pitman (1990) reported very similar symptomology regarding the use of cutting and burning to relieve "a disturbing sense of numbness" as well as "intrusive recollections" (p.123). In 2008, a study was conducted with 509 male veterans diagnosed with PTSD to determine the prevalence of self-mutilative behaviors (SMB) (Sacks, Flood, Dennis, Hertzberg, \& Beckham). The researchers found that $55 \%$ of the sample had engaged in some form of SMB within the past two weeks (Sacks et al., 2008). According to the authors, the most frequent form of SMB was punching objects (33.5\%), followed by hitting oneself (30.3\%), burning oneself (11.6\%), and finally, cutting oneself (6.5\%) (Sacks et al., 2008).

By contrast, in a meta-analysis of 56 studies examining childhood trauma and self-injury, Klonsky and Moyer (2008) concluded that the connection between the two variables was "relatively small" (p.166). More specifically, they reported that studies that controlled for psychosocial variables showed no association at all (Klonsky and Moyer, 2008). Evern and Evern (2005) found that childhood physical abuse but not childhood sexual abuse was associated with self-injury when demographic, family history, and clinical variables were controlled. Likewise, two studies that controlled for a diagnosis of borderline personality disorder reported that the connection between childhood sexual abuse and self-injury was non-significant (Gladstone et al., 1999; 
Zweig-Frank et al., 1994). One of the most recent studies determined that post-traumatic stress symptoms mediated the connection between childhood sexual abuse and nonsuicidal self-injury (Weierich \& Nock, 2008).

Although self-injury can be understood in the diagnostic context of Borderline Personality Disorder, Depression, Dissociative Identity Disorder, and Post-Traumatic Stress Disorder, van der Kolk et al. (1996) argued for a completely new diagnostic category, Disorders of Extreme Stress Not Otherwise Specified (DESNOS), to be included in the DSM V. Other well-known trauma researchers have suggested using the term Complex PTSD in these circumstances, because this terminology would imply PTSD symptomology as well as the symptoms of relationship instability and identity distortions that often accompany childhood trauma (Herman, 1992b; Zlotnick et al., 1996). At present, DESNOS and Complex PTSD are only suggestions for inclusion in the next edition of the DSM. The diagnosis of non-suicidal self-injury, however, is being seriously considered for inclusion in the upcoming DSM V. This diagnosis is currently in field trials and could possibly have two specifiers, sub-threshold and intent uncertain, listed under the main diagnosis. (www.dsm5.org/ProposedRevision/Pages/proposedrevision.aspx?rid=443).

Until a different diagnosis is available, some researchers are recognizing the possible diagnostic overlap between axis I and axis II disorders in regard to self-injury. These researchers postulate that although self-injury was a coping skill in childhood or adolescence developed as a response to trauma or maltreatment, it may evolve into a maladaptive personal style of relating to the world as an adult meriting an axis II diagnosis. A diagnosis of Borderline Personality Disorder and Posttraumatic Stress 
Disorder together, therefore, may be clinically appropriate and are not mutually exclusive (Becker, 2000; Gunderson \& Sabo, 1993; Harned et al., 2010; Murray 1993; Ochberg, 1991).

\section{Explanatory Models for Self-Injury}

Self-injury has been conceptualized and explained in a number of ways in the literature. The models are diverse and help one to understand how so many terms are used to explain the phenomenon of self-injury and why clinicians may differ when diagnosing a client who self-injures.

Explorations of models for self-injurious behavior are often difficult to tease out of the broader scope of self-injury literature. Until recently, models were based on small samples and/or anecdotal evidence. There is significant overlap among many of these theories. This is because self-injury often serves multiple purposes for clients and, therefore, may be explained by more than one model. There is also a tendency in the literature to give similar models different names. This literature review presents eight models based upon the work of Klonsky who reviewed 18 studies that examined clinicians understanding and conceptualization of self-injury (2007).

Sexual disorders and self-injury. Messer and Fremouw (2008) suggested that the sexual model of self-injury "emphasizes the importance of sexual development and sexuality concerns" (p.167). Other researchers see self-injury as providing sexual gratification/release or an attempt by the person to punish sexual feelings and/or control sexual development (Suyemoto \& MacDonald, 1995). Woods (1988) concurred and suggests that self-injury may serve as both a form of masturbation and a simultaneous form of self-punishment for the sexual desire. 
Yet another aspect of this model is that self-injury is often associated with sexual confusion and body image difficulties (Zila \& Kiselica, 2001). Parfitt (2005) described a case study of a 17 year old client who had been discharged from an inpatient unit for severely self-injuring in a sexually ritualistic manner. He suggested that for this patient self-injury supported a sadomasochistic function related to her aggression toward herself. Similarly, Simpson and Porter (1981) discovered that some patients felt that "self-injury may satisfy needs for physical or sexual stimulation which prior experience has indicated comes through violent and bizarre activity" (pp.437-38).

In the study by Klonsky (2007a), this model was the least endorsed by clinicians. It has been largely discounted and is rarely, if ever an explanation/function endorsed by clients.

Suicide/Anti-suicide and self-injury. The connection between self-injury and suicide is both long and complex. In the past self-injury was sometimes called parasuicide, strongly linking it to suicidal behavior. Considerable confusion arose not only from the term para-suicide but also from the inclusion in studies of self-poisoning as an act of self-injury rather than a suicidal gesture (Nock \& Favazza, 2009). For example, a study by Douglas et al. (2004) used the term "near-fatal deliberate self-harm" in describing behaviors such as self-poisoning that were treated as suicide attempts by hospital staff. Within this same study they state that "non-fatal deliberate self-harm" “...could act as a proxy for completed suicide in research" (p.264). Additionally, Firestone and Seiden (1990) created a continuum of negative thought patterns that places self-injury above suicidal ideation. They suggested that self-injury be seen as "microsuicides" (p.207), though they conceded it is often an active way to avoid suicide. 
Without considering the intent of the behavior, it is relatively easy to see why suicide and self-injury of this magnitude could be considered interchangeably. However, client surveys indicated that they had a good understanding of the intent behind their selfinjury.

There is no hazy line, says Lindsay, a fifteen year old cutter. If I'm suicidal I want to die, I have lost all hope. When I'm self-injuring, I want to relieve emotional pain and keep on living. Suicide is a permanent exit. Self-injury helps me get through the moment (Strong, 1998, p.32).

Some researchers have discovered that patients report self-injury as a way to cope with suicidal feelings. In this regard, self- acts as a means to avoid actual injury suicide (Messer \& Fremouw, 2008). As early as 1938, Menninger described self-injury as an active coping mechanism used to avoid suicide. Further, suicide and self-injury are different from each other in their phenomenology, characteristics, and intent (Muehlenkamp, 2005; Walsh, 2006). Self-injury can give one a sense of mastery over death (Suyemoto \& MacDonald, 1995) while doing relatively little damage in comparison to the potential after-effects of a suicide attempt.

Punishment and self-injury. While punishment may play a supporting role in the sexual model, it also has been the primary focus of research. Researchers have found that many individuals who self-injure have high levels of self-derogation and low selfesteem (Klonsky et al., 2003; Lundh et al., 2007). Self-verification theory (Swann, Hixon, Stein-Seroussi, \& Gilbert, 1990) suggested that individuals behave in ways that are consistent with their self-images. If an individual believes he or she is deserving of punishment, these thoughts and feelings may lead individuals to transfer their selfdirected anger into self-punishment through self-injury. For these people, self-injury 
"may be experienced as familiar, ego-syntonic, or self-soothing" when they are in distress (Klonsky \& Muehlenkamp, 2007, p.1050).

Behavioral/Environmental factors and self-injury. This model focuses on environmental factors that may have initiated and/or maintained self-injurious behaviors. It is based on the principle that self-injury may be reinforced through others' reactions (external environment) which results in secondary gain (Favazza, 1989; Offer \& Barglow, 1960) or by positive reinforcement which is experienced through affect relief (Simpson, 1980). Simpson and Porter (1981) suggested that self-injury may be learned due to an earlier association between pain and suffering and childhood experiences, albeit often negative. Other researchers believe that the reinforcement from others e.g., attention and/or inclusion in a group, may play a role in introducing and maintaining selfinjurious behavior (Crouch \& Wright, 2004; Favazza, 1989; Hartman, 1996).

Physiological/Biological factors and self-injury. In recent years there have been more studies of the biological underpinnings of self-injurious behaviors. These reports provide strong support for the physiological effects of self-injury. Haines, Williams, Brain, and Wilson (1995) explored responses (both physiological and subjective) to generic self-injury scripts in a group of people who self-injured and those who did not. Physiological arousal was recorded using finger blood volume, finger pulse amplitude, respiration rate, and skin resistance level. Heart rate was measured using a cardio-tachometer. Those who self-injured showed a decrease in arousal in response to the self-harming scripts but had no arousal changes to neutral scripts. Non-injuring participants showed heightened arousal in response to the self-harming scripts but no corresponding physiological decrease after viewing self-harm scripts. While the 
previous study was conducted with male college students, similar results were found in examining women diagnosed with BPD. These women showed a significant decrease in sympathetic arousal in response to self-injury scripts (Shaw-Welch, Kuo, Sylvers, Chittams, \& Linehan, 2003).

In the past decade studies have examined blood chemistry in those who selfinjure. In one case study, the relationship between self-injury and cortisol levels was examined (Sachsse, von der Heyde, \& Huether, 2002). Cortisol is a hormone naturally secreted by the body when stressed. Sachsse et al. (2002) monitored a self-injuring woman for 86 days using ambulatory monitoring methods, personal ratings of negative emotions, and self-injurious episodes. The authors found that high cortisol levels correlated with negative emotions and preceded self-injurious episodes. Further, not only did cortisol levels drop with self-injury, they stayed low for several days suggesting that the effects of self-injury lasted for this time period.

In addition to this study, several others have focused on the role that endogenous opioids may play in reducing physiological arousal after an episode of self-injury (Coid et al., 1983; Roth, Ostroff, \& Hoffman, 1996; Russ, 1992; Sher \& Stanley, 2009). This opioid hypothesis suggests that upon self-injury, natural opiates are released causing analgesia and relieving emotional distress. Coid et al. (1983) found that people who selfinjure often have higher levels of circulating opioid peptides.

An alternative to this model suggests that high levels of stress release endogenous opioids. These in turn may lead to uncomfortable feelings of numbness and/or dissociation which prompt self-injurious behavior to end this state (Saxe et al., 2002). 
Simeon et al. (1992) compared two groups (a self-injuring group and control group) on levels of CFS 5-hydroxyindoleacetic acid (5-HIAA) (a serotonin metabolite) in cerebrospinal fluid and number of imipramine binding receptor sites in platelets. While levels of serotonin showed no significant differences between the groups, lower levels of imipramine binding sites showed a strong negative correlation with more severe levels of self-injury. Further research may explore psychopharmacological treatments to increase the number of imipramine binding receptor sites in those who engage in severe selfinjury.

Interpersonal/Systemic factors and self-injury. Current models of self-injury do not combine interpersonal and systemic models, however, both involve other individuals maintaining the self-injurious behavior. Messer and Fremouw (2008) contended that combining the two models is logical. This combined model suggests that self-injury is a symptom of a dysfunctional family or environment (Messer \& Fremouw, 2008; Suymeoto \& MacDonald, 1995). The self-injury serves to hold the system in a state of homeostasis, even if this homeostasis is dysfunctional. The system may be a family, hospital, or residential treatment facility (Podovoll, 1969).

A separate but intriguing interpersonal model of self-injury states that self-injury serves to mark personal boundaries. Connors (2000) related that:

Some [trauma] survivors have a recurrent sense of being impinged upon by the world, or operate with a low threshold for perceiving safety in the face of a high volume of external information. They may 'soak in' others' feelings, especially in high affect situations, or be unable to differentiate their own feelings from others. (p.45)

Trauma survivors, therefore, need to do something to preserve or regain their inner sense of autonomy. Self-injury defines the self and can create a strong separate self-identity 
(Carroll, Shaffer, Spensley, \& Abramowitz, 1980; Favazza, 1989; Suymeoto \&

MacDonald, 1995). This sense of self can be physical such as injuring the skin and subsequently forming a physical boundary (Raine, 1982). Likewise, one can create an identity as a self-injurer (Podovoll, 1969; Simpson, 1980).

An interpersonal model of self-injury also conceptualizes self-injury as a means of non-verbal communication. Individuals may feel they are not understood or taken seriously and the behavior of self-injury speaks for them. For example: "I think it's another way of just, for me, saying, it's like my way of saying 'Help me'” (Himber, 1994, p.625). Other times this behavior may simply attempt to communicate the level of psychic pain.

When hidden pain starts to speak, it will speak silently. Its voice may appear as a cut on the leg, a burn on the arm, skin ripped and scratched repeatedly. There will be no sound, not any, only unfelt and silent pain which makes its appearance in another pain, self-inflicted, and when that second, collateral pain emerges, it will articulate in blood or blisters the open definition you desire, although it may not be in a language you care to see. This, it says, is pain, and this is real in any language you care to speak. (McLane, 1996, p.111)

Unfortunately, these models have mostly remained in the theoretical realm. The two empirical studies with an interpersonal approach used small groups for case studies and are therefore severely limited in their generalizability (Crouch \& Wright, 2004; Hartman, 1996).

Anti-dissociation/Depersonalization factors and self-injury. It has been hypothesized that feelings of dissociation stem from "feelings of abandonment or isolation which lead one to feel unreal or numb" (Messer \& Fremouw, 2008, p.169). Connors (2000) suggests that dissociation and disconnection are common reactions to trauma. Self-injury may serve as a way to regain a sense of identity. Connors (2000) 
illustrated this function stating "dissociating survivors reassure themselves about being alive" (p.56). For some, self-injury serves as a method of actually ending an episode of dissociation (Connors, 2000; Klonsky and Muehlenkamp, 2007). "They cut themselves to feel alive and to end the experience of blankness, of not existing" (Strong, 1998, p.40).

I don't enjoy the pain, but I don't mind it either: it's just a step in the process...It seems to be about attention and focus. The violence I inflict on my hands and forearms is visible: I can see where the damage is, and know why. (Umans, 1992, p.7)

Klonsky and Muehlenkamp (2007) concurred and suggested this model could be called a "feeling generation" model (p.1050). In addition, the scars left behind from selfinjury may be reminders to the individual that "they do exist and have an identity" (Messer \& Fremouw, 2008, p.169). Connors (2000) suggested that self-injury not only can end a dissociative state but also can regulate the degree of sensation a person feels. "At the point of self-injury, flashbacks recede, fade away entirely, or go into the background" (Connors, p.57).

Unfortunately the only empirical study of this model examined dissociation and self-injury on a female inpatient unit where all the participants had been diagnosed with borderline personality disorder. This study by Brodsky et al. (1995) did find that $50 \%$ of the women diagnosed with BPD showed extremely high levels of dissociation and 52\% reported a history of self-injury.

Affect regulation factors and self-injury. The vast majority of empirical research supports the theory that self-injury is primarily used to cope with strong, negative affect. Strong (1998) reported that self-injury is a complex coping mechanism that some people utilize to moderate extreme emotions and calm internal conflict. Selfinjury may be based in the need to express or control anger, anxiety, or pain, which the 
sufferer cannot express through other methods (Connors, 2000; Gratz, 2003; Suyemoto, 1998). A person may self-injure in an attempt to escape unbearable pain and to gain control or at least regulate his or her emotions (Alderman, 1997). Self-injury can provide a physical focus for those suffering from internal pain (Connors, 1996b). Many of those who self-injure report that they experience a feeling of calm following an act of selfinjury. Tension is reduced or released altogether (Brain et al., 1998; Connors, 1996b). Given the connection between self-injury and childhood trauma explored above, Chu (1991) explained that self-injury seen in the context of trauma provides a ready escape for the client, such as during a flashback.

The reliving of the trauma is experienced as a real and contemporary event. That is the patient does not talk about feeling as if he or she remembers the experience; rather, he or she feels the experience in the present. The power of such an experience is phenomenal, and points to the ability of the psyche to repress and dissociate overwhelming experiences, as well as to bring them back into consciousness with full force. (Chu, 1991, p.328)

Ross and Heath (2003) chose to specify two emotions, hostility and anxiety, that were regulated through adolescent self-injury. They found that teens that self-injure vs. those who do not, differed in their expression of hostility, had greater levels of hostility, and were more likely to react to ambiguous situations with hostility. The results validated their hypothesis that high levels of anxiety and hostility are often present just prior to acts of self-injury.

In later studies, affect regulation was broadened to include any and all intensely experienced affect. Chapman, Gratz, and Brown (2006) theorized that individuals who self-injure may have a lower tolerance for emotional arousal and may experience a "breakdown in their cognitive or information processing systems under conditions of intense emotional arousal" (p.378). Though they may possess other emotional regulation 
skills, they fail to utilize them and choose the quick and easy behavior of self-injury for relief. Gratz (2001) found that, in addition to relieving unwanted emotions, self-injury served to externalize the emotional pain, making it tangible and easier to understand.

Bennum and Phil (1983) found that those who self-injured had the highest levels of anxiety when compared with a group of depressed patients and controls. They believe that self-injury controls this arousal. These individuals, however, cannot control the urge to self-injury. The self-injury reduces the negative emotional experience associated with intense anxiety (Bennum \& Phil, 1983).

By contrast, the Experiential Avoidance Model (EAM) proposed by Chapman et al. (2006) posited that self-injury is "maintained by negative reinforcement in the form of escape from, or avoidance of, unwanted emotional experiences" (p.371). Avoided experiences include "thoughts, feelings, somatic sensations, or other internal experiences that are uncomfortable or distressing” (p.374). Chapman et al. (2006) further clarify that experiential avoidance is:

a class of behaviors that are maintained primarily through negative reinforcement, and may include a variety of seemingly dissimilar behaviors that serve this function, such as avoidant coping styles; thought suppression; drug or alcohol use to escape from unwanted moods; and avoidance of feared objects, places, or situations. (p.374)

\section{Theoretical Formulation and the Treatment of Self-Injury}

Another way of explaining the diverse manner in which self-injury is regarded in the literature is by exploring self-injury from the perspectives of different theoretical orientations. In addition, a brief review of treatment as it applies to the various theoretical orientations provides a deeper understanding of the ways in which they formulate the concept of self-injury. 
There are numerous theoretical orientations many of which have similar features.

For the purposes of this discussion, the literature on self-injury easily falls into the specific theoretical orientations that are represented below.

Psychodynamic models. Psychodynamic treatment approaches have their roots in psychoanalytic theory and the work of Sigmund Freud. Psychodynamic theory differs from psychoanalytic theory in that the former focuses on how an individual's unconscious processes manifest in his/her present day behavior, while the latter frames an individual's functioning from the perspective of Freud's psychosexual stages of development and other metapsychological constructs unique to psychoanalysis. It is believed that unconscious processes are the cause of all neurotic symptoms and behaviors (Corey, 2009; Levy, Yeomans, \& Diamond, 2007). Out of this belief, several psychodynamic theories emerged including Ego Psychology and the work of Erik Erikson. Erikson's theory stresses psychosocial development throughout stages of the lifespan (Corey, 2009). Self-Psychology, the work of Heinz Kohut (1971), places its focus on a person's use of interpersonal relationships or 'self objects' in the development of a sense of self (Corey, 2009). Finally, object-relations theory and the work of Otto Kernberg $(1976,1984)$ focus on the unconscious identification and internalization of other people, and how those internal identifications are represented intrapsychically (Corey, 2009).

Nearly all of the empirical studies of psychodynamic treatment methods addressing self-injury used clinical populations diagnosed with borderline personality disorder (Klonsky \& Muehlenkamp, 2007). The few studies that specify psychodynamic treatment of self-injurious behavior do show evidence of effectiveness (Bateman \& 
Fonagy, 2001; Monsen, Odland, Faugli, Daae, \& Eilertsen 1995; Ryle, 2004). Across the psychodynamic treatment studies that include self-injury, a number of common themes emerge. These include "processing past relationships and building new, positive interpersonal relationships; increasing awareness and expression of affect; and focusing upon the development of a client's self-image" (Klonsky \& Muehlenkamp, 2007, p.1052).

The psychodynamic approach makes conceptual sense if we accept the hypothesis of Walsh and Rosen (1988), who stated that any threatened or actual loss in the current life of someone who self-injures would reactivate unbearable tension and anxiety originally experienced from a narcissistic injury in childhood. In addition, the possible lack of individuation that resulted from this injury could lead to self-injury later in life (Walsh \& Rosen, 1988).

Suyemoto and MacDonald (1995) examined teens who cut themselves and suggested that there are four possibilities for why self-injury is the "behavior of choice" to cope with the threat of "self-dissolution" (p.169). The first possibility is that selfinjury is a concrete representation of individual's internal pain and anguish (Connors, 2000; Ettinger, 1992). Adolescents often have difficulty expressing their emotions; coupled with an inability to distance them from experience which may lead to selfinjurious behavior (Doctors, 1981; Walsh \& Rosen, 1988). More specifically, Doctors (1981) and Sarnoff (1988) suggested that self-injury results from the failure of the developmental process of communication. Self-injury serves as a strategy to distance the individual from his or her overwhelming emotions. 
The second possibility is that self-injury allows the body to be used as a transitional object. A transitional object, first coined by Donald Winnicott (1953), is any material object that an infant uses to shift from the oral relationship with the mother to true object-relations. Expanding this idea into teenage years and beyond, the body can facilitate the separation of living and dead, inside and outside, self and other, in the developmental process of separation-individuation (Doctors, 1981; Kafka, 1969; Simpson, 1980; Woods, 1988). "The blood, the scars, and the act of cutting are particularly good and always available transitional objects" (Suymeoto \& MacDonald, 1995, p.169).

The third possibility is related to the use of the body as a transitional object. In this case however, the self-injury can reaffirm the physical boundary of the body, the most basic boundary related to a sense of self (Connors, 2000; Raine, 1982; Simpson, 1980). "Blood flowing from the wound proves there is life inside the body instead of nothingness. ...Stimulation of the skin through self-mutilation helps reintegrate the splintered sense of self by reactivating the body ego" (Strong, 1998, p.47).

Finally, the fourth possibility is that self-injury can provide a specific identity to the self-injurer. The identity of "cutter" is supported both internally and by others in noticing the injuries (Simpson, as cited in Farberow, 1980). The identity as a self-injurer may counteract dissociation and merger by creating a concrete self-definition (Suymeoto \& MacDonald, 1995).

If one accepts these possibilities and wants to utilize a psychodynamic approach to treat someone who self-injures, the focus of therapy would be on developing the skills to communicate emotions and needs and learning alternative behaviors to channel 
feelings, both of which require development of introspection and self-reflection (Bennum \& Phil, 1983; Levy, Yeomans, \& Diamond, 2007; Simpson, 1980). In addition, selfobject individuation and merger would need to be addressed through the process of therapy and the therapeutic alliance (Suymeoto \& MacDonald, 1995).

Cognitive-Behavioral models. Cognitive-Behavioral treatment approaches are a combination of Albert Ellis's Rational Emotive Behavior Therapy (REBT) and Aaron Beck's Cognitive Therapy (CT). REBT's assumption is that "cognitions, emotions, and behaviors interact significantly and have a reciprocal cause-and-effect relationship" (Corey, 2009, p.275). The focus of REBT is to work with thinking and acting and not expression of emotion. It differs from other forms of therapy in that it does not incorporate "free association, working with dreams, focusing on the client's past history, expressing and exploring feelings, or dealing with transference phenomena" (Corey, 2009, p.276). Therapy goals include separating self-evaluation from behaviors, disrupting irrational beliefs, completing cognitive homework, and psychoeducation (Corey, 2009; Ellis, 2001; Ellis \& Harper, 1997).

Cognitive therapy is similar to REBT and behavior therapy. Beck realized when working with depressed clients that they often had a negative bias in the interpretation of some life events that supported specific cognitive distortions (Beck, 1963; Dattilio, 2000). Cognitive therapy places the cause of psychological problems in a person's "faulty thinking, making incorrect inferences on the basis of inadequate or incorrect information, and failing to distinguish between fantasy and reality" (Corey, 2009, p.287). Cognitive theory supposes that people with emotional problems commit one or more cognitive distortions that skew their view of objective reality. These distortions include 
arbitrary inferences, selective abstraction, overgeneralization, magnification and minimization, personalization, labeling and mislabeling, and dichotomous thinking (Corey, 2009). Cognitive therapy focuses on helping clients identify their cognitive distortions in order to change these distortions into something more constructive and reality based.

Meichenbaum (1977) combined REBT and Cognitive therapy into what he called cognitive behavior modification (CBM). Meichenbaum (1977) suggested that "behavior change occurs through a sequence of mediating processes involving the interaction of inner speech, cognitive structures, and behaviors and their resultant outcomes" (p.218). In order to change client behavior it was first necessary for clients to become aware of their self-talk. Therapy focuses on helping clients to "modify the instructions they give to themselves" (Corey, 2009, p.296). Change was believed to occur in three phases; self-observation, starting a new internal dialog, and learning new coping skills (Corey, 2009; Meichenbaum, 1977).

From a Cognitive-Behavioral Therapy (CBT) stance, self-injury is a learned behavior supported by self-defeating thoughts and beliefs and maintained by both negative reinforcement, e.g. relief of distress and positive reinforcement, e.g. attention and nurturance from others (Strong, 1998). Negative thought patterns include "I'm bad", "I'm ugly", "I deserve to be punished", and "Cutting is the only thing that makes me feel better" (Strong, 1998, p.173). Treatment focuses upon identifying and changing negative thought patterns, learning and using "thought stopping" and developing a "coping plan" which might allow the client to self-injure as long as they have attempted several other alternative behaviors (Strong, 1998, p.173). 
While CBT has proved to be an efficacious treatment approach for many diagnoses, it has been overpowered by another cognitive-behavioral approach, dialectical behavioral therapy (DBT), which expands its focus and treatment methods.

Dialectical-Behavioral models. Dialectical behavior therapy is a manualized outpatient approach developed by Marsha Linehan, specifically for clients who have been diagnosed with borderline personality disorder many of whom self-injure. Strong (1998) interpreted Linehan's belief of the underlying problems for BPD patients, who selfinjure, stating;

...borderline patients, due to painful upbringings and possible biological factors, respond abnormally to emotional stimulation. Their level of arousal escalates more quickly than the average person, peaks at a higher level, and takes more time to return to normal. She views self-injury as the result of a lack of coping and problem solving skills for dealing with such intense surges of emotion. (p.173)

DBT has four treatment components and requires at least a year commitment.

The four components are weekly individual therapy sessions, weekly group skills training, therapist consultation/supervision meetings, and telephone support as needed between clients and their individual therapists outside of the therapy hour (Gratz, 2007). The main foci of DBT are "affect regulation, distress tolerance, improvement in interpersonal relationships, and mindfulness training" (Corey, 2009, p.255). More specifically, Gratz (2007) explained that emotion regulation skills teach clients to identify and label emotions, thereby increasing emotional awareness and understanding. In addition, Gratz (2007) explained that patients are "taught to identify all components of an emotional response (physiological, subjective, and behavioral), as well as the events (and interpretations of these events) that prompt different emotions and the after-effects of emotions on their functioning" (p.1095). 
The efficacy of DBT treatment for self-injury was demonstrated through empirical research (Linehan et al., 2006). Some researchers believe the DBT approach works well because therapists and clients set a goal of stopping self-injury which may be a symptom of trauma but without having to focus on the trauma itself (Gardner \& Cowdry, 1986). Many therapists in private practice, however, may not be able to offer the commitment of 24 hours a day phone support outside of treatment sessions.

Feminist models. Feminist therapy is not a single, unified approach. Instead, it is often an integrative model in which feminist ideals strongly influence the process (Brown \& Bryan, 2007). Feminist theory and therapy have their roots in the second wave of feminism in the 1960's. As women formed consciousness-raising groups, therapists who attended these groups began to adopt the power-sharing structure within a therapeutic setting (Corey, 2009).

One of the most important contributions of feminist therapy was to change the focus when considering mental health problems. Corey (2009) stated that feminist therapists

"took the stance that therapy needed to move away from an intrapsychic, psychopathology focus (in which the sources of woman's unhappiness reside within her) to a focus on understanding the social, political, and pathological forces in society that damage and constrain girls and women, as well as males." (pp.342-343)

This change in focus led to an effort by feminist therapists in the 1980's to define feminist therapy as its own entity (Enns, 1993). Carol Gilligan (1982) and her seminal book, In a Different Voice, suggested men and women experienced the world in significantly different ways. The works of the Stone Center, such as Miller (1996) and Jordan, Kaplan, Miller, Striver, and Surrey (1991) developed the self-in-relation model 
that has evolved into the relational-cultural model. These models emphasize and respect the relational and cooperative nature of women's experiences (Corey, 2009; Enns, 1991, 2003, 2004). Though diverse in nature, Feminist Therapy does have articulated, core principles that overlap and are interrelated.

The first is the belief that the personal is political. Second is the commitment to social change. Third is that the voices and ways of knowing of women and girls are valued and their experiences are honored. Fourth is that the counseling relationship is egalitarian. Fifth is a focus on strengths and a reformulated definition of psychological distress. Sixth and finally, all types of oppression are recognized (Corey, 2009, pp.247248).

As noted above, while there is a specific feminist theory that has emerged, relational-cultural therapists of other theoretical orientations may incorporate feminist ideals in their practice. This merging of theory can be seen in the case of self-injury.

Feminist therapists locate the source of psychological stress outside of the person. They also recognize that women are more likely to be victims of violent sexually based crimes on the basis of being female (http://www.ojp.usdoj.gov/bjs/cvict_v.htm\#gender). They also recognize that those who self-injure are often people with "histories of severe and repetitive childhood maltreatment and invalidation" (Brown \& Byran, 2007, p.1121). Within the context of childhood abuse, a feminist therapist defines almost all symptoms, including self-injury, as attempts to cope with a situation whether or not those symptoms work well (Brown \& Byran, 2007).

Self-injury is understood as a coping strategy to manage emotions and/or situations. Self-injury becomes a focus of treatment if, and only if, the client requests it 
(Brown \& Byran, 2007; M.P. Kane, personal communication, March, 20, 2008). Noncoercion is a main tenet of feminist therapy. Coercing a client to stop self-injuring is interpreted as violating the egalitarian focus of therapy. "A therapist may wish her client to no longer practice SIV [self inflicted violence], but if this is not the client's agenda then a feminist therapist is not free to impose this therapeutic goal on the client", "Stopping the SIV is, consequently, rarely if ever the initial goal of therapy, unless, and only if, a client specifically identifies it as her or his own goal and is not under coercion from others to adopt that goal" (Brown \& Byran, 2007, p.1124). If the self-injury is adopted as a focus of treatment, it can be normalized for the client as a method of emotional regulation with the effect of self-soothing for the client (Brown \& Byran, 2007; Connors, 2000). Therefore, therapy may focus on empowering the client to make alternative choices for self-soothing, locating the need for self-injury within the larger context of trauma, and most importantly acknowledging the various meanings and value for the client (Brown \& Byran, 2007; Connors, 2000).

Feminist therapists who work with self-injuring clients recognize that there is often ambivalence and even a reluctance to stop (Brown \& Byran, 2007; M.P. Kane, personal communication, March 20, 2008). If the client decides she or he is ready to stop, a DBT approach is often best and can be effectively employed within a feminist model.

Multi-Modal therapy. Many clinicians recognize the multiple functions selfinjury may serve for a client and therefore understand that self-injury is significantly more complex than a single theory can explain. They may then employ multiple theories and foci within the treatment frame. However, there is yet to be an integrative theory that 
leads to an integrative treatment with proven effectiveness for self-injuring clients. One possible approach that is not tied to a specific theory is Multi-Modal Therapy.

Multi-Modal therapy (MMT) was introduced first by Arnold Lazarus in 1976 when he described a "broad spectrum" treatment approach for alcohol abusers. Over time this approach has been refined to encompass eight dimensions or modalities of a client's life that may or may not need to be addressed in therapy.

Before exploring this approach in detail it is important to recognize that Lazarus does not suggest randomly picking techniques from different theoretical orientations and applying them randomly. In fact, he suggests that if a different evidence based approach has already been established, then that approach should be used. "Eclecticism is warranted only when well-document treatments of choice do not exist for a particular disorder, or when well-established methods are not achieving the desired results" (Lazarus, 1997, p.43). He strongly discourages the use of a "smorgasbord conception of eclecticism" that lacks stated and replicable processes (Lazarus, 1997, p.43).

Multi-modal therapy acknowledges that most therapeutic orientations recognize up to three of his modalities. There are four others that are often overlooked or ignored. The seven modalities are signified by the acronym BASIC ID which stands for B: behavior, A: affect, S: sensation, I: imagery, C: cognition, I: interpersonal, and D: drugs/biology (Lazarus, 1997, p.2). Within these different modalities Lazarus suggests that different techniques from various theoretical orientations can be used, and therefore, any theoretical orientation can effectively apply the approach. "It makes sense to select effective techniques from any discipline without necessarily subscribing to the theories that begot them" (Lazarus, 1997, p.42). Kazdin (1984) stated that "premature integration 
of specific positions that are not well supported on their own may greatly impede progress" (p.142). The theoretical underpinnings of MMT are such that any theoretical orientation can be seen as utilizing the MMT approach when a clinician steps outside that orientation for other useful techniques. One does not need to give up a theoretical orientation explaining behavior in order to use effective techniques.

Lazarus initially called his approach multi-modal behavioral therapy (1976) but later dropped the word behavioral as the different modalities were defined. In his book Brief but Comprehensive Psychotherapy (1997) Lazarus described how the BASIC ID approach is embodied by four principles:

1. Human beings act and interact across the seven modalities of the BASIC ID.

2. These modalities are connected by complex chains of behavior and other psychophysiological events, and they exist in a state of reciprocal transaction.

3. Accurate evaluation (diagnosis) is served by the systematic assessment of each modality and its interaction with every other.

4. Comprehensive therapy calls for specific correction of significant problems across the BASIC ID (p.5).

In addition, Lazarus (1997) articulated eight issues that "must be ruled out or adequately dealt with" if a therapist wants to be "effective, retain a constructive focus, arrive at creative solutions and be both short-term and comprehensive" (p.9). These eight issues may span one or more of the BASIC ID modalities and are:

1. Conflicting or ambivalent feelings or reactions

2. Maladaptive behaviors

3. Misinformation (especially dysfunctional beliefs)

4. Missing information (e.g., skill deficits, ignorance, or naiveté)

5. Interpersonal pressures and demands 
6. Biological dysfunctions

7. External stressors outside the immediate interpersonal network (e.g., poor living conditions, unsafe environment)

8. Traumatic experiences (e.g., sexual abuse or gross neglect in childhood)

Although MMT has not been examined specifically in relation to treating clients who self-injure, it certainly offers a more comprehensive approach to treatment. Multimodal therapy encompasses the elements of dialectical behavioral therapy and cognitive behavior therapy in the B (behavior), A (affect), \& C (cognition) domains, while also examining elements traditionally thought of as psychodynamic such as the I (interpersonal) represents. Additionally, S (sensation), I (imagery), and D (drugs/biology) are considered.

\section{Therapist Factors in Relation to Self-Injury}

The broad range of terminology, diagnoses, and models of treatment for selfinjury found in the professional literature warrants a consideration of how individual clinician factors other than theoretical orientation affect clinicians' decisions about selfinjuring clients. More specifically, is there evidence that factors such as age, gender, and years in practice have a relationship with a clinician's choice of terminology, diagnosis and ultimately treatment?

Suyemoto and MacDonald (1995) conducted the only empirical assessment to date of therapists who treat self-injuring clients. The study consisted of 500 therapists from two different organizations, National Register of Health Service Providers in Psychology and the National Association of Social Workers Register of Clinical Social 
Workers. Subjects were requested to use a "referent" patient who was female, between the ages of 13 and 25 and who had engaged in more than one incident of self-cutting.

The total response rate was $68 \%$, but a significant portion of respondents did not meet the study criteria. They subsequently were excluded from the analysis leaving a sample size of 44 therapists. In this study $60 \%$ were female and $40 \%$ male. The average time they had been practicing was 14.08 years, $47 \%$ had a Ph.D. and the modal theoretical orientation (45\%) was eclectic (Suyemoto \& MacDonald, 1995). The models given as options for participants for understanding self-injury were behavioral, systemic, suicide, sexual, expression, control, boundaries, and depersonalization. The most common models selected by therapists were the expression (29.5\%) and control models (22.7\%), while depersonalization (15.9\%) and boundary models (13.6\%) were also highly rated. The least highly endorsed model was the sexual model with zero percent endorsing it as an underlying dynamic for the patient (Suyemoto \& MacDonald, 1995). These authors discovered that regardless of the explanatory model the therapists subscribed to, they "indicated great confidence in the generalizability of their own conceptualizations" stating that other "cutters" they treated indicated the same reasons for engaging in this behavior (Suyemoto \& MacDonald, 1995, p.168). This study had two limitations: the researchers did not examine whether therapists' understanding of selfinjury guided their treatment and members of the American Psychological Association where not part of the sample despite being the largest professional group of mental health providers.

Poznanski and McLennan (1995) stated that theoretical orientation is not synonymous with one's preference for a particular therapeutic intervention/strategy, even 
though therapeutic techniques are often presented and taught as extensions of a particular theory. "What counselors actually do in a given session may not always reflect the theory to which they adhere" (p.412). Further, "therapeutic interventions or strategies should not be viewed as theoretical orientations per se, but rather that they are likely to be expressive of a counselor's consistent set of underpinning conceptual assumptions" (p.412).

There is a plethora of information regarding self-injury origins and functions for the client (Nock, 2009a, 2009b; Pattison \& Kahan, 1983; Rosenthal, Rinzler, Walsh, \& Klausner, 1972; Ross \& Heath, 2003; Suyemoto, 1998; Warm et al., 2003; Woods, 1988); however, relatively little is known about the interactions between self-injury terminology, diagnoses, and salient therapist characteristics. Given the frequency of selfinjury in the clinical populations and the need for effective treatment it would be helpful to increase our understanding regarding the association between therapist characteristics and theoretical orientation.

A better understanding of these associations may help to focus and improve the research and training of therapists regarding self-injury. Additionally, research into therapists' interpersonal responses and their relationship to treatment with those clients who self-injure could become foci for future proposals.

\section{Research Hypotheses}

As the review of the literature regarding self-injury indicates, there are four terms that stand out as descriptors of this behavior, self-injury, deliberate self-harm, nonsuicidal self-injury and self-mutilation. These terms seem to be equally used throughout the literature. Consequently, they may lead some practitioners to be confused, because 
different terms will include or exclude the same behavior. It is not known to what extent doctoral level practitioners use common terms or descriptors for actions that cause harm to the self, nor is it known what factors are associate with clinicians' choices of terminology and diagnoses.

The first research question explored the hypothesis that doctoral level practitioners would indicate a preference for a term used to describe self-injurious behaviors. A simple frequency test was utilized to examine clinician preference for terminology (self-injury, deliberate self-harm, self-mutilation, non-suicidal self-injury, and other).

The second research question explored the hypothesis that doctoral level therapists' theoretical orientations would be associated with preferred terminology used to describe the behavior in question (self-injury, deliberate self-harm, self-mutilation, non-suicidal self-harm, and other). Theoretical orientation was based on a participant's self-report using the 11 categories supplied in the survey (Behavioral, Biological, Cognitve-Behavioral, Eclectic, Humanistic, Existential, Integrative, Interpersonal, Psychodynamic, Systems, Feminist and Other). The chi-square statistic was used to evaluate the possible association between these variables.

The third research question explored the hypothesis that doctoral level therapists' theoretical orientations would be associated with diagnoses assigned to clients who selfinjure (Anxiety, Borderline Personality Disorder, Depression, Dissociative Identity Disorder, Post-Traumatic Stress Disorder and Other). The chi-square statistic was used to evaluate the possible association between these variables. 
The fourth research question explored the hypothesis that doctoral level therapists' choices of terminology would be associated with specific diagnoses given to clients who self-injure. The chi-square statistic was used to evaluate the possible association between these variables.

The fifth research question explored the hypothesis that doctoral level therapists' theoretical orientations would be associated with a preferred term used to describe selfinjurious behavior and the diagnoses most often assigned to clients who engage in these behaviors. This analysis required a comparison among three categorical variables and the preferred technique for such an analysis is log-linear modeling. See Appendix D for a discussion of log-linear modeling and analysis as compared to Chi-squared analysis.

The sixth and final research question explored a series of potential interactions to determine if three therapist variables: (1) years in practice, (2) age and (3) gender would be associated with two response variables (1) preferred diagnosis, and (2) preferred terminology. Multiple chi-square analyses were used to evaluate the possible association between these variables. 


\section{Chapter 3}

\section{Methods}

\section{Sample}

The research sample for this study consisted of 460 doctoral level therapists who responded to a posted request for participation on the following American Psychological Association division listservs: Society for Clinical Psychology (12), Society of Counseling Psychology (17), Psychotherapy (29), Society for the Psychology of Women (35), Psychologists in Independent Practice (42), Society for the Psychological Study of Lesbian, Gay, and Bisexual Issues (44), Society for the Psychological Study of Ethnic Minority Issues (45), Society of Clinical Child and Adolescent Psychology (53), and Trauma Psychology (56). While the American Psychological Association has approximately 88,450 members with doctoral degrees representing $91 \%$ of the membership, this study was drawn from a total population of 19,063 APA members who were also members of a division listserv (American Psychological Association, 2009). Of the 460 participants who responded to the request and went to the opening page of the survey, 346 responded that they had experience with clients who used deliberate violence against one's body that resulted in tissue damage, was socially unacceptable, was not intended to cause death, was not the result of cognitive deficits such as autism or mental retardation and was not part of an accepted cultural or spiritual practice. The other 114 respondents did not indicate having experience with treating clients who engaged in these behaviors and were excluded from the study. Therefore the total sample size for the study was 346. 
In this sample, $62 \%$ were women (215 respondents), 36.3\% were male (126 respondents), $0.3 \%$ were transgender (1 respondent) and $1.2 \%$ did not answer the question (4 respondents). Participants ranged in age from 24 to 85 years old and the average age of participants was 50.4 years old $(\mathrm{SD}=13.16)$. Eleven participants $(3.0 \%)$ did not answer this question. Participants years in practice ranged from under 1 year to 55 years with an average years in practice of 18.03 years $(S D=13.16)$. Given the overall size of the sample (346), the small number of missing values (15) was not considered significant.

\section{Procedure}

The Institutional Review Board of West Virginia University examined this study in May of 2010 and it was given exempt status on May 26, 2010. A copy of the IRB Consent and Information form is located in Appendix A. The online survey program, SurveyMonkey, was used to collect data. See Appendix B for a copy of the survey that appeared on SurveyMonkey. A copy of the invitation to participate (cover letter) is in Appendix C. The first question asked whether respondents had experience with treating clients who engaged in self-injury. If they answered no, they were thanked for their participation and the assessment ended. If they answered in the affirmative, they were directed to the survey questions.

The initial three questions after respondents indicted they had experience with clients who self-injure involved personal demographic information such as years in practice, gender, and age. Next participants were asked to rank the primary, secondary, and tertiary preferred terminology for the behavior of deliberate violence against one's body that results in tissue damage, is socially unacceptable, is not intended to cause 
death, is not the result of cognitive deficits such as autism or mental retardation and is not part of an accepted cultural or spiritual practice. Following this question the participants were asked to rank the primary, secondary, and tertiary diagnoses they most frequently assigned to clients who engaged in the above behaviors.

Finally, participants were asked to rank their primary, secondary, and tertiary theoretical orientations. Theoretical orientation was assessed using the criteria of the AAPI (APPIC Application of Psychology Internship) (http://www.appic.org).

Participants were asked to rank their theoretical orientations from the following list: behavioral, biological, cognitive-behavioral, eclectic, humanistic/existential, integrative, interpersonal, psychodynamic/psychoanalytic, systems, feminist, or other.

\section{Data Analysis}

One of the goals in this dissertation was to determine if there were common terms that doctoral level therapists utilized to describe or report self-injury so that future research and treatment may be focused via this term and definition. In addition, another goal was to discover if doctoral level therapists' theoretical orientations are associated with preferred terminology and diagnoses for client who self-injure. A one-way chisquare statistic was used to analyze the frequency distribution for preferred nomenclature (self-injury, deliberate self-harm, self-mutilation, non-suicidal self-injury or other) that comprised the first research question as already described.

Likewise a two-way chi-square statistic was used to evaluate those hypotheses that explored associations between theoretical orientation and terminology and diagnosis. In aggregate then, the analyses to that point yielded four chi-squared values testing for (one-way) goodness of fit or (two-way) independence of the variables. 
To evaluate the association among the three therapist demographic variables, (gender; years in practice, and age) and the other pertinent categories (theoretical orientation, terminology and diagnosis) required multiple chi-square evaluations with several variables. Calculating so many individual statistics required by this approach served to increase the experiment-wise Type I error rate to an unacceptable level. In addition, so many comparisons with multiple variables could have led to results that were extremely difficult to interpret across categories. For example, when looking at the association of gender and preferred diagnosis for clients who self-injure and preferred terminology, the chi-squared analyses would have compared males for the two variables (terminology and diagnosis) and separate chi-squared analyses would have been calculated for females. While any number of the individual chi-square results might have proven significant, the approach did not afford the ability of assessing higher order interactions.

Log-linear modeling provided a more appropriate approach to the data analysis (Lowry, 2009; Pope \& Tabachnick, 1995; Witta, 1997). In this approach, the following potential associations were computed: therapist theoretical orientation x preferred terminology x preferred diagnosis. Log-linear modeling allows interaction effects across three categorical variables instead of the usual two variables and is a "more effective way of analyzing multi-way contingency tables" (Witta, 1997, p2). This model was necessary when examining the variables of gender (3 categories), years in practice ( 5 categories), and age (5 categories), with the variables of theoretical orientation (11 categories), diagnosis (5 categories), and preferred terminology (5 categories). Log-linear analysis is an extension of the chi-squared analysis. The conditional relationship between two or 
more discrete, categorical variables is analyzed by taking the natural logarithm of the cell frequencies within a contingency table (Jeansonne, 2002). In addition, the loglinear transformation generates an additive model which allows a more direct interpretation as the relationship among the transformed values became linear.

One of the drawbacks of log-linear modeling is the possibility of inadequate sample size may result in cells being inadequately filled. A low frequency in any specific category may create analysis problems. A second drawback to log-linear modeling is the possibility that low return rates could affect the power of the analysis. Jeansonne (2002) suggested having five times the number of cases as cells in the data. In the current study, there were a maximum of 11 categories of theoretical orientation (APPI) (http://www.appic.org) and 5 categories for the preferred diagnosis, thereby requiring a minimum of 275 completed surveys. Jeansonne (2002) suggested collapsing categories to allow analysis if this condition is not met. See Appendix D for a thorough discussion of log-linear modeling.

The likelihood ratio $\left(\mathrm{L}^{2}\right)$ was used to evaluate multi-way contingency tables with log-linear analysis, because that statistic could be partitioned uniquely for a more powerful test of conditional independence in multi-way tables (Knoke \& Burke, 1980). In addition to the $\mathrm{L}^{2}$ likelihood statistic being generated to compare three categorical variable models, the quality of the fit was examined utilizing the log-linear residuals that were generated from the $\mathrm{L}^{2}$ analysis. Residual testing pinpointed which cells detract from an otherwise well-fitting model. The strongest models are those with the smallest residuals and those that are equally divided between positive and negative values. 
This study explored whether clinicians had preferred terminology to describe clients' self-injurious behaviors. Further, it investigated whether clinicians had diagnostic preferences for these same clients. Finally, this study examined potential therapist factors, such as theoretical orientation, age, gender, and years in practice for their possible relationship with terminology preference and diagnostic preference. 


\section{Chapter IV}

Results

The literature concerning self-injury has covered significant ground since its resurgence in the popular and scientific forums. However, while we have a plethora of information about clients who self-injure and even the behaviors they engage in, we do not yet know what factors a therapist may possess that could influence the terms they use to discuss and report self-injury, or the diagnoses they are likely to assign to clients who engage in this behavior. This study explored whether a significant number of clinicians prefer a certain term to label self-injurious behavior even though the professional literature is replete with numerous terms to describe this behavior. In addition, this study examined the possible association between therapist variables that could influence the diagnosis of clients who self-injure.

In order to investigate these research questions, six hypotheses were generated and the results presented below. A sample of 346 doctoral level practitioners was obtained through an internet survey. Members of the American Psychological Association (APA) who were also members of specific listservs were invited to participate.

One of the goals of this dissertation was to determine if there are common terms that doctoral level therapists used to describe or report self-injury so that future research and treatment may be focused via this term and definition. In addition, another goal was to discover if doctoral level therapists' theoretical orientations were associated with preferred terminology and diagnoses for clients who self-injure. 


\section{Terminology Preference}

The first research hypothesis was that doctoral level clinicians would show a preference in terminology for describing self-injurious behavior. There were five choices for preferred terminology (self-harm, self-injury, self-mutilation, non-suicidal self-injury, and other). Of the 346 doctoral level practitioners who completed the survey, the following is the distribution among the terms: 135 participants chose self-harm as their preferred term (39.0\%); 114 participants chose self-injury (32.9\%); 42 participants chose self-mutilation (12.1\%); 21 participants chose non-suicidal self-injury (6.1\%); 13 participants chose other (3.9\%); and 21 participants did not answer the question $(6.1 \%)$. Because the non-suicidal self-injury and other categories were so small (6.1\% and 3.9\%), they did not add to the overall understanding of terminology preference. Therefore, the participants who chose non-suicidal self-injury as their preferred term were collapsed into the other category and the final analysis consisted of only four terms. The final distribution of participants utilized in the analysis is presented in Table 1.

Table 1

\begin{tabular}{|c|c|c|}
\hline Term & Frequency & Percent \\
\hline Self-Harm & 135 & 39.0 \\
\hline Self-Injury & 114 & 32.9 \\
\hline Self-Mutilation & 42 & 12.1 \\
\hline Other & 34 & 9.8 \\
\hline Total & 325 & 93.6 \\
\hline Missing & 21 & 6.1 \\
\hline Total & 346 & 100.0 \\
\hline
\end{tabular}

In order to determine if there was a significant preference for a specific term a one-way chi-square analysis was conducted. This analysis is also called the "goodness of fit" test because it compares the observed frequencies (data collected) to a set of expected 
frequencies. In a chi-square analysis, the expected frequencies are equally distributed across all "cells" or choices. A significant chi-square value indicates not only that there is an unequal distribution of frequencies, but also that the differences are of such magnitude as to be statistically important. In this case there was a significant chi-square value $\left(X^{2}=95.197, d f=3, p=.000\right)$ thereby indicating that the respondents did not have an equal preference for terminology. Among doctoral level therapists, the preferred terms to describe client self-injuring behaviors were self-harm (39.0\%) and self-injury (32.9\%).

\section{Theoretical Orientation and Terminology}

The second research hypothesis in this dissertation was that clinicians' theoretical orientations would show a relationship to the terminology preferred by clinicians to describe self-injurious behaviors. A clinician's conceptual understanding of a client's presenting issue is often guided by the theoretical orientation to which her or she subscribes. In this way, theoretical orientation can be said to lead the clinician's treatment approach. Therefore it is helpful to know if a clinician with a specific theoretical orientation also has a preference for certain terminology.

After reviewing the frequency distribution of the original theoretical orientation choices, the low frequency categories of biological (0.9\%), feminist (5.7\%), systems (2.6\%), and humanistic (3.7\%) were collapsed into the other $(10.3 \%)$ category.

Additionally, as discussed in the methods section, the categories of eclectic $(13.5 \%)$ and integrative $(17.8 \%)$ were unlikely to represent completely different theoretical orientation conceptualizations and therefore were combined to create a new combined category, eclectic/integrative, which represented $31.5 \%$ of the sample. The resulting theoretical orientation variable distribution is shown in Table 2. 
Table 2

Frequency Distribution for Theoretical Orientation Variable

\begin{tabular}{lrr}
\hline Theory & Frequency & Percent \\
\hline Cognitive Behavioral & 110 & 31.8 \\
Eclectic/Integrative & 109 & 31.5 \\
Interpersonal & 23 & 6.6 \\
Dynamic & 36 & 10.4 \\
Other & 63 & 18.2 \\
Total & 341 & 98.6 \\
Missing & 5 & 1.4 \\
Total & 346 & 100.0 \\
\hline
\end{tabular}

In order to explore the possible relationship between theoretical orientation and preferred terminology a two-way chi-square statistic was generated. A Pearson's chisquare is sometimes called a test of independence. A test of independence assesses whether expected frequencies are similar to the observed frequencies on two discrete variables (Tabachnick \& Fidell, 2007). For example, in this study, this measure was used to assess whether clinicians with different theoretical orientations differed in the frequency with which they used a specific term to label self-injuring behaviors. Stated differently, is the frequency of theoretical orientations equally distributed across terminology choices? A chi-square that is significant would indicate that the frequencies of the two variables were not independent. In such a case, if we were to know the theoretical orientation of a participant, we also would have some information as to which term they would prefer.

In this study the chi-square analysis result was non-significant $\left(X^{2}=11.122, d f=\right.$ $12, p=.518$ ) and is shown in Table 3. These results indicated clinicians' primary theoretical orientations and preferred terminology when describing self-injurious type behaviors were independent. Knowing a clinician's theoretical orientation does not tell us anything about the terminology they may prefer. 
Table 3

Frequency Distribution: new Theoretical Orientation $x$ new Terminology Terminology Theory

\begin{tabular}{lrrrrrr}
\hline & $\begin{array}{r}\text { Cognitive } \\
\text { Behavioral }\end{array}$ & $\begin{array}{r}\text { Eclectic/ } \\
\text { Integrative }\end{array}$ & Interpersonal & Dynamic & Other & Total \\
\hline Self-Harm & 42 & 40 & 14 & 12 & 25 & 133 \\
Self-Injury & 37 & 37 & 7 & 14 & 19 & 114 \\
Self-Mutilat & 18 & 12 & 0 & 5 & 7 & 42 \\
Other & 9 & 14 & 1 & 2 & 7 & 33 \\
Total & 106 & 103 & 22 & 33 & 58 & 322 \\
\hline
\end{tabular}

While examining the frequencies of theoretical orientation, this author was struck by the small number of clinicians who indicated feminist as their primary theoretical orientation. Given the strong feminist presence in the literature regarding self-injury, this was unexpected. It was possible that the sample was not representative due to age. Therefore, an analysis was conducted exploring the possible relationship between those clinicians who identified feminist as their primary, secondary, or tertiary theoretical orientation, a total of 58 participants, and the clinicians' ages (see Table 4). The results for this analysis were illuminating, as no relationship was found between an identification of feminist as a preferred theoretical orientation and the clinicians' ages $\left(X^{2}=11.676\right.$, $d f=12, p=.472)$.

Table 4 Chi-square test: Feminism Choice x Participant Age

\begin{tabular}{lrrrr}
\hline AgeCombo & \multicolumn{3}{c}{ Fem Choice } & \\
\hline & Primary & Secondary & Tertiary & Total \\
\hline 24-30 years & 0 & 2 & 2 & 4 \\
$30-39$ years & 6 & 3 & 8 & 17 \\
40-49 years & 4 & 0 & 4 & 8 \\
$50-59$ years & 8 & 2 & 8 & 18 \\
60-69 years & 1 & 3 & 3 & 7 \\
70 or more & 2 & 0 & 0 & 1 \\
Not Stated & 1 & 1 & 1 & 3 \\
Total & 21 & 11 & 26 & 58 \\
\hline
\end{tabular}




\section{Theoretical Orientation and Diagnosis}

The third hypothesis was that clinicians' theoretical orientations would be associated with preferred diagnoses assigned to clients who self-injure. The treatment approach of clinicians often is the outgrowth of their diagnostic conceptualization of the client's presenting issues. It may be an important factor to consider whether one's preferred diagnosis for clients who self-injure has a relationship to a clinician's theoretical orientation.

After reviewing the frequency distribution of the original preferred diagnosis choices, the low frequency category of dissociative identity disorder (1.7\%) was collapsed into the other category bringing the total participants in that category to 21 (6.1\%). Anxiety (6.4\%) is often considered a key component of PTSD (13.6\%) and was collapsed into the PTSD category which then had a total of 69 participants and together represented $19.9 \%$ of the sample. The resulting preferred diagnosis category frequencies are presented in Table 5.

Table 5

Frequency Distribution for new Preferred Diagnosis variable

\begin{tabular}{lrr}
\hline Diagnosis & Frequency & Percent \\
\hline Borderline P.D. & 139 & 40.2 \\
Depression & 47 & 13.6 \\
PTSD/Anxiety & 69 & 19.9 \\
Borderline/PTSD & 40 & 11.6 \\
Other & 21 & 6.1 \\
Total & 316 & 91.3 \\
Missing & 30 & 8.7 \\
Total & 346 & 100.0 \\
\hline
\end{tabular}

In order to explore the possible relationship between theoretical orientation and preferred diagnosis, a two-way chi-square statistic was generated. For the created variables of theoretical orientation (see previous hypothesis) and preferred diagnosis, the 
chi-square analysis was significant $\left(X^{2}=35.018, d f=16, p=.004\right)$ and is shown in Table 6. These results indicate that there is a relationship between a clinician's theoretical orientation and the preferred diagnosis for clients who self-injure. Knowing a clinician's theoretical orientation tells us something about the diagnosis they prefer to assign to clients who self-injure.

Post-hoc analyses revealed that there is an especially strong relationship between the theoretical orientation of cognitive-behavioral and the diagnosis of borderline personality disorder (adjusted residual $=3.2$ ) as well as the theoretical orientation category of other and the diagnosis of PTSD/Anxiety (adjusted residual $=3.7$ ).

Table 6

Frequency Distribution: new Theoretical Orientation x Diagnosis

\begin{tabular}{lrrrrrr}
\hline Diagnosis & \multicolumn{2}{c}{ Theory } \\
& $\begin{array}{r}\text { Cognitive } \\
\text { Behavioral }\end{array}$ & $\begin{array}{r}\text { Eclectic/ } \\
\text { Integrative }\end{array}$ & Interpersonal & Dynamic & Other & Total \\
\hline Borderline PD & 59 & 42 & 3 & 17 & 18 & 139 \\
Depression & 12 & 20 & 5 & 4 & 5 & 46 \\
PTSD/Anxiety & 13 & 16 & 8 & 8 & 23 & 68 \\
Borderline/PTSD & 12 & 12 & 3 & 4 & 9 & 40 \\
Other & 7 & 8 & 2 & 1 & 3 & 21 \\
Total & 103 & 98 & 21 & 34 & 58 & 314 \\
\hline
\end{tabular}

\section{Terminology and Diagnosis}

The fourth hypothesis was that clinicians' preferred terminology would be associated with preferred diagnoses assigned to clients who self-injure. Previous hypotheses have examined the frequency distributions of these two variables and in both cases categories were collapsed in order to improve cell frequencies. Therefore, this analysis also used the modified variables for terminology and diagnosis.

In order to explore the possible relationship between preferred terminology and preferred diagnosis, a two-way chi-square statistic was generated. In this case the chi- 
square analysis was significant $\left(X^{2}=29.185, d f=12, p=.004\right)$ and is shown in Table 7 . The results indicated that there is a relationship between preferred terminology and preferred diagnosis related to client's who self-injure. Knowing the terminology a doctoral level clinician prefers tells us something about the diagnosis that clinician will most likely assign. The post-hoc analyses revealed a relationship between the following: preference for the term self-injury and diagnostic preference for PTSD/Anxiety (adjusted residual $=2.5$ ), preference for the term self-mutilation and diagnostic preference for borderline personality disorder (adjusted residual $=2.5$ ), and a significant lack of preference for terminology other and a diagnosis of borderline personality disorder (adjusted residual $=-2.6$.

Table 7

Frequency Distribution: new Diagnosis $x$ new Terminology

\begin{tabular}{lrrrrrr}
\hline Terminology & \multicolumn{3}{c}{ Diagnosis } \\
& Borderline & Depression & PTSD/Anx & $\begin{array}{c}\text { Borderline } \\
\text { and PTSD }\end{array}$ & Other & Total \\
\hline Self-Harm & 51 & 21 & 26 & 17 & 11 & 126 \\
Self-Injury & 49 & 14 & 32 & 8 & 4 & 107 \\
Self-Mutilation & 24 & 4 & 4 & 6 & 1 & 39 \\
Other & 6 & 7 & 4 & 7 & 5 & 29 \\
Total & 130 & 46 & 66 & 38 & 21 & 301 \\
\hline
\end{tabular}

\section{Theoretical Orientation, Terminology and Diagnosis}

The fifth research hypothesis was that clinicians' theoretical orientations would interact with preferred terminology and preferred diagnoses for clients who self-injure. Previous hypotheses have generated variables with collapsed categories which were used in the log-linear analysis necessary to examine this question.

Log-linear analysis generates a likelihood ratio that is similar to a chi-square statistic except that it is used for three or more categorical variables. As the chi-square statistic is compared to a likely distribution, the log-linear statistic $\left(\mathrm{L}^{2}\right)$ is compared to a 
Poisson distribution. This distribution predicts the frequency of individual observations within three or more variables if the variables are independent of each other. A significant $\mathrm{L}^{2}$ means that the variables differ significantly from these expectations and are not independent of each other, therefore indicating a relationship between however many variables are being examined.

In this hypothesis, the variables of theoretical orientation, preferred terminology, and preferred diagnosis generated a significant likelihood ratio $\left(L^{2}=202.153, d f=153, p\right.$ $=.004)$. This significant result indicates that the three variables act in relationship to one another. Knowing which theoretical orientation a doctoral level clinician subscribes to and her or his preferred terminology regarding self-injurious behaviors, tells us something about which diagnosis will mostly likely be assigned to clients who selfinjure.

Despite the significant results, only two cells revealed a relationship. The first was the combination of preference for other theoretical orientation, self-injury, and diagnosis of PTSD/Anxiety which had an adjusted residual of 2.282. Additionally, there was a connection between the combination of preference for an eclectic/integrative theoretical orientation, other terminology, and a diagnosis of Borderline/PTSD which had an adjusted residual of 3.630 .

\section{Clinician Characteristics}

The final hypotheses explored the possible relationships between clinicians' primary theoretical orientations, preferred terminology, or preferred diagnoses, and ages, years in practice, or genders. A chi-square was generated for each of these possible relationships using the collapsed category variables of the previous hypotheses. 
Only preferred terminology was shown to have a significant relationship with therapist characteristics. Preferred terminology and age was significant $\left(X^{2}=30.388, d f\right.$ $=18, p=.034)$ with a significant lack of preference for the term self-mutilation in clinicians in the 30 - 39 year old range (adjusted residual $=-2.4$ ) as well as a lack of preference for the term self-harm in clinicians in the 60-69 year old range (adjusted residual $=-2.4)$. Preferred terminology and years in practice was significant $\left(X^{2}=\right.$ $37.867, d f=21, p=.013$ ) with a preference for the term self-mutilation by those who had been in practice for 31 or more years (adjusted residual $=3.7$ ) and a separate preference for the term self-harm by those who had been in practice only one to five years (adjusted residual $=2.8)$. Finally, preferred terminology and gender was significant $\left(X^{2}=17.667\right.$, $d f=9, p=.039$ ) with men showing a preference for the term self-mutilation (male adjusted residual $=3.5$ ) and women showing a significant lack of preference for this term (female adjusted residual $=-3.3$ ). The above results are depicted in Tables 8, 9, 10 .

Neither theoretical orientation nor diagnosis showed a significant relationship with clinician characteristics. Theoretical orientation and age was non-significant with $X^{2}$ $=24.184, d f=24, p=.451$. Theoretical orientation and years in practice was nonsignificant with $X^{2}=29.185, d f=28, p=.403$. Theoretical orientation and gender was non-significant with $X^{2}=20.700, d f=12, p=.055$. Preferred diagnosis and age was nonsignificant with $X^{2}=34.367, d f=24, p=.078$. Preferred diagnosis and years in practice was non-significant with $X^{2}=39.894, d f=28, p=.068$. Preferred diagnosis and gender was non-significant with $X^{2}=16.080, d f=12, p=.188$. 
Table 8

Frequency Distribution: Terminology $x$ Age

\begin{tabular}{lrrrrrrrr}
\hline Term & \multicolumn{1}{c}{ Age } & \multicolumn{1}{c}{ A } \\
\hline & $24-29$ & $30-39$ & $40-49$ & $50-59$ & $60-69$ & $70+$ & $\begin{array}{c}\text { Not } \\
\text { Stated }\end{array}$ & Total \\
\hline Self-Harm & 16 & 30 & 25 & 32 & 24 & 5 & 2 & 134 \\
Self-Injury & 8 & 17 & 13 & 38 & 31 & 3 & 4 & 114 \\
Self-Mutilation & 1 & 2 & 4 & 14 & 15 & 3 & 3 & 42 \\
Other & 1 & 9 & 5 & 8 & 10 & 1 & 0 & 34 \\
Total & 26 & 58 & 47 & 92 & 80 & 12 & 9 & 324 \\
\hline
\end{tabular}

Table 9

Frequency Distribution: Terminology $x$ Years in Practice

\begin{tabular}{lrrrrrrrrr}
\hline Term & \multicolumn{7}{c}{ Years in } & Practice & \\
\hline & 1 & $1-5$ & $6-10$ & $11-15$ & $16-20$ & $21-30$ & $31+$ & NoAns & Total \\
\hline Self-Harm & 11 & 39 & 12 & 9 & 16 & 27 & 20 & 0 & 134 \\
Self-Injury & 3 & 21 & 10 & 13 & 14 & 37 & 15 & 1 & 114 \\
Self-Mutilation & 1 & 3 & 0 & 4 & 7 & 11 & 16 & 0 & 42 \\
Other & 1 & 7 & 5 & 3 & 4 & 8 & 6 & 0 & 34 \\
Total & 16 & 70 & 27 & 29 & 41 & 83 & 57 & 1 & 324 \\
\hline
\end{tabular}

Table 10

Frequency Distribution: Terminology x Gender

\begin{tabular}{lrrrrr}
\hline Terminology & \multicolumn{5}{l}{ Gender } \\
\hline & Female & Male & Transgender & $\begin{array}{r}\text { Not } \\
\text { Stated }\end{array}$ & Total \\
\hline Self-Harm & 87 & 46 & 0 & 2 & 135 \\
Self-Injury & 74 & 39 & 1 & 0 & 114 \\
Self-Mutilation & 16 & 26 & 0 & 0 & 42 \\
Other & 23 & 10 & 0 & 1 & 34 \\
Total & 200 & 121 & 1 & 3 & 325 \\
\hline
\end{tabular}




\section{Chapter 5}

\section{Discussion}

In spite of the growing numbers of both clinical and non-clinical populations who engage in self-injurious behaviors, there is a lack of consensus in the literature regarding basic terminology and definitions of self-injury. Further, there are few if any studies concerning self-injury that examine therapist factors and which of these factors contribute to the clinicians' choices of terminology and diagnoses. This study sheds light on the factors that have a relationship with a clinician's choices regarding self-injury.

This study had numerous objectives. First, determine if there was a preference for terminology used by doctoral level clinicians who treat clients who engage in self-injury. Second, explore the possible relationship between clinicians' theoretical orientations and their preferred terminology for self-injury. Third, explore the possible relationship between clinicians' theoretical orientations and their preferred diagnoses for clients who engage in self-injury. Fourth, explore the possible relationship between clinicians' preferred terminology and their preferred diagnoses for clients who self-injure. Fifth, explore the possible interaction of clinicians' theoretical orientations with both preferred terminology and preferred diagnoses. Sixth, and finally, explore the possible relationships between clinicians' ages, years in practice, and genders and their preferences for terminology and diagnoses.

There were multiple findings in this study. First, doctoral level clinicians showed a preference for the terms self-injury and self-harm over the terms self-mutilation and non-suicidal self-injury. Second, clinicians' theoretical orientations did not have a relationship with their preferred terminology for self-injury. Third, clinicians' theoretical 
orientations had a relationship to their preferred diagnoses for clients who engage in selfinjury. Fourth, clinicians' preferred terminology had a relationship to their preferred diagnoses for clients who self-injure. Fifth, there was an interaction between clinicians' theoretical orientations, preferred terminology and preferred diagnoses. Sixth, and finally, clinicians' ages, years in practice, and genders did not have a relationship with their theoretical orientations or diagnoses but did have a relationship to their preferred terminology.

\section{Terminology}

The results of this study indicate that clinicians show more of a consensus regarding self-injury terminology than exists in the professional literature. In the professional literature spanning decades, a specific, well-defined, and accepted term to label self-injurious behaviors has yet to appear. The literature continues to use the terms self-injury, deliberate self-harm, and self-mutilation, among others, almost interchangeably (Nock, 2009b). By contrast, the clinicians in this study demonstrated a preference for the terms self-injury and self-harm. This terminology trends more toward the most current formulations in the professional literature to describe the phenomenon. Of note is the recent shift toward the term non-suicidal self-injury (NSSI) that is evident in the articles published after the data for this study were collected (Hankin \& Abela, 2011; Heath, Toste, Sornberger, \& Wagner, 2011; Muehlenkamp et al., 2011; You et al., 2011). The term non-suicidal self-injury may move toward acceptance as the preferred terminology within the literature and among clinicians due to its current inclusion in field trials for the upcoming DSM-V. In this study, only 21 respondents preferred NSSI. The lack of preference for this term may be a function of time as it is only the most current 
literature that utilizes this terminology. To add to the confusion, the term non-suicidal self-injury is not only being used as terminology for a set of behaviors, it is also proposed as a separate, stand-alone diagnosis.

\section{Theoretical Orientation and Terminology}

While a clinician's conceptual understanding of a client's presenting issues is often guided by his or her orientation, there is a lack of literature exploring the relationship between theoretical orientation and preference for the terminology used to describe the behaviors of self-injury. These results indicated that clinicians' theoretical orientations were not associated with their choices of terminology. In this study it appeared that clinicians' choices of terminology were a reflection of their observations of behavior or a set of behaviors and were not related to clinicians' theoretical orientations. Stated differently, the terminology used to describe self-injury was independent of clinicians' theoretical orientations.

\section{Theoretical Orientation and Diagnosis}

By contrast, the results showed that clinicians' theoretical orientations were associated with their preferences for diagnoses assigned to clients who self-injure. While there is no literature specifically examining the connection between these two variables in regard to self-injury, the significant result in this study suggests that a clinician's theoretical orientation is an influential factor in diagnosing clients who self-injure.

Suyemoto and MacDonald (1995), in their study of 44 therapists, identified a modal theoretical orientation, eclectic, and common diagnoses on both Axis I and Axis II. They did not, however, look at the relationship between the variable of theoretical orientation and diagnosis. While the current study also found that a significant number of 
clinicians ascribed to an eclectic/integrative model, the significant relationship between diagnosis and theoretical orientation was evident in several of the alternately endorsed theoretical orientations.

More specifically, in this study a clinician with a cognitive-behavioral theoretical orientation was most likely to assign a diagnosis of borderline personality disorder to clients who self-injure. This same clinician was least likely to assign a diagnosis of PTSD/Anxiety. It is possible that the present day focus of cognitive-behavior therapy is a factor in conceptualizing client behavior and assignment of a diagnosis. Moreover, dialectical behavior therapy (DBT) evolved out of cognitive behavioral therapy for the initial purpose of addressing symptoms of borderline personality disorder (Koons, Robins, Tweed, Lynch, Gonzalez, Morse, et al., 2001; Linehan, 1993; Miller, Rathus, \& Linehan, 2007). The focus of DBT, similar to CBT, is the control and reduction of unhealthy behaviors such as self-injury. Originally, the intended population for this treatment was women diagnosed with borderline personality disorder who showed maladaptive coping responses such as self-injury (Linehan, 1993; Linehan, Armstrong, Suarez, Allmon, \& Heard, 1991; Linehan et al., 2006).

Concomitantly, those clinicians in this study with an interpersonal or "other" theoretical orientation were least likely to assign a diagnosis of borderline personality disorder. It is possible that these clinicians were more focused on historical information as the underpinnings of the client's presenting issues.

In the case of an "other" theoretical orientation, the diagnosis of PTSD/Anxiety was most likely to be assigned for clients who self-injure. This "other" theoretical orientation category is difficult to interpret as it includes those with theoretical 
orientations of biology, feminist, humanist, systems, as well as those who did not identify a primary theoretical orientation. One possible explanation is that the other category may represent those clinicians who conceptualize self-injury as a coping mechanism or a response to childhood trauma. When considering the context of a client's trauma history, clinicians may not necessarily place as much significance on borderline type symptoms such as self-injury.

Some researchers are examining the significant overlap in symptoms between non-suicidal self-injury and borderline personality disorder leading to differing conceptualizations of self-injury. Healy et al., (2010) stated that "non-suicidal self-injury and borderline personality disorder share a central feature of emotional dysregulation" (2010, p.327). Further, some researchers suggest dropping the diagnosis of borderline personality disorder from the DSM-V completely. Herman (1992) stated that "some clinicians have argued that the term 'borderline' has become so prejudicial that it should be abandoned altogether, just as its predecessor term, hysteria, had to be abandoned" (p.123). It appears in this study that clinicians who endorsed an "other" theoretical orientation may have conceptualized self-injury within a context of trauma rather than borderline personality disorder.

\section{Terminology and Diagnosis}

The results of this study indicated that clinicians' preferences for terminology had a relationship to their preferred diagnoses. This result mirrors the strong dichotomous thinking in the professional literature regarding the diagnosis of clients who self-injure (Herman, 1996a, 1996b; Herman et al., 1989; Luxenberg, Spinazzola, Hidalgo, Hunt, \& van der Kolk, 2001; Sacks et al., 2008; Wiederman et al., 1999). More specifically, 
clinicians who preferred the term self-mutilation were most likely to assign a diagnosis of borderline personality disorder, while those clinicians who preferred the term self-injury were most likely to assign a diagnosis of PTSD/Anxiety. By contrast, use of the term self-harm was not clearly associated with a preference for any particular diagnosis.

Given the more introspective and retrospective nature of treatment from an interpersonal approach, the consideration of previous trauma may assist in understanding these diagnostic preferences. Experts in the field who have argued for a new diagnosis that will include self-injury most often diagnose a trauma related disorder. In describing their rationale, these authors almost exclusively use the terms self-harm or self-injury (Herman, 1992b; Weismoore \& Esposito-Smythers, 2010; Wise, 1990; Yates, 2004). A consideration of terminology, diagnosis, and theoretical orientation appears to shed some light on these associations of terminology and diagnosis.

\section{Theoretical Orientation, Terminology and Diagnosis}

While clinicians' theoretical orientations had a relationship with preferred diagnoses for clients who self-injure but not terminology, analysis of the three factors together was warranted. The hypothesis that a relationship exists between clinicians' theoretical orientations, specific terminology and diagnoses together was confirmed.

This relationship was most evident for clinicians with an eclectic/integrative theoretical orientation who preferred a term other than self-harm, self-injury, or selfmutilation. These clinicians were most likely to assign diagnoses of borderline personality disorder and co-morbid PTSD. Alternately, clinicians who endorsed a theoretical orientation covered by the "other" category and preferred the term self-injury were most likely to assign a diagnosis of PTSD alone. 


\section{Clinician Characteristics}

The final research question was addressed by multiple hypotheses. First, the results indicated that doctoral level clinicians' primary theoretical orientations were not related to their ages. This result may be explained by the fact that clinicians can be taught a wide variety of theoretical orientations and/or may switch conceptualizations as they grow more experienced or as they review research that may recommend differing approaches for different presenting problems.

The above explanation regarding theoretical orientation and age also holds true for theoretical orientation and the lack of its relationship with years in practice. The results indicated that years in practice did not have a relationship with clinicians' theoretical orientations. Finally, the results suggested that theoretical orientation is not related to clinicians' genders. This result supports the understanding that theoretical orientations assist clinicians in conceptualizing client behavior and presenting concerns and are unlikely to be affected by factors such as gender.

The results indicate that preferred diagnoses of clients who self-injure were not related to clinicians' age or years in practice. This author hypothesized that diagnostic preference would have changed and evolved over time as reflected in the literature (Adler

\& Adler, 2007; Allen, 2004; Andover et al., 2005; Beitman, Goldfried, \& Norcross, 1989; Brooks-Harris, 2007; Brown \& Bryan, 2007; Claes \& Vandereycken, 2007) and, therefore, be reflective of clinicians' ages and years in practice. The earliest and primary conceptualization of self-injury was within the context of a borderline personality disorder, a diagnosis that continues to be relevant for many people who self-injure. Given the established nature of this diagnosis, one would anticipate that older clinicians 
who have been in practice longer would diagnose clients who self-injure as having a borderline personality disorder while younger clinicians, newer to practice, would trend toward one of the alternative, newer diagnoses now being presented in the literature (e.g., complex PTSD). This was not the case. Neither age nor years in practice was associated with preferred diagnosis. This may be a reflection of the extent to which clinicians stay current with the professional literature and assimilate new research into their own practices.

Diagnosis also was not related to clinician gender. This author assumed that female clinicians would be less likely to assign a diagnosis of borderline personality disorder given the history of over-diagnosing of this disorder in women (Becker, 2000; Brown, 1992; Enns, 1993; Herman, 1993; Strong, 1998). This was not the case, however.

The hypotheses regarding the relationship with ages, years in practice, and genders on terminology were all confirmed. Given the lack of relationship between clinician variables so far, it was somewhat surprising that terminology would have a relationship to clinician factors. The results indicated that preferred terminology is associated with the age of the clinician. For example, clinicians who were 24 to 30 years old preferred the term self-harm. Alternatively, those clinicians who were 60 to 69 years old endorsed the term self-mutilation. This may reflect the fact that self-mutilation was the first, and for a time, the only term used to describe self-injurious behaviors within the literature. For clinicians who were 30 to 39 years old, the term self-mutilation was least likely to be preferred and may be indicative of their exposure to multiple terms describing similar behavior. 
This preference for or against a specific term based upon clinician age was consistent with the results indicating that terminology had an association with the number of years in practice. Those clinicians who were in practice less than five years were likely to prefer the term self-harm, whereas those therapists in practice for 21 or more years were more likely to prefer the term self-mutilation. It is understandable that young clinicians who are also newer to practice would prefer terminology that represents the subtle shift away from self-mutilation and toward terms such as self-harm or self-injury.

In addition to age and years in practice, terminology for self-injury was related to clinicians' genders. In this study men were most likely to prefer the term self-mutilation while women were least likely to prefer this term. Female therapists may be more inclined to view this term as pejorative and not representative of the nature of self-injury. The influence of gender did not extend to preferred theoretical orientation or preferred diagnosis.

There appears to be a significant shift in clinician preference away from the term self-mutilation to terms such as self-harm and self-injury. However, clinicians are still diagnosing self-injuring clients primarily with borderline personality disorder. While this could truly represent large numbers of clients with an Axis II disorder, it may also reflect a lack of a better fitting diagnosis at the current time. Many clinicians and researchers alike are lobbying for a change in the diagnostic criterion of borderline personality disorder regarding self-injury in the upcoming DSM-V. It has been suggested that the authors remove self-injury as a criterion of Borderline Personality Disorder and incorporate the behavior of self-injury into a trauma focused diagnosis such as PTSD (Alexander, 1999; Becker \&Lamb, 1994; Burstow, 1992; Cavanaugh, 2002; Herman, 
1992; Herman et al., 1989; Herman \& van der Kolk, 11992; Herman et al., 1989; Herman \& van der Kolk, 1987; Hodges, 2003; Klonsky \& Moyer, 2008; Lang \& Sharma-Patel, 2011; Miller, 1996; Trepal, 2010; van der Kolk et al., 1996) This shift may be occurring prior to the release of the DSM-V as evidenced by the clinicians who chose depression and PTSD rather than BPD as the most common diagnosis for clients who self-injure.

Results of this study indicate that clinician factors such as theoretical orientation appear to be associated with the terms that clinicians prefer and that terminology in turn has a relationship to preferred diagnoses for clients who self-injure. This study was able to shed light on interactions between clinicians' theoretical orientations, preferred terminology for self-injury, and preferred diagnoses for those clients who engage in this behavior. In addition, age of clinicians, years in practice and gender influence terminology. It was beyond the scope of this study to explore how and why these characteristics interact.

\section{Limitations}

While the results of this study were informative, there were multiple limitations that affect the generalizability and validity of the results. The first limitation is also the most significant, the need to recode several of the research variables. While it was enlightening to have clinicians rank their primary, secondary, and tertiary theoretical orientation, preferred terminology, and preferred diagnosis, this type of question made comparisons and analysis difficult. Therefore, secondary variables were created that included only a respondent's primary choice of those three variables. Additionally, because of the large number of empty cells in the chi-square analysis, it was necessary to combine some of the choices from those variables. Fortunately, this did not actually 
change the over-all significance of the analysis. It did, in some cases, make the analysis more fruitful and increased interpretive value as well as statistical clarity.

The second limitation, the composition of the sample, is a common one. As with many other research studies, this study used a convenience sample of a population of clinicians. As a large group, members of the American Psychological Association (APA) seemed to offer a substantial and diverse population with a 2009 membership of approximately 97,000 members (APA, 2009). One can safely assume, however, that not all practicing doctoral level clinicians are members of the APA. Additionally, not all APA members had an equal chance of selection. In order to be included in the sample respondents needed to be APA members and members of at least one of the following divisions: Society for Clinical Psychology (12), Society of Counseling Psychology (17), Psychotherapy (29), Society for the Psychology of Women (35), Psychologists in Independent Practice (42), Society for the Psychological Study of Lesbian, Gay, and Bisexual Issues (44), Society for the Psychological Study of Ethnic Minority Issues (45), Society of Clinical Child and Adolescent Psychology (53), and Trauma Psychology (56). Membership in a particular division was required in order to be eligible for participation in the division's electronic listserv that was used to solicit participation. There is no current data concerning the number of people who belong to or are active on the electronic listservs. However, given the total number of participants who visited the survey site and the total number of completed surveys this sample was large enough to assume that it reflected statistical heterogeneity. This sample limits the extent to which interpretations can be generalized to all doctoral level psychologists. 
A third limitation was the fact that clinicians were forced to rank their preferences for theoretical orientation, preferred terminology, and preferred diagnosis. This type of question is limiting in that clinicians may see themselves as having no primary theoretical orientation or as being unable to single out one orientation above others. Additionally, this style of question may have also frustrated respondents who wanted more narrow or broad choices for terminology and diagnosis as indicated by the respondents who chose the "other" category for their responses. Many of the respondents who chose the "other" category explained this choice by providing their preferred terminology that was often a description of the behavior such as "cutting" or "scratching." This qualifying data indicates that for a few of the respondents the terminology choices may have been too broad.

The last limitation to be discussed is one that all researchers and clinicians examining self-injury and diagnosis face at the present time. That is, when self-injury is a client's presenting concern, only Borderline Personality Disorder explicitly includes self-injury as a criterion for diagnosis. Clinicians in these cases may feel compelled to diagnose BPD. It is possible that if the upcoming DSM-V includes a separate diagnosis of non-suicidal self-injury, considers the behavior of self-injury as a criterion under multiple diagnoses, and/or removes the criterion from BPD as suggested by some, a shift in diagnostic preference may become evident.

\section{Directions for Future Research}

This study was limited to an examination of clinicians' preferences for terminology and diagnosis of clients who self-injure. A precise understanding of the factors that influence these choices is yet to be explored. One factor influencing the shift 
of terminology preference toward self-harm and self-injury may be the stigma and negative connotation professed by some researchers related to other terms such as selfmutilation (Claes et al., 2007; Connors, 2000; Herman, 1996b; Kakhaovets, Young, Purnell, Huebner, \& Bishop, 2010; Whipple \& Fowler, 2011). Investigation of clinician attitudes regarding specific terms and diagnoses for clients who self-injure, therefore, may prove enlightening.

Future research may find it fruitful to examine the following questions. Given the multiple terms used to describe self-injury in the literature and by clinicians, is it possible to develop a single, systemic and thorough treatment approach for various conceptualizations and definitions of self-injury? Will the possible inclusion of nonsuicidal self-injury as a diagnosis in the upcoming DSM-V change the preferred terminology of clinicians? Further, since the DSM-V inclusion of NSSI is currently being investigated as a diagnosis that would be listed under childhood impulse control disorders, how could it be utilized for clients who first self-injure in adulthood? It will be enlightening to witness what changes, if any, occur with a settling of literature on a specific term, with a specific definition, and a more clearly defined diagnostic picture.

Finally, this research laid the groundwork for future investigation into the relationship between clinicians' theoretical orientation and multiple facets of self-injury and the treatment of those who engage in the behavior. Given the relationship between clinicians' theoretical orientations on preferred diagnoses for clients who self-injure, are clinicians' theoretical orientations related to treatment approaches for these clients? If so, is there evidence for a more or less successful treatment approach that might be adopted by a wider audience of clinicians? Are they doing something specific in response to a 
theoretical orientation? If theoretical orientation is not related to treatment approaches, then what are clinicians actually doing during their treatment of clients who self-injure, and does it work? Are clinicians adopting an eclectic/integrative approach, or perhaps a more formal multi-modal approach?

\section{Summary}

Self-injury is a complex and often disturbing behavior that continues to show rising trends throughout clinical and non-clinical populations. While there is widespread identification of the behavior and even understanding of the functions the behaviors serve for clients, there is a lack of agreement over terminology and diagnosis in the literature. It is hoped that the DSM-V will adopt specific terminology and increase diagnostic clarity regarding self-injury.

While there is certainly a shift occurring in the literature toward the terminology of non-suicidal self-injury, the DSM-V workgroup consideration of this term as both behavioral terminology and a diagnosis is bound to create some confusion. This author agrees that a common terminology is long overdue and necessary, and that non-suicidal self-injury is a clear, accurate, and definable choice. However, non-suicidal self-injury as a standalone diagnosis is more troublesome. This is especially true if included under childhood impulse disorders. This clinician believes that self-injury rarely occurs without other presenting issues. Additionally, it does occur, quite frequently into adulthood as well as initiated in adulthood in some clients. Add to this the fact that the majority of research participants most frequently endorse an affect regulation/tension reduction model of explanation, and self-injury seems less a single problematic behavior and more a behavior within a larger context. Therefore, a diagnosis of non-suicidal self-injury may 
be undeserved or there may not be sufficient context to understand the role the behavior is playing in a given client.

Prior to this study, little was known about possible connections between therapist variables and aspects of self-injury. We now know there are significant relationships between therapist characteristics and their preferences for terminology and diagnoses for clients who self-injure. These results suggest that while there appear to be major differences between clinical literature and those doing clinical practice, there may also be a convergence toward a shared common language and a wider discussion on appropriate diagnosis for clients who self-injure. More specifically, it appears more clinicians are exploring the role trauma has in the formation of borderline-like personality traits and the possibility that BPD may not be as widespread as it currently appears.

The diagnostic and statistical manual of the American Psychiatric Association often precedes or mirrors societal shifts and changes, e.g. removal of homosexuality as a disorder in the DSM-III (1980). This author hopes that the DSM-V will continue this tradition and broaden the diagnostic choices available to clinicians in regard to the behavior of self-injury. While there are certainly clients who self-injure and whose presentation and life challenges clearly fit the diagnostic criteria for borderline personality disorder, there are others for whom the diagnosis is less clear. The variability in diagnosis by clinicians in this study suggest that there is reluctance for many clinicians to assign a diagnosis of borderline personality disorder even though it is still the only diagnosis in the DSM that lists self-injury as a possible criterion. For those clients with traumatic backgrounds, it may be more fruitful to understand the behavior within a complex trauma context. A shift in the DSM-V would mirror the shift in our culture 
toward openly recognizing the long-term effects of traumatic events, especially for women. The results of this study suggest that clinicians are trending toward a less pejorative stance with a greater recognition of the effects of trauma. The inclusion of the diagnosis of Complex PTSD or DESNOS as suggested by Herman, van der Kolk, and others, with a criterion of self-injury, would enhance clinicians diagnostic accuracy, spur additional research into the nuances of trauma and self-injury, and allow for wider treatment approaches for this difficult behavior. Only through continued research and practice by clinicians' can a more fully conceptualized, efficacious approach to addressing this complex behavior be realized. 


\section{References}

Adler, P.A., \& Adler, P. (2007). The demedicalization of self-injury: From psychopathology to sociological deviance. Journal of Contemporary Ethnography, 36(5), 537-570.

Akyuz, G., Sar, V., Kugu, N., \& Dogan, O. (2005). Reported childhood trauma, attempted suicide and self-mutilative behavior among women in the general population. European Psychiatry, 20, 268-273.

Alderman, T. (1997). The scarred soul: Understanding and ending self-inflicted violence. Oakland, CA: New Harbinger.

Alexander, Laurel Ann (1999). The functions of self-injury and its link to traumatic events in college students (Doctoral dissertation). Available from ProQuest Dissertations and Theses database. (Order No. 9932285).

Alexander, N., \& Clare, L. (2004). You still feel different: The experience and meaning of women's self-injury in the context of a lesbian or bisexual identity. Journal of Community and Applied Social Psychology, 14(2), 70-84.

Allen, C. (2004). Borderline personality disorder: Towards a systemic formulation. Journal of Family Therapy, 26, 126-141.

American Psychological Association. (2009). Current major field of APA members by membership status. APA Centers for Workplace Studies. Retrieved from http://www.apa.org/ads/about/ad-demographics.pdf

American Psychological Association. (2000). Diagnostic and Statistical Manual of Mental Disorders, fourth edition, text revision. Washington, D.C.: American Psychiatric Association. 
Andover, M.S., Pepper, C.M., \& Gibb, B.E. (2007). Self-mutilation and coping strategies in a college sample. Suicide and Life-Threatening Behavior, $37(2), 238-243$.

Andover, M.S., Pepper, C.M., Ryabchenko, K.A., Orrico, E.G., \& Gibb, B.E. (2005). Self-mutilation and symptoms of depression, anxiety, and borderline personality disorder. Suicide and Life-Threatening Behavior, 35, 581-591.

Andover, M.S., Primack, J.M., Gibb, B.E., \& Pepper, C.M. (2010). An examination of non-suicidal self-injury in men: Do men differ from women in basic NSSI characteristics? Archives of Suicide Research, 14(1), 79-88.

Armey, M.F., \& Crowther, J.H. (2008). A comparison of linear versus non-linear models of aversive self-awareness, dissociation, and non-suicidal self injury among young adults. Journal of Consulting and Clinical Psychology, 76(1), 9-14.

Austin, L., \& Kortum, J. (2004). Self-injury: The secret language of pain for teenagers. Education, 124, 517-527.

Aviram, R.B., Hellerstein, D.J., Gerson, J., \& Stanley, B. (2004). Adapting supportive psychotherapy for individuals with borderline personality disorder who self-injure or attempt suicide. Journal of Psychiatric Practice, 10(3), 145-155.

Babiker, G., \& Arnold, L. (1997). The language of injury: Comprehending selfmutilation. Leicester, UK: British Psychological Society.

Banyard, V.L., Williams, L.M., \& Siegel, J.A. (2000). The long-term mental health consequences of child sexual abuse: An exploratory study of the impact of multiple traumas in a sample of women. Journal of Traumatic Stress, 14, $697-$ 715. 
Baral, I., Kora, K., Yuksel, S., \& Sezgin, U. (1998). Self-mutilating behavior of sexually abused female adults in Turkey. Journal of Interpersonal Violence, 13, 427-437.

Bateman, A., \& Fonagy, P. (2001). Treatment of borderline personality disorder with psychoanalytically oriented partial hospitalization: An 18-month follow-up. American Journal of Psychiatry, 158, 36-42.

Beck, A. (1963). Thinking and depression: Idiosyncratic content and cognitive distortions. Archives of General Psychiatry, 9, 324-333.

Becker, D. (2000). When she was bad: Borderline personality disorder in a posttraumatic age. American Journal of Orthopsychiatry, 70(4), 422-432.

Becker, D. \& Lamb, S. (1994). Sex bias in the diagnosis of borderline personality disorder and posttraumatic stress disorder. Professional Psychology: Research and Practice, 25(1), 55-61.

Becker, D.F., McGlashan, T.H., \& Grilo, C.M. (2006). Exploratory factor analysis of borderline personality disorder criteria in hospitalized adolescents: Comparison with hospitalized adults. American Journal of Psychiatry, 159, 2042-2047.

Beitman, B.D., Goldfried, M.R., \& Norcross, J.C. (1989). The movement toward integrating psychotherapies: An overview. American Journal of Psychiatry, 146(2), 138-147.

Bennum, I., \& Phil, M. (1983). Depression and hostility in self-mutilation. Suicide and Life-Threatening Behavior, 14, 166-186.

Bergmann, G. (1846). Ein Fall von religioser Monomanie. Algemeine Z Psychiatrie, 3, 365-380.

Bernstein, D.P., Cohen, P., Velez, C.N., Schwab-Stone, M., Siever, L.J., \& Shinsato, L. 
(1993). Prevalence and stability of the DSM-III-R personality disorders in a community-based survey of adolescents. American Journal of Psychiatry, 150, 1237-1243.

Best, R. (2005). An educational response to deliberate self-harm: Training, support, and school agency links. Journal of Social Work Practice, 19(3), 275-287.

Blessing, S. (1990). Self-inflicted violence: perspectives on women's self injury. Paper presented at the Seventh International Conference on Multiple Personality/ Dissociative States, Chicago, IL, November.

Bohus, M., Limberger, M., Ebner, U., Glocker, F.X., Schwarz, B., Wernz, M., \& Lieb, K. (2000). Pain perception during self-reported distress and calmness in patients with borderline personality disorder and self-mutilating behavior. Psychiatry Research, 95, 251-260.

Bondurant, H., Greenfield, B., \& Tse, S.M. (2004). Construct validity of the adolescent borderline personality disorder: A review. Canadian Child and Adolescent Psychiatry Review, 13, 53-57.

Boudewyn, A., \& Liem, J. (1995). Childhood sexual abuse as a precursor to depression and self-destructive behavior in adulthood. Journal of Traumatic Stress, 8, 445459.

Boxer, P. (2010). Variations in risk and treatment factors among adolescents engaging in different types of deliberate self-harm in an inpatient sample. Journal of Clinical Child \& Adolescent Psychology, 39(4), 470-480.

Brain, K., Haines, J., \& Williams, C. (1998). The psychophysiology of self-mutilation: Evidence of tension reduction. Archives of Suicide Research, 4, 227-242. 
Briere, J., \& Gil, E. (1998). Self-mutilation in clinical and general population samples: prevalence, correlates and functions. American Journal of Orthopsychiatry, 68(4), 609-620.

Brittlebank, A.D., Cole, A., Hassanych, F., Kenny, M., Simpson, D., \& Scott, K. (1990). Hostility, hopelessness, and deliberate self-harm: A prospective follow-up study. Acta Psychiatrica Scandinavica, 81, 280-283.

Brodsky, B., Cloitre, M., \& Dulit, R. (1995). Relationship of dissociation to selfmutilation and childhood abuse in borderline personality disorder. American Journal of Psychiatry, 152, 1788-1792.

Brooks-Harris, J.E. (2007). Integrative Multitheoretical psychotherapy. Florence, KY: Wadsworth.

Brown, L.S. (1992). A feminist critique of the personality disorders. In L.S. Brown \& M. Ballou (Eds.), Personality and psychopathology: Feminist reappraisals (pp.206-228). New York, NY: Guilford Press.

Brown, L.S. \& Bryan, T.C. (2007). Feminist therapy with people who self-inflict violence. Journal of Clinical Psychology, 63(11), 1121-1133.

Brown, M.Z., Comtois, K.A., \& Linehan, M.M. (2002). Reasons for suicide attempts and nonsuicidal self-injury in women with borderline personality disorder. Journal of Abnormal Psychology, 111(1), 198-202.

Brown, M.Z., Linehan, M.M., Comtois, K.A., Murray, A., \& Chapman, A.L. (2009). Shame as a prospective predictor of self-inflicted injury in borderline personality disorder: A multi-modal analysis. Behaviour Research and Therapy, 47, 815-822. 
Bryer, J., Nelson, B., Miller, J., \& Krol, P. (1987). Childhood sexual and physical abuse as factors in adult psychiatric illness. American Journal of Psychiatry, 144, 14261430.

Burstow, B. (1992). Radical feminist therapy: Working in the context of violence. Newbury Park, CA: Sage.

Busfield, J. (1996). Men, women, and madness: Understanding gender and mental disorder. Basingstoke, U.K.: Macmillan Press.

Callanghan, P. (2004). Exercise: A neglected intervention in mental health care? Journal of Psychiatric and Mental Health Nursing, 11, 476-483.

Carr. E.G. (1977). The motivation of self-injurious behavior. Psychological Bulletin, 85, 800-816.

Carroll, J., Shaffer, C., Spensley, J., and Abramowitz, S.I. (1980). Family experiences of self-mutilating patients. American Journal of Psychiatry, 137, 852-853.

Castille, K., Prout, M., Marczyk, G., Shmidheiser, M., Yoder, S., \& Howlett, B. (2007). The early maladaptive schemas for self-mutilators: Implications for therapy. Journal of Cognitive Psychotherapy: An International Quarterly, 21(1), $58-71$.

Cavanaugh, R.M. (2002). Self-mutilation as a manifestation of sexual abuse in adolescent girls. Journal of Pediatric Adolescent Gynecology, 15, 97-100.

Chapman, A.L., \& Dixon-Gordon, K.L. (2007). Emotional antecedents and consequences of deliberate self-harm and suicide attempts. Suicide and LifeThreatening Behavior, 37(5), 543-552.

Chapman, A.L., Gratz, K.L., \& Brown, M.Z. (2006). Solving the puzzle of deliberate 
self-harm: The experiential avoidance model. Behaviour Research and Therapy, 44, 371-394.

Chiesa, M., Sharp, R., \& Fonagy, P. (2011). Clinical associations of deliberate selfinjury and its impact on the outcome of community-based and long-term inpatient treatment for personality disorder. Psychotherapy and Psychosomatics, 80, 100-109.

Chu, J.A. (1991). The repetition compulsion revisited: Reliving dissociated trauma. Psychotherapy: Theory, Research, Practice, Training, 28(2), 327-332.

Claes, L., Muehlenkamp, J., Vandereycken, W., Hamelinck, L., Martens, H., \& Claes, S. (2010). Comparison of non-suicidal self-injurious behavior and suicide attempts in patients admitted to a psychiatric crisis unit. Personality and Individual Differences, 48, 83-87.

Claes, L., \& Vandereycken, W. (2007). Self-injurious behavior: Differential diagnosis and functional differentiation. Comprehensive Psychiatry, 48, 137-144.

Claes, L., Vandereycken, W., \& Vertommen, H. (2007). Self-injury in female versus male psychiatric patients: A comparison of characteristics, psychopathology, and aggression regulation. Personality and Individual Difference, 42, 611-621.

Clarkin, J.F., Widiger, T.A., Frances, A., Hurt, S.W., \& Gilmore, M. (1983). Prototypic typology and the borderline personality disorder. Journal of Abnormal Psychology, 92(3), 263-275.

Cloutier, P., Martin, J., Kennedy, A., Nixon, M., \& Muehlenkamp, J. (2010). Characteristics and co-occurrences of adolescent non-suicidal self-injury and suicidal behaviours in pediatric emergency crisis services. Journal of Youth 
\& Adolescence, 39, 259-269.

Coid, J., Allolio, B., \& Rees, L.H. (1983). Raised plasma metenkephalin in patients who habitually mutilate themselves. Lancet, 2, 545-546.

Commons-Treloar, A.J., \& Lewis, A.J. (2008). Professional attitudes towards deliberate self-harm in patients with borderline personality disorder. Australian and New Zealand Journal of Psychiatry, 42, 578-584.

Comtois, K.A. (2002). A review of interventions to reduce the prevalence of parasuicide. Psychiatric Services, 53, 1138-1144.

Conn, L., \& Lion, J. (1983). Self-mutilation: A review. Psychiatric Medicine, 1, 21-33.

Connors, R. (1996a). Self-injury in trauma survivors: Levels of clinical response. American Journal of Orthopsychiatry, 66(2), 207-216.

Connors, R. (1996b). Self-injury in trauma survivors: Functions and meanings. American Journal of Orthopsychiatry, 66(2), 197-206.

Connors, R. (2000). Self-injury: Psychotherapy with people who engage in self-inflicted violence. Northvale, NJ: Aronson Press.

Corey, G. (2009). Theory and practice of counseling and psychotherapy, $8^{\text {th }}$ ed. Belmont, CA: Thompson Press.

Cornsweet, C. (1983). Nonspecific factors and theoretical choice. Psychotherapy: Theory, Research, and Practice, 20(3), 307-313.

Courtois, C.A. (1988). Healing the incest wound: Adult survivors in therapy. New York, NY: W.W. Norton \& Co.

Crouch, W., \& Wright, J. (2004). Deliberate self-harm at an adolescent unit: A qualitative investigation. Clinical Child Psychology and Psychiatry, 9(2), 
185-204.

Croyle, K.L., \& Waltz, J. (2007). Subclinical self-harm: Range of behaviors, extent, and associated characteristics. American Journal of Orthopsychiatry, 77(2), 332-342.

Csorba, J., Ferencz, S., Solymossy, M., Vados, M., \& Pali, E. (2007). Diagnoses and detailed behavioural characteristics of self-injurious adolescent outpatients. [Hungarian]. Mentalhigiene es Pszichoszomatika, 8(2), 97-110.

Darche, M.A. (1990). Psychological factors differentiating self-mutilating and nonself mutilating adolescent inpatient females. The Psychiatric Hospital, 21, 31-35.

Dattilio, F.M. (2000). Cognitive-behavioral strategies. In J.Carlson \& L.Sperry (Eds.). Brief therapy with individuals and couples (pp.33-70). Phoenix, AZ: Zeig, Tucker \& Theisen.

Davies, J.M., \& Frawley, M.G. (1994). Treating the adult survivor of childhood sexual abuse: A psychoanalytic perspective. New York, NY: Basic Books.

Deiter, P.J., \& Pearlman, L.A. (1998). Responding to self-injurious behavior. In P.M. Kleespies (Ed.), Emergencies in mental health practice: Evaluation and Management (pp.235-257). New York, NY: Guilford Press.

De Leo, D., \& Heller, T.S. (2004). Who are the kids who self-harm? An Australian self-report school survey. Medical Journal of Australia, 181(3), 140-144.

Dellinger-Ness, L.A., \& Handler, L. (2007). Self-injury, gender, and loneliness among college students. Journal of College Counseling, 10(2), 142-152.

Derouin, A., \& Bravender, T. (2004). Living on the edge: The current phenomenon of self-mutilation in adolescents. The American Journal of Maternal/Child Nursing, 29(1), 12-18. 
DiClemente, R., Ponton, L., \& Hartley, D. (1991). Prevalance and correlates of cutting behavior: Risk for HIV transmission. Journal of the American Academy of Child and Adolescent Psychiatry, 30(5), 735-739.

Diekstra, R. (1993). The epidemiology of suicide and parasuicide. Acta Psychiatrica Scandinavia, suppl. 371, 9-20.

Doctors, S. (1981). The symptom of delicate self-cutting in adolescent females: A developmental view. In S.C. Feinstein, J.G. Looney, A.Z. Schwartzberg, and A.D. Sorosky (Eds.), Adolescent Psychiatry, (pp.443-460). Chicago: University of Chicago Press.

Dorer, C. (1998). An evaluation of protocols for child and adolescent deliberate selfharm. Child Psychology \& Psychiatry Review, 3(4), 156-160.

Douglas, J., Cooper, J., Amos, T., Webb, R., Guthrie, E., \& Appleby, L. (2004). "Near-fatal" deliberate self-harm: Characteristics, prevention and implications for the prevention of suicide. Journal of Affective Disorders, 79, 263-268.

Dubo, E.D., Zanarini, M.C., Lewis, R.E., \& Williams, A.A. (1997). Childhood antecedents of self-destructiveness in borderline personality disorder. Canadian Journal of Psychiatry, 42, 63-69.

Dulit, R.A., Fyer, M.R., Leon, A.C., Brodsky, B.S., \& Frances, A.J. (1994). Clinical correlates of self-mutilation in borderline personality disorder. American Journal of Psychiatry, 151, 1305-1311.

Dyer, K., Dorahy, K., Hamilton, G., Corry, M., Shannon, M., MacSherry, A., McRobert, G., Elder, R., \& McElhill, B. (2009). Anger, aggression, and self-harm in PTSD and complex PTSD. Journal of Clinical Psychology, 65(10), 1099-1114. 
Ellis, A. (2001). Overcoming destructive beliefs, feelings, and behaviors. Amherst, NY: Prometheus Books.

Ellis, A., \& Harper, R.A. (1997). A guide to rational living ( $3^{\text {rd }}$ ed.). North Hollywood, CA: Wilshire Books.

Enns, C.Z. (1991). The “new" relationship models of women's identity: A review and critique for counselors. Journal of Counseling and Development, 69, 209-217.

Enns, C.Z. (1993). Twenty years of feminist counseling and therapy: From naming biases to implementing multifaceted patients. The Counseling Psychologist, $21(1), 3-87$.

Enns, C.Z. (2003). Contemporary adaptations of traditional approaches to the counseling of women. In M. Kopala \& M. Keitel (Eds.), Handbook of Counseling Women (pp.1-21), Thousand Oaks, CA: Sage.

Enns, C.Z. (2004). Feminist theories and feminist psychotherapies: Origins, themes, and diversity ( $2^{\text {nd }}$ ed.). New York, NY: Haworth.

Ettinger, S.L. (1992). Transforming psychic pain: The meaning and function of selfinjury in women's lives. (Unpublished master's thesis). Smith College, Massachusetts.

Evans, E., Hawton, K., \& Rodham, K. (2004). Factors associated with suicidal phenomena in adolescents: A systematic review of population-based studies. Clinical Psychology Review, 24, 957-979.

Evans, J. (2000). Interventions to reduce repetition of deliberate self-harm. International Review of Psychiatry, 12, 44-47.

Evern, C., \& Evern, B. (2005). Self-mutilation in substance-dependent patients and 
relationship with childhood abuse and neglect, alexithymia, temperament, and character dimensions of personality. Drug and Alcohol Dependence, 80, 15-22.

Farberow, N.L (1980) The many faces of suicide: self-destructive behavior.

New York, NY: McGraw-Hill.

Favazza, A. (1989). Why patients mutilate themselves. Hospital and Community Psychiatry, 40(2), 137-145.

Favazza, A. (1992). Repetitive self-mutilation. Psychiatric Annals, 22, 60-63.

Favazza, A. (1996). Bodies Under Siege. Baltimore, MD: Johns Hopkins University Press.

Favazza, A. (1998). The coming of age of self-mutilation. The Journal of Nervous and Mental Disease, 186(5), 259-268.

Favazza, A., \& Conterio, K. (1988). The plight of chronic self-mutilators. Community Mental Health, 24, 22-30.

Favazza, A., DeRosear, L., \& Conterio, K. (1989). Self-mutilation and eating disorders. Suicide and Life Threatening Behaviors, 19, 352-361.

Figueroa, M. (1988). A dynamic taxonomy of self-destructive behavior. Psychotherapy, $25,280-287$.

Firestone, R.W. \& Seiden, R.H. (1990). Suicide and the continuum of self-destructive behavior. Journal of American College Health, 38(5), 207-231.

Galley, M. (2003). Student self-harm: Silent school crisis. Education Weekly, 23, 1-3. Gallop, R., Lancee, W., \& Garfinkel, P. (1989). How nursing staff respond to the label “borderline personality disorder." Hospital and Community Psychiatry, 40(8), 815-819. 
Gardner, D.L., \& Cowdry, R.W. (1986). Positive effects of carbamazepine on behavioral dyscontrol in borderline personality disorder. American Journal of Psychiatry, 143, 519-522.

Gaston, L., \& Ring, J.M. (1992). Preliminary results on the Inventory of Therapeutic Strategies. Journal of Psychotherapy Practice and Research, 1, 135-146.

Gilligan, C. (1982). In a different voice. Cambridge, MA: Harvard University Press. Gladstone, G.L., Parker, G.B., Mitchell, P.B., Malhi, G.S., Wilhelm, K., \& Austin, M.P. (2004). Implications of childhood trauma for depressed women: An analysis of pathways from childhood sexual abuse to deliberate self-harm and revictimization. American Journal of Psychiatry, 161(8), 1417-1425.

Glassman, L.H., Weierich, M.R., Hooley, J.M., Deliberto, T.L., \& Nock, M.K. (2007). Child maltreatment, non-suicidal self-injury, and the mediating role of selfcriticism. Behaviour Research and Therapy, 45, 1483-1490.

Goddard, N., Subotsky, F., \& Fombonne, E. (1996). Ethnicity and adolescent deliberate self-harm. Journal of Adolescence 19, 513-521.

Gollust, S.E., Eisenberg, D., \& Golberstein, E. (2008). Prevalence and correlates of self-injury among university students. Journal of American College Health, 56(5), 491-498.

Gratz K. (2001). Measurement of deliberate self-harm: Preliminary data on the Deliberate Self-Harm Inventory. Journal of Psychopathology and Behavioral Assessment, 23(4), 253-263.

Gratz, K. (2003). Risk factors for and functions of deliberate self-harm: An empirical 
and conceptual review. Clinical Psychology: Science and Practice, 10(2), 192205.

Gratz, K. (2006). Risk factors for deliberate self-harm among female college students: The role and interaction of childhood maltreatment, emotional inexpressivity, and affect intensity/reactivity. American Journal of Orthopsychiatry, 76(2), 238-250.

Gratz, K. (2007). Targeting emotion dysregulation in the treatment of self-injury. Journal of Clinical Psychology: In Session, 63(11), 1091-1103.

Gratz, K.L., \& Chapman, A.L. (2007). The role of emotional responding and childhood maltreatment in the development and maintenance of deliberate self-harm among male undergraduates. Psychology of Men and Masculinity, 8(1), 1-14.

Gratz, K.L., \& Gunderson, J.G. (2006). Preliminary data on acceptance-based emotional regulation group intervention for deliberate self-harm among women with borderline personality disorder. Behavior Therapy, 37(1), 25-35.

Gratz, K.L., \& Roemer, L. (2004). Multidimensional assessment of emotion regulation and dysregulation: Development, factor structure, and initial validation of the difficulties in emotional regulation scale. Journal of Psychopathology and Behavioral Assessment, 26(1), 41-54.

Gratz, K.L., Sheree, C.D., \& Roemer, L. (2002). Risk factors for deliberate selfharm among college students. American Journal of Orthopsychiatry, 72(1), 128-140.

Green, Jaclyn Mae (2008). Predicting self-harm: Factors associated with self-injurious behaviors in college students. (Doctoral dissertation). Available from ProQuest 
Dissertations and Theses database. (Order No. 3305457).

Grilo, C.M., Becker, D.F., Fehon, D.C., Walker, M.L., Edell, W.S., \& McGlashan, T.H. (1956). Gender differences in personality disorders in psychiatrically hospitalized adolescents. American Journal of Psychiatry, 153, 1089-1091.

Grove, W.M., \& Tellegen, A. (1991). Problems in the classification of personality disorders. Journal of Personality Disorders, 5(1), 31-41.

Gunderson, J.G. (1991). Borderline personality disorder: A clinical guide. Washington, DC: American Psychiatric Press.

Gunderson, J.G., \& Sabo, A.N. (1993). The phenomenological and conceptual interface between borderline personality disorder and PTSD. American Journal of Psychiatry, 150(1), 19-27

Haines, J., Williams, C., Brain, K., \& Wilson, G. (1995). The psychophysiology of selfmutilation. Journal of Abnormal Psychology. 104(3), 471-489.

Hankin, B.L., \& Abela, J.R.Z. (2011). Nonsuicidal self-injury in adolescence: Prospective rates and risk factors in a $2 \frac{1}{2}$ year longitudinal study. Psychiatry Research, 186, 65-70.

Harned, M.S., Jackson, S.C., Comtois, K.A., \& Linehan, M.M. (2010). Dialectical behavior therapy as a precursor to PTSD treatment for suicidal and/or self-injuring women with borderline personality disorder. Journal of Traumatic Stress, 23(4), 421-429.

Harrington, R. (2001). Depression, suicide and deliberate self-harm in adolescence. British Medical Bulletin, 57, 47-60.

Harriss, L, Hawton, K., \& Zahl, D. (2005). Value of measuring suicidal intent in the 
assessment of people attending hospital following self-poisoning or self-injury. The British Journal of Psychiatry, 186, 60-66.

Hartman, D. (1996). Cutting among young people in adolescent units. Therapeutic Communities, 17, 5-17.

Hasking, P., Momeni, R., Swannell, S., \& Chia, S. (2008). The nature and extent of non-suicidal self-injury in a non-clinical sample of young adults. Archives of Suicide Research, 12, 208-218.

Haw, C., Houston, K., Townsend, E., \& Hawton, K. (2002). Deliberate self harm patients with depressive disorders: Treatment and outcome. Journal of Affective Disorders, 70(1), 57-65.

Hawton, K., Fagg, J., Simkin, S., Bale, E., \& Bond, A. (2000). Deliberate self-harm in adolescents in Oxford, 1985-1995. Journal of Adolescence, 23, 47-55.

Hawton, K., Rodham, K., Evans, E., \& Weatherall, R. (2002). Deliberate self harm in adolescents: Self-report survey in schools in England. British Medical Journal, $325(7374), 1207-1211$.

Hawton, K., Townsend, E., Arensman, E., Gunnell, D., Hazell, P., House, A., van Herringen, K. (2009). Psychosocial and pharmacological treatments for deliberate self harm, (Cochran Review). The Cochrane Library, 2.

Healey, A.C., Trepal, H.C., \& Emelianchik-Key, K. (2010). Nonsuicidal self-injury: Examining the relationship between diagnosis and gender. Journal of Mental Health Counseling, 32(4), 324-341.

Heath, N.L., Baxter, A.L., Toste, J.R., \& McLouth, R. (2010). Adolescents' willingness to access school-based support for non-suicidal self-injury. Canadian Journal 
of School Psychology, 25(3), 260-276.

Heath, N.L., Ross, S., Toste, J.R., Charlebois, A., \& Nedecheva, T. (2009). Retrospective analysis of social factors and nonsuicidal self-injury among young adults. Canadian Journal of Behavioural Science, 41(3), 180-186.

Heath, N.L., Toste, J.R., Nedecheva, T. \& Charlebois, A. (2008). An examination of nonsuicidal self-injury among college students. Journal of Mental Health Counseling, 30(2), 137-156.

Heath, N.L., Toste, J.R., Sornberger, M.J., \& Wagner, C. (2011). Teachers' perceptions of non-suicidal self-injury in the schools. School Mental Health, 3, 35-43.

Herman, J.L. (1992a). Complex PTSD: A syndrome in survivors of prolonged and repeated trauma. Journal of Traumatic Stress, 5(3), 377-391.

Herman, J.L. (1992b). Trauma and Recovery. New York, NY: Basic Books.

Herman, J., Perry, C., \& van der Kolk, B. (1989). Childhood trauma in borderline personality disorder. American Journal of Psychiatry, 146(4), 490-495.

Hilt, L.M., Cha, C.B., \& Nolen-Hoeksema, S. (2008). Nonsuicidal self-injury in young adolescent girls: Moderators of the distress-function relationship. Journal of Consulting and Clinical Psychology, 76(1), 63-71.

Himber, J. (1994). Blood rituals: Self-cutting in female psychiatric inpatients. Psychotherapy, 31, 620-630.

Hodges, S. (2003). Borderline personality disorder and posttraumatic stress disorder: Time for integration? Journal of Counseling and Development, 81(4), 409-417. Hodgson, S. (2004). Cutting through the silence: A sociological construction of 
self-injury. Sociological Inquiry, 74(2), 162-179.

Hoffman, R.M., \& Kress, V.E. (2010). Adolescent nonsuicidal self-injury: Minimizing client and counselor risk and enhancing client care. Journal of Mental Health Counseling, 32(4), 342-347.

Hooley, J. (2008). Self-harming behavior: Introduction to the special series on non-suicidal self-injury and suicide. Applied and Preventive Psychology, 12, $155-158$.

Huband, N., \& Tantam, D. (1999). Clinical management of women who self-wound: A survey of mental health professionals' preferred strategies. Journal of Mental Health, 8(5), 473-488.

Hulbert, C., \& Thomas, R. (2010). Predicting self-injury in BPD: An investigation of the experiential avoidance model. Journal of Personality Disorders, 24(5), 651-663.

Hurry, J. (2000). Deliberate self-harm in children and adolescents. International Review of Psychiatry, 12(1), 31-36.

Jacobson, C.M., Muehlenkamp, J.J., Miller, A.L., \& Turner, J.B. (2008). Psychiatric impairment among adolescents engaging in different types of deliberate selfharm. Journal of Clinical Child \& Adolescent Psychology, 37(2), 363-375.

Jeansonne, A. (2002). Loglinear models. Retrieved from userwww.sfsu.edu/ efc/classes/biol710//oglinear/Log\%20Linear\%20Models.htm

Jeffreys, S. (2000). 'Body Art' and social status: cutting, tattooing and piercing from a feminist perspective. Feminism \& Psychology, 10(4), 409-429.

Johnston, A., Cooper, J., Webb, R., \& Kapur, N. (2006). Individual and area level 
predictors of self-harm repetition. British Journal of Psychiatry, 189, 416-421.

Johnstone, L. (1997). Self-injury and the psychiatric response. Feminism and Psychology, 7, 421-426.

Jordan, J.V., Kaplan, A.G., Miller, J.B., Stiver, I.P., \& Surrey, J.L. (Eds.). (1991). Women's growth in connection: Writings from the Stone Center. New York, NY: Guilford Press.

Joyce, P.R., Light, K.J., Rowe, S.L., Cloninger, C.R., \& Kennedy, M.A. (2010). Self-mutilation and suicide attempts: Relationships to bipolar disorder, borderline personality disorder, temperament, and character. Australian and New Zealand Journal of Psychiatry, 44, 250-257.

Kafka, J.S. (1969). The body as transitional object: A psychoanalytic study of a selfmutilating patient. British Journal of Medical Psychology, 42, 207-213.

Kahan, J., \& Pattison, E. (1984). Proposal for a distinctive diagnosis: The deliberate self-harm syndrome (DSH). Suicide and Life-Threatening Behavior, 14, 17-35.

Kakhnovets, R., Young, H.L., Purnell, A.L., Huebner, E., \& Bishop, C. (2010). Self-reported experience of self-injurious behavior in college students. Journal of Mental Health Counseling, 32(4), 309-323.

Kazdin, A.E. (1984). Integration of psychodynamic and behavioral psychotherapies: Conceptual versus empirical synthesis. In H. Arkowitz \& S.B. Messner (Eds.), Psychoanalytic therapy and behavior therapy: Is integration possible? New York: Basic.

Kemperman, I., Russ, M.J., \& Shearin, E. (1997). Self-injurious behavior and mood regulation in borderline patients. Journal of Personality Disorders, 11(2), 


\section{$146-157$.}

Kernberg, O. (1976). Object-relations theory and clinical psychoanalysis. New York, NY:Aronson.

Kernberg, O. (1984). Diagnosis and clinical management of patients with suicide potential (pp.255-263). In Severe Personality Disorders: Psychotherapeutic Strategies. New Haven, CT: Yale University Press.

Kleespies, P.M., AhnAllen, C.G., Knight, J.A., Presskreischer, B., Barrs, K.L., Boyd, B.L., \& Dennis, J.P. (2011). A study of self-injurious and suicidal behavior in a veteran population. Psychological Services, 8(3), 236-250.

Klonsky, D. (2007a). The functions of deliberate self-injury: A review of the evidence. Clinical Psychology Review, 27, 226-239.

Klonsky, D. (2007b) Non-suicidal self-injury: An introduction. Journal of Clinical Psychology: In Session, 63(11), 1039-1043.

Klonsky, D., \& Moyer, A. (2008). Childhood sexual abuse and non-suicidal selfinjury: Meta-analysis. The British Journal of Psychiatry, 192, 166-170.

Klonsky, D., \& Muehlenkamp, J. (2007). Self-injury: A research review for the practitioner. Journal of Clinical Psychology: In Session, 63(11), 1045-1056.

Klonsky, D., Oltmann, T., \& Turkheimer, E. (2003). Deliberate self-harm in a nonclinical population: Prevalence and psychological correlates. American Journal of Psychiatry, 160(8), 1501-1508.

Knoke, D., \& Burke, P.J. (1980). Log-linear models. Thousand Oaks, CA: Sage. Kocourkova, J., \& Koutek, J. (2005). Self-destructiveness spectrum in adolescence - 
risk behavior, self-mutilation, suicidal attempts. [Slovak]. Psychologia a Patopsychologia Dietata, 40(4), 374-379.

Kohut, H. (1971). The analysis of self. New York, NY: International Universities Press.

Lang, A.J., Rodgers, C.S., Laffaye, C.S., Satz, L.E., Dresselhaus, T.R., \& Stein, M.D. (2003). Sexual trauma, posttraumatic stress disorder and health behaviors. Behavioral Medicine, 28, 150-158.

Lang, C.M., \& Sharma-Patel, K. (2011). The relationship between childhood maltreatment and self-injury: A review of the literature and conceptualization and intervention. Trauma, Violence, \& Abuse, 12(1), 23-37.

Laye-Gindhu, A., \& Schonert-Reichl, K. (2005). Nonsuicidal self-harm among community adolescents: Understanding the "whats" and "whys" of self-harm. Journal of Youth and Adolescence, 34(5), 447-457

Lazarus, A.A. (1976). Multimodal behavioral therapy. New York, NY: Springer.

Lazarus, A.A. (1997). Brief but comprehensive psychotherapy: The multi-modal way. New York, NY: Springer.

Leibenluft, E., Gardner, D., \& Cowdry, R. (1987). The inner experience of the borderline self-mutilator. Journal of Personality Disorders, 1(4), 317-324.

Levenkron, S. (1998). Cutting: Understanding and overcoming self-mutilation. New York, NY: Norton.

Levy, L.H. (1963). Psychological interpretation. New York, NY: Holt, Rinehart \& Winston.

Levy, K.N., Yeomans, F.E., \& Diamond, D. (2007). Psychodynamic treatments of self-injury. Journal of Clinical Psychology: In Session, 63(11), 1105-1120. 
Lieb, K., Zanarini, M.C., Schmahl, C., Linehan, M.M., \& Bohus, M. (2004).

Borderline personality disorder. The Lancet, 364(9432), 453-461.

Liebling, H., Chipchase, H., \& Velangi, R. (1997). An evaluation of nurse training and support needs: Working with women patients who harm themselves in a special hospital. Issues in Criminological and Legal Psychology, 29 47-56.

Linehan, M.M. (1993). Cognitive-behavioral treatment of borderline personality disorder. New York, NY: Guilford.

Linehan, M.M., Armstrong, H.E., Suarez, A., Allmon, D., \& Heard, H.L. (1991). Cognitive behavioral treatment of chronically parasuicidal borderline patients. Archives of General Psychiatry, 48(12), 1060-1064.

Linehan, M.M., Comtois, K.A., Murray, A.M., Brown, M.Z., Gallop, R.J., Heard, H.L., Korslund, K.E., Tutek, D.A., Reynolds, S.K., \& Lindenboim, N. (2006). Twoyear randomized controlled trial and follow-up of dialectical behavior therapy vs. therapy by experts for suicidal behaviors and borderline personal disorder. Archives of General Psychiatry, 63(7), 757-766.

Lloyd-Richardson, E. (2008). Adolescent nonsuicidal self-injury: Who is doing it and why? Journal of Developmental and Behavioral Pediatrics, 29(3), 216-218.

Lowry, R. Log-linear analysis for an AXBXC contingency table. Retrieved from http://faculty.vassar.edu/lowry/abc.html

Ludolph, P.S., Westen, D., Misle, B., Jackson, A., Wixom, J., \& Wiss, F.C. (1990). The borderline diagnosis in adolescents: Symptoms and developmental history. American Journal of Psychiatry, 147, 470-476. 
Lundh, L.G., Karim, J., \& Quilisch, E. (2007). Deliberate self-harm in 15-year-old adolescents: A pilot study with a modified version of the Deliberate Self-Harm Inventory. Scandinavian Journal of Psychology, 48(1), 33-41.

Magnall, J., \& Yurkovich, E. (2008). A literature review of deliberate self-harm. Perspectives in Psychiatric Care, 44(3), 175-184.

Marchetto, M. (2006). Repetitive skin-cutting: Parental bonding, personality, and gender. Psychology and Psychotherapy: Theory, Research and Practice, $79,445-459$.

Matsumoto, T., Azekawa, T., Yamaguchi, A., Asami, T., \& Iseki, E. (2004). Habitual self-mutilation in Japan. Psychiatry and Clinical Neurosciences, $58,191-198$.

Matsumoto, T., Imamura, F., Chiba, Y., Katsumata, Y., Kitani, Y., \& Masahiko, T. (2008). Prevalences of lifetime histories of self-cutting and suicidal ideation in Japanese adolescents: Differences by age. Psychiatry and Clinical Neurosciences, 62(3), 362-364.

Matsumoto, T., Yamaguchi, A., Chiba, Y., Asami, T., Iseki, E., \& Hirayasu, Y. (2005). Self-burning versus self-cutting: Patterns and implications of self-mutilations; A preliminary study of differences between self-cutting and self-burning in a Japanese juvenile detention center. Psychiatry and Clinical Neurosciences, 59, $62-69$.

Mazelis, R. (1990). What is SIV about? Self-inflicted violence. The Cutting Edge, l(1), 1.

Mazelis, R. (1992). SIV: Searching for Allies. The Cutting Edge, 3(3), 1-10. 
McIntyre, S.M., \& Schwartz, R.C. (1998). Therapists' differential countertransference reactions toward clients with major depression or borderline personality disorder. Journal of Clinical Psychology, 54(7), 923-931.

McLane, J. (1996). The voice on the skin: Self-mutilations and Merleau-Ponty's theory of language. Hypatia, 11(4), 107-121.

Meichenbaum, D. (1977). Cognitive behavior modification: An integrative approach. New York, NY: Plenum Press.

Meijer, M., Goedhart, A.W., \& Treffers, P.D.A. (1998). The persistence of borderline personality disorder in adolescence. Journal of Personality Disorders, 12, 13-22. Menninger, K.A. (1938). Man against himself. New York, NY: Harcourt, Brace \& World.

Messer, S.B., \& Winokur, M. (1981). Therapeutic common principles: Are commonalities more apparent than real? American Psychologist, 36, 1547-1548.

Messner, J.M., \& Fremouw, W.J. (2007). A critical review of explanatory models for self-mutilating behaviors in adolescents. Clinical Psychology Review, 28, 162178.

Michelman, J.D., Eicher, J.B., \& Michelman, S.O. (1991). Adolescent dress: 1. Dress and body markings of psychiatric outpatients and inpatients. Adolescence, 26, $375-385$.

Miller, A.L., Muehlenkamp, J.J., \& Jacobson, C.M. (2008). Fact or fiction: Borderline personality disorder in adolescents. Clinical Psychology Review, 28, 969-981. Miller, A.L., \& Smith, H.L. (2008). Adolescent non-suicidal self-injurious behavior: The latest epidemic to assess and treat. Applied and Preventive Psychology, 
$12,178-188$.

Miller, D. (1994). Women who hurt themselves. New York, NY: Basic Books.

Miller, D. (1996). Challenging self-harm through transformation of the trauma story. Sexual Addiction and Compulsivity, 3, 213-227.

Milnes, D., Owens, D., \& Blenkiron, P. (2002). Problems reported by self-harm patients: Perception, hopelessness and suicidal intent. Journal of Psychosomatic Research 53, 819-822.

Monsen, J., Odland, T., Faugli, A., Daae, E. \& Eilertsen, D. (1995). Personality disorders and psychosocial changes after intensive psychotherapy: A prospective follow-up study of an outpatient psychotherapy project, 5 years after end of treatment. Scandinavian Journal of Psychology, 36, 256-268.

Muehlenkamp, J. (2005). Self-injurious behavior as a separate clinical syndrome. American Journal of Orthopsychiatry, 75(2), 324-333.

Muehlenkamp, J. (2006). Empirically supported treatments and general therapy guidelines for non-suicidal self-injury. Journal of Mental Health Counseling, 28(2), 166-185.

Muehlenkamp. J.J., Ertelt, T.W., Miller, A.L., \& Claes, L. (2011). Borderline personality symptoms differentiate non-suicidal and suicidal self-injury in ethnically diverse adolescent outpatients. Journal of Child Psychology and Psychiatry, 52(2), 148-155.

Muehlenkamp, J.J., \& Gutierrez, P.M. (2004). An investigation of differences between self-injurious behavior and suicide attempts in a sample of adolescents. Suicide and Life Threatening Behavior, 34, 12-23. 
Muehlenkamp. J.J., Walsh, B.W., \& McDade, M. (2010). Preventing non-suicidal self-injury in adolescents: The signs of self-injury program. Journal of Youth and Adolescence, 39, 306-314.

Murray, J. (1993). Relationship of childhood sexual abuse to borderline personality disorder, and multiple personality disorder. Journal of Psychology, 127(6), $657-677$.

Nehls, N. (1999). Borderline personality disorder: The voice of patients. Research in Nursing \& Health, 22(4), 285-293.

Nicholson, C. (2004). Creating the self through self-harm. Therapeutic Communities, 25(1), 31-42.

Nixon, M.K., Cloutier, P., \& Jansson, S.M. (2008). Nonsuicidal self-harm in youth: A population-based survey. Canadian Medical Association Journal, 178(3), 306-312.

Nock, M.K. (2009a). Understanding non-suicidal self-injury: Origins, assessment, and treatment. Washington, DC: American Psychological Association.

Nock, M.K. (2009b). Why do people hurt themselves? New insights into the nature and functions of self-injury. Current Directions in Psychological Science, 18(2), $78-83$.

Nock, M.K., \& Favazza, A.R. (2009). Nonsuicidal self-injury: Definition and Classification. In M.K. Nock (Ed.) Understanding non-suicidal self-injury: Origins, assessment, and treatment (pp.9-18). Washington, DC: American Psychiatric Press.

Nock, M., \& Prinstein, M. (2004). A functional approach to the assessment of self- 
mutilative behavior. Journal of Consulting and Clinical Psychology, 72(5), 885890.

Nock, M., \& Prinstein, M. (2005). Contextual features and behavioral functions of selfmutilation among adolescents. Journal of Abnormal Psychology, 114(1), 140146.

Noll, J.G., Horowitz, L.A., Bonanno, G.A., Trickett, P.K. \& Putnam, F.W. (2003). Revictimization and self-harm in females who experienced childhood sexual abuse: Results from a prospective study. Journal of Interpersonal Violence, 18(12), 1452-1471.

Ochberg, F.M. (1991). Post-traumatic therapy. Psychotherapy, 28(1), 5-15.

O’Connor, R.C., Rasmussen, S., \& Hawton, K. (2010). Predicting depression, anxiety, and self-harm in adolescents: The role of perfectionism and acute life stress. Behaviour Research and Therapy, 48(1), 52-59.

Offer, D., \& Barglow, P. (1960). Adolescent and young adult self-mutilation incidents in a general psychiatric hospital. Archives of General Psychiatry, 3, 194-204.

Ogundipe, L.O. (1999). Suicide attempts vs. deliberate self-harm. British Journal of Psychiatry, 175, 90.

Oliver, C., Hall, S., \& Murphy, G. (2005). The early development of self-injurious behaviour: Evaluating the role of social reinforcement. Journal of Intellectual Disability Research, 49(8), 591-599.

Owens, D., Horrocks, J., \& House, A. (2002). Fatal and non-fatal repetition of selfharm: Systematic review. British Journal of Psychiatry, 181,193-199.

Pao, P.N. (1969). The syndrome of delicate self-cutting. British Journal of Medical 
Psychology, 42, 195-206.

Parfitt, A. (2005). On aggression turned against the self. Psychoanalytic Psychotherapy, 19, 160-173.

Pattison, E.M., \& Kahan, J. (1983). The deliberate self harm syndrome. American Journal of Psychiatry, 140, 867-872.

Penn, J.V., Esposito, C.L., Schaeffer, L.E., Fritz, G.K., \& Spirito, A. (2003). Suicide attempts and self-mutilative behavior in a juvenile correctional facility. Journal of the American Academy of Child and Adolescent Psychiatry, 42, 1-14.

Perry, J.C., \& Herman, J.I. (1993). Trauma and defense in the etiology of borderline personality disorder. In J. Paris (Ed.), Borderline personality disorder: Etiology and Treatment (pp. 123-140). Washington, DC: American Psychiatric Press.

Perseius, K.I., Kaver, A., Ekdahl, S., Asberg, M., \& Samuelsson, M. (2007). Stress and burnout in psychiatric professionals when starting to use dialectical behavioural therapy in the work with young self-harming women showing borderline personality symptoms. Journal of Psychiatric and Mental Health Nursing, 14, 635-643.

Pitman, R.K. (1990). Self-mutilation in combat-related PTSD. American Journal of Psychiatry, 147(1), 123-124.

Platt, S., Bille-Brahe, U., Kerkof, A., Schmidtke, A., Bjerke, T., Crept, P., DeLeo, D., Haring, C., Lonnqvist, J., Michel, K., Philippe, A., Pommereau, X., Querejets, I., Salander-Renberg, E., Temesvary, B., Wasserman, D., \& Samaio F. (1992). 
Parasuicide in Europe: the SHO/EURO multicentre study on parasuicide. Acta Psychiatria Scandinavia 85, 97-104.

Podovoll, E.M. (1969). Self-mutilation within a hospital setting: A study of identity and social compliance. British Journal of Medical Psychology, 42, 213-231.

Pope, K.S., \& Tabachnick, B.G. (1995). Recovered memories of abuse among therapy patients: A national survey. Ethics \& Behavior, 5(3), 237-248.

Poznanski, J.J., \& McLennan, J. (1995). Conceptualizing and measuring counselors' theoretical orientation. Journal of Counseling Psychology, 42(4), 411-422.

Raine, W.J.B. (1982). Self-mutilation. Journal of Adolescence, 5, 1-13.

Ray, E.M. (2007). A multidimensional analysis of self-mutilation in college students. (Doctoral dissertation) Available from ProQuest Dissertations and Theses database. (Order No. 3277611).

Rissanen, M.L., Kylma, J., Laukkanen, E. (2008). Descriptions of self-mutilation among Finnish adolescents: A qualitative descriptive inquiry. Issues in Mental Health Nursing, 29(3), 331.

Rodham, K., Hawton, K., \& Evans, E. (2004). Reasons for deliberate self-harm: Comparison of self-poisoners and self-cutters in a community sample of adolescents. Journal of the American Academy of Child and Adolescent Psychiatry, 43(1), 80-87.

Rodriguez, G., \& Maritza, G. (2007). Frequency and phenomenology of selfinflicted injuries in Colombian women with eating disorders. [Spanish]. Revista Colombiana de Psiquiatria, 34(3), 343-354. 
Romans, S.E., Martin, J.L., Anderson, J.C., Herbison, P.G., \& Mullen, P.E. (1995). Sexual abuse in childhood and deliberate self-harm. American Journal of Psychiatry, 152(9), 1336-1342.

Rosenthal, R.J., Rinzler, C., Walsh, R., \& Klausner, E. (1972). Wrist-cutting syndrome: The meaning of a gesture. American Journal of Psychiatry, $128,1363-1368$.

Ross, R.R., \& McKay, H.B. (1979). Self-mutilation. Lexington, MA: Lexington Books.

Ross, S., \& Heath, N. (2002). A study of the frequency of self-mutilation in a community sample of adolescents. Journal of Youth and Adolescence, 31(1), $67-77$.

Ross, S., \& Heath, N. (2003). Two models of adolescent self-mutilation. Suicide and Life-Threatening Behavior, 33(3), 277-287.

Roth, A.S., Ostroff, R.B., \& Hoffman, R.E. (1996). Naltrexone as a treatment for repetitive self-injurious behavior: An open-label trial. Journal of Clinical Psychiatry, 57(6), 233-237.

Rowling, J. (1999). Harry Potter and the Chamber of Secrets. New York, NY: Scholastic.

Russ, M.J. (1992). Self-injurious behavior in patients with borderline personality disorder: Biological perspectives. Journal of Personality Disorders, 6, 64-81.

Russ, M.J., Roth, S.D., Kakuma, T., Harrison, K. and Hull, J.W. (1994). Pain perception in self-injurious borderline patients: Naloxone effects. Biological Psychiatry, 35(3), 207-209. 
Ryle, A. (2004). The contribution of cognitive analytic therapy to the treatment of borderline personality disorder. Journal of Personality Disorders, 18, 3-35.

Sachsse, U., von der Heyde, S., \& Huether, G. (2002). Stress regulation and selfmutilation. American Journal of Psychiatry, 159, 672.

Sacks, M.B., Flood, A.M., Dennis, M.F., Hertzberg, M.A., \& Beckham, J.C. (2008). Self-mutilative behaviors in male veterans with posttraumatic stress disorder. Journal of Psychiatry Research, 42, 487-494.

Sansone, R.A., Gaither, G.A., \&Songer, D.A. (2001). Self-harm behaviors and mental healthcare utilization among sexually abused males: A pilot study. General Hospital Psychiatry, 23, 97-101.

Sansone, R.A., Gaither, G.A., \& Songer, D.A. (2002). Self-harm behaviours across the life cycle: A pilot study of inpatients with borderline personality disorder. Comprehensive Psychiatry, 43(3), 215-218.

Santa-Mina, E.E. (2010). Self-harm intentions: Can they be distinguished based upon a history of childhood physical and sexual abuse? Canadian Journal of Nursing Research, 42(4), 122-143.

Saxe, G., Chawla, N., \& van der Kolk, B. (2002). Self-destructive behavior in patients with dissociative disorders. Suicide and Life-Threatening Behavior, 32(3), 313-319.

Selby, E.A., Anestis, M.D., \& Joiner, T.E. (2008). Understanding the relationship between emotional and behavioral dysregulation: Emotional cascades. Behaviour Research and Therapy, 46(5), 593-611.

Shaw-Welch, S., Kuo, J.R., Sylvers, P., Chittams, J., \& Linehan, M.M. (2003). 
Correlates of parasuicidal behaviors in women meeting criteria for borderline personality disorder. Poster session presented at the $27^{\text {th }}$ annual meetings of the Association for the Advancement of Behavior Therapy, Boston, MA.

Sher, L., \& Stanley, B. (2009). Biological models of non-suicidal self-injury. In M.K. Nock (Ed.). Understanding non-suicidal self-injury: Origins, assessment, and treatment. Washington, D.C.: American Psychological Association.

Simeon, D., Stanley, B., Frances, A., Mann, J.J., Winchel, R., \& Stanley, M. (1992). Self-mutilation in personality disorders: Psychological and biological correlates. American Journal of Psychiatry, 149, 221-227.

Simpson, A., \& Porter, L. (1981). Self mutilation in children and adolescents. Bulletin of the Menninger Clinic, 45, 428-438.

Simpson, M.A. (1976). The phenomenology of self-mutilation in a general hospital setting. The Canadian Psychiatric Association Journal, 20(6), 429-434.

Simpson, M.A. (1980). Self-mutilation as indirect self-destructive behavior. In N.L. Farberow (Ed.), The many faces of suicide: self-destructive behavior (pp.257283). New York, NY: McGraw-Hill.

Skegg, K. (2005). Self-harm. The Lancet, 366, 1471-1483.

Skegg, K., Nada-Raja, S., Dickson, N., Paul, C., \& Williams, S. (2003). Sexual orientation and self-harm in men and women. American Journal of Psychiatry, 160(3), 541-546.

Soloff, P.H., Lynch, K.G., Kelly, T.M., Malone, K.M., \& Mann, J.J. (2000). Characteristics of suicide attempts of patients with major depressive episode and borderline personality disorder: A comparative study. American Journal of 
Psychiatry, 157(4), 601-608.

Stanley, B., Gameroff, M., Michalsen, V., \& Mann, J. (2001). Are suicide attempters who self-mutilate a unique population? The American Journal of Psychiatry, 158(3), 427-432.

Stirn, A., \& Hinz, A. (2008). Tattoos, body piercings, and self-injury: Is there a connection? Investigations on a core group of participants practicing body modification. Psychotherapy Research, 18(3), 326-333.

Stone, M.H. (1993). Long-term outcomes in personality disorders. British Journal of Psychiatry, 162(3), 299-313.

Strong, M. (1998). A Bright Red Scream. New York, NY: Penguin Books.

Suyemoto, K. (1998). The functions of self-mutilation. Clinical Psychology Review, 18, $531-554$.

Suyemoto, K.L. \& MacDonald, M.L. (1995). Self-cutting in female adolescents. Psychotherapy, 32(1), 162-171.

Swann, W.B., Hixon, J.G., Stein-Seroussi, A., \& Gilbert, D.T. (1990). The fleeting gleam of praise: Cognitive processes underlying behavior reactions to selfrelevant feedback. Journal of Personality and Social Psychology, 59, 17-26.

Swanson, J.L. (2006). Man-hunt: The twelve-day search for Lincoln's killer. New York, NY: Harper Collins

Tabachnick, B.G., \& Fidell, L.S. (2007). Using multi-variate statistics $\left(5^{\text {th }}\right.$ ed.). Boston, MA: Allyn \& Bacon.

Taiminen, T.J., Kallio-Soukainen, K., Nokso-Koivisto, H., Kaljonen, A., \& Helenius, 
H. (1998). Contagion of deliberate self-harm among adolescent inpatients. Journal of the American Academy of Child and Adolescent Psychiatry, 37(2), 211-217.

Tantam, D., \& Whittaker, J. (1992). Personality disorder and self-wounding. British Journal of Psychiatry, 161, 451-464.

Taylor, B. (2003). Exploring the perspectives of men who self-harm. Learning in Health and Social Care, 2(2), 83-91.

Taylor, T.L., Hawton, K., Fortune, S., \& Kapur, N. (2010). Attitudes towards clinical services among people who self-harm: Systematic review. British Journal of Psychiatry, 194(2), 104-110.

Trepal, H.C. (2010). Exploring self-injury through a relational cultural lens. Journal of Counseling \& Development, 88, 492-4993.

Trippany, R.L., Helm, H.M., \& Simpson, L. (2006). Trauma reenactment: Rethinking borderline personality disorder when diagnosing sexual abuse survivors. Journal of Mental Health Counseling, 28(2), 95-110.

Tuisku, V., Pelkonen, M., Kiviruusu, O., Karlsson, L., Ruuttu, T., \& Marttunen, M. (2009). Factors associated with deliberate self-harm behavior among depressed adolescent outpatients. Journal of Adolescence, 32(5), 1125-1136.

Turell, S., \& Armsworth, M. (2000). Differentiating incest survivors who self-mutilate. Child Abuse and Neglect, 24(2), 237-249.

Umans, Leslie P. (1998). Countertransference in the treatment of child victims of sexual abuse (Doctoral dissertation). Available from ProQuest Dissertations and Theses database. (Order No. 9826220). 
Vajani, M., Annest, J., Crosby, A., Alexander, J., \& Millet, L. (2007). Nonfatal and fatal self-harm injuries among children ages 10-14 years- United States and Oregon, 2001-2003. Suicide and Life-Threatening Behavior, 37(5), 493-506.

van der Kolk, B. (1989). The compulsion to repeat the trauma: Re-enactment, revictimization, and masochism. Psychiatric Clinics of North America, $12,389-411$.

van der Kolk, B. (1994). The body keeps the score: Memory and the evolving psychobiology of posttraumatic stress. Harvard Review of Psychiatry, 1(5), 253-265.

van der Kolk, B., McFarlane, A., \& Weisaeth, L. (Eds). (1996). Traumatic stress: The effects of overwhelming experience on mind, body, and society. New York, NY: Guilford Press.

van der Kolk, B., Perry, J., \& Herman, J. (1991). Childhood origins of self-destructive behavior. American Journal of Psychiatry, 148, 1665-1671.

Velez, K. (2007). Clinical correlates of self-mutilation in individuals diagnosed with borderline personality disorder (Doctoral dissertation). Available from ProQuest Dissertations \& Theses. (Order No. 3282358).

Wachter, T., Murphy, S., Kennerley, H., \& Wachter, S. (2009). A preliminary study examining childhood maltreatment, dissociation, and self-injury in psychiatric outpatients. Journal of Trauma \& Dissociation, 10(3), 261-275.

Walsh, B. (2006). Treating self-injury: A practical guide. New York, NY: Guilford Press.

Walsh, B., \& Rosen, P. (1985). Self-mutilation and contagion: An empirical test. 
American Journal of Psychiatry, 142(1), 119-120.

Walsh, B., \& Rosen, P. (1988). Self-mutilation: Theory, research and treatment. New York, NY: Guilford.

Warm, A., Murray, C., \& Fox, J. (2003). Why do people self-harm? Psychology, Health \& Medicine, 8, 71-79.

Webb, L. (2002). Deliberate self-harm in adolescence: A systematic review of psychological and psychosocial factors. Journal of Advanced Nursing, 38(3), 235-244.

Wedig, M.M., \& Nock, M.K. (2007). Parental expressed emotion and adolescent selfinjury. Journal of the American Academy of Child and Adolescent Psychiatry, 46(9), 1171-1178.

Weierich, M.R., \& Nock, M.K. (2008). Posttraumatic stress symptoms mediate the relation between childhood sexual abuse and nonsuicidal self-injury. Journal of Consulting and Clinical Psychology, 76(1), 39-44.

Weismoore, J.T., \& Esposito-Smythers, C. (2010). The role of cognitive distortion in the relationship between abuse, assault, and non-suicidal self-injury. Journal of Youth \& Adolescence, 39, 281-290.

Welch, S.S., Sylvers, P., Linehan, M.M., Chittams, J., \& Rizvi, S.L. (2008). Emotional responses to self-injury imagery among adults with borderline personality disorder. Journal of Consulting and Clinical Psychology, 76(1), $45-51$.

Whipple, R., \& Fowler, J.C. (2011). Affect, relationship schemas, and social cognition: Self-injuring borderline personality disorder inpatients. Psychoanalytic 
Psychology, 28(2), 183-195.

White, V.E., Trepal-Wollenzier, H., \& Nolan, J.M. (2002). College students and self injury: Intervention strategies for counselors. Journal of College Counseling, $5(2), 105-113$.

Whitlock, J., Eckenrode, J., \& Silverman, D. (2006). Self-injurious behaviors in a college population. Pediatrics, 117(6), 1939-1948.

Whitlock, J., Powers, J., \& Eckenrode, J. (2006). The virtual cutting edge: The internet and adolescent self-injury. Developmental Psychology, 42(3), 407-417.

Wiederman, M.W., Sansone, R.A., \& Sansone, L.A. (1999). Bodily self-harm and its relationship to childhood abuse among women in a primary care setting. Violence Against Women, 5(2), 155-163.

Wilkinson, P., \& Goodyer, I. (2011). Non-suicidal self injury. European Child and Adolescent Psychiatry, 20, 103-108.

Winchel, R.A., \& Stanley, M. (1991). Self-injurious behavior: A review of the behavior and biology of self-mutilation. American Journal of Psychiatry, 148, 306-316.

Winnicott, D. (1953). Transitional objects and transitional phenomena: A study of the first not-me possession. International Journal of Psycho-analysis, 34, 89-97.

Wise, M.L. (1990). Adult self-injury as a survival response in victim-survivors of childhood abuse. Journal of Chemical Dependency Treatment, 3(1), 185-201.

Witta, E.L. (1997). Chi-square or loglinear modeling: Is there a difference? Paper presented at the annual meeting of the southwest educational research association (Austin, TX, January 23-25, 1997).

Wolfradt, U., Veith, C., Jany, C., \& Frank, D. (2002). Depersonalization and self- 
mutilation: An empirical study. [German]. Zeitschrift fur Klinische Psychologie, Psychiatrie und Psychotherapie, 50(1), 75-90.

Wong, J., Stewart, S., Ho, S., \& Lam, T. (2007). Risk factors associated with suicide attempts and other self-injury among Hong Kong adolescents. Suicide and Life Threatening Behavior, 37(4), 453-466.

Woods, J. (1988). Layers of meaning in self-cutting. Journal of Child Psychotherapy, 14, 51-60.

Wurr, C.J., \& Partridge, I.M. (1996). The prevalence of a history of childhood sexual abuse in an acute adult inpatient population. Child Abuse and Neglect, 20(9), 867-872.

Yates, T.M. (2004). The developmental psychology of self-injurious behavior: Compensatory regulation in posttraumatic adaptation. Clinical Psychology Review, 24(1), 35-75.

Yates, T.M., Luthar, S.S., \& Tracy, A.J. (2008). Nonsuicidal self-injury among "privileged" youths: Longitudinal and cross-sectional approaches to developmental process. Journal of Consulting and Clinical Psychology, 76(1), $52-62$.

Yip, K. (2006). A strengths perspective in working with an adolescent with self-cutting behaviors. Child and Adolescent Social Work Journal, 23(2), 134-146.

You, J., Leung, F., Fu, K., \& Lai, C.M. (2011). The prevalence of nonsuicidal self-injury and different subgroups of self-injurers in Chinese adolescents. Archives of Suicide Research, 15(1), 75-86.

Zahl, D.L. \& Hawton, K. (2004). Repetition of deliberate self-harm and subsequent 
suicide risk: Long-term follow-up study of 11,583 patients. British Journal of Psychiatry, 185, 70-75.

Zakiullah, N., Saleem, S., Sadiq, S., Sani, N., Shahpurwala, M., Shamim, A., Yousu, A., Kahn. M., \& Nayani, P. (2008). Deliberate self-harm: Characteristics of patients presenting to a tertiary care hospital in Karachi, Pakistan. Crisis: The Journal of Crisis Intervention and Suicide Prevention, 29(1), 32-37.

Zanarini, M.C. (1993). Borderline personality disorder as an impulse spectrum disorder. In J. Paris (Ed.), Borderline personality disorder: etiology and treatment (pp.6786). Washington, DC: American Psychiatric Press.

Zanarini, M.C., Frankenberg, F., Hennen, J., Reich, B., \& Silk, K. (2006). Axis I co-morbidity in clients with borderline personality disorder: Prediction of the 10-year course of borderline personality disorder. American Journal of Psychiatry, 163(5), 827-832.

Zanarini, M.C., Frankenburg, F.R., Khera, G.S., \& Bleichmar, J. (2001). Treatment histories of borderline inpatients. Comprehensive Psychiatry, 42(2), 144-150.

Zanarini, M.C., Frankenburg, F.R., Reich, D.B., Fitzmaurice, G., Weinberg, I., \& Gunderson, J.G. (2008). The 10-year course of physically self-destructive acts reported by borderline patients and axis II comparison subjects. Acta Psychiatrica Scandinavica, 177, 177-184.

Zanarini, M.C., Gunderson, J.G., Frankenburg, F.R., \& Chauncey, D.L. (1990). Discriminating borderline personality disorder from other axis II disorders. American Journal of Psychiatry, 147(2), 161-167.

Zila, L.M., \& Kiselica, M.S. (2001). Understanding and counseling self-mutilation in 
female adolescents and young adults. Journal of Counseling and Development, 79, 46-79.

Zlotnick, C., Mattia, J., \& Zimmerman, M. (1999). Clinical correlates of selfmutilation in a sample of general psychiatric patients. The Journal of Nervous \& Mental Disease, 187(5), 296-301.

Zlotnick, C., Mattia, J., \& Zimmerman, M. (2001). Clinical features of survivors of sexual abuse with major depression. Child Abuse \& Neglect, 25, 357-367.

Zoroglu, S.S., Tuzun, U., Sar, V., Tutkin, H., Savas, H., Ozturk, M., Alyanak, B., \& Kora, M. (2003). Suicide attempt and self-mutilation among Turkish high school students in relation with abuse, neglect, and dissociation. Psychiatry and Clinical Neurosciences, 57, 119-126.

Zweig-Frank, H., Paris, J., \& Guzder, J. (1994). Psychological risk factors for dissociation and self-mutilation in female patients with borderline personality disorder. Canadian Journal of Psychiatry, 39, 259-264. 


\section{Appendix A}

\section{CONSENT AND INFORMATION FORM}

*The following information is required by the Institutional Review Board (IRB) at West Virginia University (WVU). To proceed directly to the short survey, please scroll to the bottom of the page and read the participation and consent paragraph.

Principal Investigator: Bartee, James

Department: WVU HR\&E, Counseling Psychology

Tracking Number: (unassigned)

\section{Study Title:}

May $19^{\text {th }}, 2010$ - Behavior that hurts: Theoretical orientation, terminology, and diagnosis of clients who self-injure.

\section{Co-Investigator:}

S. Rowan Flamm, M.A.

Pre-doctoral Intern

\section{Contact Person}

In the event you experience any side effects of injury related to this research, you should contact Dr. Bartee at (304) 293-2227. If you have any questions, concerns, or complaints about this research, you can contact Dr. Bartee or Rowan Flamm at (412) 606-1326.

For information regarding your rights as a research subject, to discuss problems, concerns, or suggestions related to the research, to obtain information or offer input about the research, contact the Office of Research Compliance at (304) 293-7073.

\section{Introduction}

You have been asked to participate in this research study, which has been explained to you by Dr. James Bartee and Rowan Flamm. This study is being conducted in the Department of Human Resources \& Education: Counseling Psychology at West Virginia University, under the supervision of Dr. Bartee, Ph.D.

\section{Purpose}

The purpose of this study is to learn more about the attitudes and beliefs regarding specific client behaviors by their treating psychologists. WVU expects to survey 276 participants in total to participate in this study.

\section{Description of Procedures}

It will take approximately five minutes for you to complete. You will be asked to fill out a short questionnaire regarding your theoretical orientation, preferred terminology and preferred diagnosis regarding a specific client behavior. You do not have to answer all the questions. 


\section{Risks and Discomforts}

There are no known or expected risks from participating in this study, except for the mild frustration associated with answering the questions.

\section{Alternatives}

You do not have to participate in this study.

\section{Benefits}

You may not receive any direct benefit from this study. The knowledge gained from this study may eventually benefit others.

\section{Financial Considerations}

There are no fees for participating in this study. There are also no financial incentives for participation.

\section{Confidentiality}

No identifying information regarding individual participation will be recorded during this study. You will not be asked for your name, email address, internet service provider (ISP), internet network address, or any other identifying information.

\section{Persons/Organizations receiving the information:}

- The research site carrying out this study.

- The members and staff of any Institutional Review Board (IRB) that oversees this research study.

\section{The following information will be used:}

Answers to survey questions including but not limited to: participant theoretical orientation in psychotherapy, attitudes, beliefs, and practices regarding specific client behavior.

\section{The information is being disclosed for the following reasons:}

- Review of your data for quality assurance purposes

- Publication of study results (without identifying you)

- Other research purposes such as developing a better understanding of diagnosis and behavior

You may cancel this authorization at any time by discontinuing study participation. There is no identifying information collected and therefore any information previously submitted cannot be withdrawn. 


\section{Voluntary Participation}

Participation in this study is completely voluntary.

Upon clicking below to continue to the survey, you are implying your consent to participate in this research.

You are free to withdraw your consent to participate in this study at any time. You may simply exit out of the survey and close your internet browser.

Thank you for your attention and participation in this short survey.

S. Rowan Flamm, M.A.

Pre-doctoral Intern

James Bartee, Ph.D.

Chair

Department of Counseling Psychology 


\section{Appendix B}

Dear Prospective Participant,

We would like to invite you to participate in my doctoral research study survey investigating the diagnostic labels and terminology used to describe client/patients who engage in a range of specific behaviors. You are receiving this email via your professional organization's list serve and if you wish to participate please follow the link below or cut and past the following URL into your web browser http://www.surveymonkey.com/s/XF2L9KD

It will take FIVE minutes to complete the six question survey. Your involvement in this project will be kept as confidential as legally possible. All data will be reported in the aggregate. You must be 18 years of age or older to participate. No names or identifying information will be gathered during the study and your responses cannot be linked to your identity, which is anonymous to the researchers.

Your participation is completely voluntary. You may skip any question that you do not wish to answer and you may discontinue at any time.

There are no expected risks or costs to you from participating in this research study however, if a problem should arise as a result of your participation, please contact the researchers with your concerns.

If you choose to participate by following the link provided you will be taken to a webbased survey maintained by Survey Monkey. In order to take the survey you must read and agree to the "informed consent" document that will be the first page you see upon beginning the survey. By clicking on the "next" key on the first page you are implying your consent to participate in the research.

If you have any questions regarding this email or the research study please contact either of the persons named below.

This research project has been approved by the Institutional Review Board for the protection of human research participants at West Virginia University.

Thank you for considering our request and we appreciate your time and thought if you choose to participate in this study.

Co-Investigator: Rowan Flamm, M.A. $\quad$ Principal Investigator: James Bartee, Ph.D.

Email: flammsc@muohio.edu

Phone: (412) 606-1326

Email: james.bartee@mail.wvu.edu

Phone: (304) 293-4447 


\section{Appendix C}

\section{Survey}

1. Do you have experience treating clients who use deliberate violence against one's body that results in tissue damage, is socially and culturally unacceptable, is not intended to cause death, is not the result of cognitive deficits such as autism or mental retardation and is not part of an accepted cultural or spiritual practice?

If yes, please continue to question 2 .

If no, thank you for your time, you do not need to answer any further questions.

2. Years in practice post-doctorate:

3. Gender: please check answer

Male ___ Female ___ Transgender

4. Age

5. Rank in order of most to least frequent, the term you use to describe the behavior of clients who use deliberate violence against one's body that results in tissue damage, is socially and culturally unacceptable, is not intended to cause death, is not the result of cognitive deficits such as autism or mental retardation and is not part of an accepted cultural or spiritual practice.

Self-Harm Self-Injury Self-Mutilation

Non-Suicidal Self-Injury___ Other (please specify) 
6. Rank in order of most to least frequent, the diagnosis you give to clients who engage in the above behaviors.
Anxiety
Borderline Personality Disorder
Depression
Dissociative Identity Disorder
Post Traumatic Stress Disorder

Both Borderline Personality Disorder and Post Traumatic Stress Disorder

Other (please specify)

7. Rank your primary, secondary, and tertiary theoretical orientations:

Biological ___ Cognitive-Behavioral ___ Feminist ___ Eclectic

Humanistic/Existential ___ Integrative ___ Interpersonal

Psychodynamic/Psychoanalytic ___ Systems ___ Other (please specify) __ 


\section{Appendix D}

The variables examined by log linear models are all treated as 'response variables' therefore log-linear models only demonstrate association between variables (Jeansonne, 2002). Jeansonne (2002) further explains that log-linear modeling "involves fitting models to the observed frequencies in the cross-tabulation of categorical variables" (p.2). Similar to the chi-squared analysis, log-linear analysis examines the ratio of expected and observed frequencies. Instead of using the standard, two variable, chisquare distribution, a Poisson distribution is used for three or more categorical variables. The Poisson distribution shows the likelihood of independent events occurring in a given time and space compared to the expected distribution. Log-linear analysis, allows for the testing of the odds ratio of more than one categorical variable. A person may fall into a specific category for variable 1 which may have a relationship with a specific category in variable 2 which together may have a relationship to a category of variable 3 . The pattern of association among variables can be described by a set of odds and by one or more odds ratios derived from them. Once expected frequencies are obtained, "we then compare models that are hierarchical to one another and choose a preferred model" which is the model that most closely fits the data (Jeansonne, 2002, p.4). Instead of the chisquared statistic $\left(\mathrm{X}^{2}\right)$ the likelihood ratio $\left(\mathrm{L}^{2}\right)$ is used because it is the statistic that is minimized in maximum likelihood estimation and can be partitioned uniquely for more powerful test of conditional independence in multi-way tables (Knoke \& Burke, 1980). The formula for the $\mathrm{L}^{2}$ statistic is as follows:

$$
\mathrm{L}^{2}=2 \sum \mathrm{f}_{\mathrm{ij}} \ln \left(\mathrm{f}_{\mathrm{ij}} / \mathrm{F}_{\mathrm{ij}}\right)
$$


As $L^{2}$ increases, the more the expected frequencies depart from the actual cell entries indicating that the model does not fit the observed data well. Essentially, the larger the $\mathrm{L}^{2}$ statistic, the more likely the rejection of the model based on fit.

For all analysis within this dissertation, the alpha level will be set at .05 .

Table D1

Contingency table for 3 categorical variables.

\begin{tabular}{lll}
\hline Therapist Gender & Terminology & Preferred Diagnosis \\
\hline Female, Male, Transgender & $\begin{array}{l}\text { Self-injury, Deliberate self- } \\
\text { harm, Self-mutilation, Non- } \\
\text { suicidal self-injury, Other }\end{array}$ & DID, PTSD, Other \\
& & \\
\hline
\end{tabular}

The following is the equation for the hierarchical approach to log-linear modeling. This model exists when lesser complex interrelationships also exist within the model. For example, a two-way effect existing within a potential three-way interaction.

$\operatorname{Ln}\left(\mathrm{F}_{\mathrm{ij}}\right)=\mu+\lambda_{\mathrm{i}}{ }^{\mathrm{A}}+\lambda_{\mathrm{j}}{ }^{\mathrm{B}}+\lambda_{\mathrm{k}}{ }^{\mathrm{C}}+\lambda_{\mathrm{ij}}{ }^{\mathrm{AB}}+\lambda_{\mathrm{ik}}{ }^{\mathrm{AC}}+\lambda_{\mathrm{jk}}{ }^{\mathrm{BC}}+\lambda_{\mathrm{ijk}}{ }^{\mathrm{ABC}}$

In this model:

$\operatorname{Ln}\left(\mathrm{F}_{\mathrm{ij}}\right)$ represents the natural log of the frequency counts in each cell $\mu=$ grand mean

$\lambda$ represents the "effects" that the variables have on each cell frequency,

$\lambda_{\mathrm{i}}^{\mathrm{A}}=$ the main effect for variable $\mathrm{A}$ (therapist gender)

$\lambda_{j}{ }^{B}=$ the main effect for variable B (preferred terminology)

$\lambda_{\mathrm{k}}{ }^{\mathrm{C}}=$ the main effect for variable $\mathrm{C}$ (preferred diagnosis)

$\lambda_{\mathrm{ij}}{ }^{\mathrm{AB}}=$ the 2-way interaction of variables $\mathrm{A}$ (therapist gender) and $\mathrm{B}$ (preferred terminology) 
$\lambda_{\mathrm{ik}}{ }^{\mathrm{AC}}=$ the 2-way interaction of variables A (therapist gender) and C (preferred diagnosis)

$\lambda_{\mathrm{jk}}{ }_{\mathrm{BC}}^{\mathrm{BC}}=$ the 2-way interaction effect of variables B (preferred terminology) and C (preferred diagnosis)

$\lambda_{\mathrm{ijk}}{ }^{\mathrm{ABC}}=$ the 3-way interaction of variables A (therapist gender), B (preferred terminology), and $\mathrm{C}$ (preferred diagnosis) together. 
Appendix E

Table E1

ThcomboIngEcl ${ }^{a} \times$ TermnoNssi $^{b}$ Crosstabulation

\begin{tabular}{llrrrrr}
\hline & & \multicolumn{3}{c}{ TermnoNssi } & \\
\cline { 3 - 6 } & & & & \multicolumn{2}{c}{ Self } & \\
\hline ThcomboIngE & Missing & Self Harm Self Injury & Mutilation & Total \\
\cline { 3 - 6 } & Missing & 2 & 2 & 0 & 0 & 4 \\
& CBT & 4 & 43 & 37 & 19 & 103 \\
& Feminist & 1 & 11 & 7 & 0 & 19 \\
& Humanistic & 0 & 5 & 1 & 3 & 9 \\
& Interpersonal & 1 & 13 & 7 & 0 & 21 \\
& Dynamic & 4 & 11 & 13 & 4 & 32 \\
& Integrative or & 6 & 42 & 37 & 13 & 98 \\
& Eclectic & & & & 39 & 286 \\
\hline
\end{tabular}

a. Theoretical orientation without biological, system, or other and the combination of eclectic and integrative.

b. Terminology without NSSI or other.

Table E2

FEMCombo ${ }^{a}$ Frequencies

\begin{tabular}{llrrrr}
\hline & & & & Cumulative \\
& & Frequency & Percent Valid Percent & Percent \\
\hline Valid & First Choice & 21 & 6.0 & 35.6 & 35.6 \\
& Second Choice & 11 & 3.2 & 18.6 & 54.2 \\
& Third Choice & 27 & 7.8 & 45.8 & 100.0 \\
& Total & 59 & 17.0 & 100.0 & \\
Missing & System & 289 & 83.0 & & \\
Total & 348 & 100.0 & & \\
\hline
\end{tabular}

a. Feminist orientation selected as primary, secondary, or tertiary. 
Table E3

ThcomboIngEcl ${ }^{a} \times$ DXNoDidOt ${ }^{b}$ Crosstabulations

\begin{tabular}{|c|c|c|c|c|c|c|c|c|c|}
\hline & \multicolumn{6}{|c|}{ DXNoDidOt } & \multirow[b]{2}{*}{ Total } & \\
\hline & & Missing & Anxiety & BPD & DEP PTS & & Both & & \\
\hline \multirow[t]{7}{*}{ ThcomboIngE } & Missing & 3 & 0 & 0 & 1 & 1 & 0 & 5 & \\
\hline & CBT & 7 & 10 & 59 & 13 & 4 & 13 & 106 & \\
\hline & Feminist & 2 & 5 & 2 & 0 & 8 & 2 & 19 & \\
\hline & Humanistic & 1 & 2 & 3 & 3 & 1 & 2 & 12 & \\
\hline & Interpersonal & 2 & 2 & 3 & 4 & 6 & 3 & 20 & \\
\hline & Dynamic & 2 & 1 & 15 & 3 & 8 & 4 & 33 & \\
\hline & $\begin{array}{l}\text { Integrative ol } \\
\text { Eclectic }\end{array}$ & r & 1 & 44 & 21 & 15 & 12 & 104 & \\
\hline \multicolumn{2}{|l|}{ Total } & 28 & 21 & 126 & 45 & 43 & 36 & 299 & \\
\hline \multicolumn{10}{|c|}{$\begin{array}{l}\text { a. Theoretical Orientation without biology, systems, or other and the combining of } \\
\text { eclectic and integrative. }\end{array}$} \\
\hline \multicolumn{10}{|c|}{ b. Diagnosis without DID or other. } \\
\hline \multicolumn{10}{|c|}{$\begin{array}{l}\text { Table E4 } \\
\text { TermnoNssi }{ }^{a} \text { x DXNoDidOt }{ }^{b} \text { Crosstabulation }\end{array}$} \\
\hline \multirow{2}{*}{\multicolumn{2}{|c|}{ TermnoNssi }} & \multicolumn{7}{|c|}{ DXNoDidOt } & \multirow[b]{2}{*}{ Total } \\
\hline & & Missing & Anxiety & BPD & DEP & & TSD & Both & \\
\hline \multicolumn{2}{|l|}{ Missing } & 6 & 1 & 9 & 1 & & 2 & 2 & 21 \\
\hline \multicolumn{2}{|l|}{ Self Harm } & 9 & 6 & 51 & 21 & & 20 & 17 & 124 \\
\hline \multicolumn{2}{|l|}{ Self Injury } & 7 & 12 & 49 & 13 & & 20 & 8 & 109 \\
\hline \multicolumn{2}{|l|}{ Self Mutilat } & 3 & 2 & 24 & 5 & & 2 & 6 & 42 \\
\hline \multicolumn{2}{|l|}{ Total } & 25 & 21 & 133 & 40 & & 44 & 33 & 296 \\
\hline
\end{tabular}

a. Terminology without NSSI or other.

b. Diagnosis without DID or other. 
Table E5

Chi-Square Tests Gender $x$ TermnoNssi ${ }^{b}$

\begin{tabular}{lrrr}
\hline & \multicolumn{2}{c}{ Asymp. Sig. } \\
& \multicolumn{1}{c}{ Value } & df & (2-sided) \\
\hline Pearson Chi-Square & $14.940^{\mathrm{a}}$ & 9 & .093 \\
Likelihood Ratio & 15.215 & 9 & .085 \\
Linear-by-Linear & 8.333 & 1 & .004 \\
Association & & & \\
N of Valid Cases & 310 & & \\
\hline
\end{tabular}

a. 8 cells $(50.0 \%)$ have expected count less than 5 . The minimum expected count is .06 .

b. Terminology without NSSI or other

Table E6

Chi-Square Tests Gender x DXNoDidOt ${ }^{b}$

Asymp. Sig.

\begin{tabular}{lrrr} 
& \multicolumn{1}{c}{ Value } & df & (2-sided) \\
\hline Pearson Chi-Square & $24.369^{\mathrm{a}}$ & 15 & .059 \\
Likelihood Ratio & 21.128 & 15 & .133 \\
Linear-by-Linear & .075 & 1 & .785 \\
Association & & & \\
N of Valid Cases & 323 & & \\
\hline
\end{tabular}

a. 12 cells $(50.0 \%)$ have expected count less than 5 . The minimum expected count is .07 .

b. Diagnosis without DID or other 
Table E7

AGECombo $^{a} \times$ TermnoNssi $^{b}$ Crosstabulation

\begin{tabular}{|c|c|c|c|c|c|c|}
\hline & \multicolumn{4}{|c|}{ TermnoNssi } & \multirow[b]{2}{*}{ Total } \\
\hline & & Missing & Self Harm & $\begin{array}{l}\text { Self } \\
\text { Injury }\end{array}$ & $\begin{array}{c}\text { Self } \\
\text { Mutilation }\end{array}$ & \\
\hline \multirow[t]{7}{*}{ AGEComb } & 24 to 30 years & 2 & 16 & 7 & 2 & 27 \\
\hline & 30 to 39 years & 2 & 30 & 17 & 2 & 51 \\
\hline & 40 to 49 years & 2 & 25 & 13 & 4 & 44 \\
\hline & 50 to 59 years & 9 & 32 & 38 & 14 & 93 \\
\hline & 60 to 69 years & 4 & 24 & 31 & 15 & 74 \\
\hline & 70 or more years & 1 & 5 & 3 & 3 & 12 \\
\hline & Not stated & 1 & 2 & 4 & 3 & 10 \\
\hline Total & & 21 & 134 & 113 & 43 & 311 \\
\hline
\end{tabular}

a. Age of clinician separated into categories.

b. Terminology without NSSI and other.

Table E8

Chi-Square Tests AGECombo x TermnoNssi

\begin{tabular}{lrrr}
\hline & & & Asymp. Sig. \\
& Value & df & (2-sided) \\
\hline Pearson Chi-Square & $27.371^{\mathrm{a}}$ & 18 & .072 \\
Likelihood Ratio & 28.200 & 18 & .059 \\
Linear-by-Linear & 11.306 & 1 & .001 \\
Association & & & \\
$\mathrm{N}$ of Valid Cases & 311 & & \\
\hline
\end{tabular}

a. 12 cells $(42.9 \%)$ have expected count less than 5 . The minimum expected count is .68 . 
Table E9

AGECombo x Diagnosis Crosstabulation

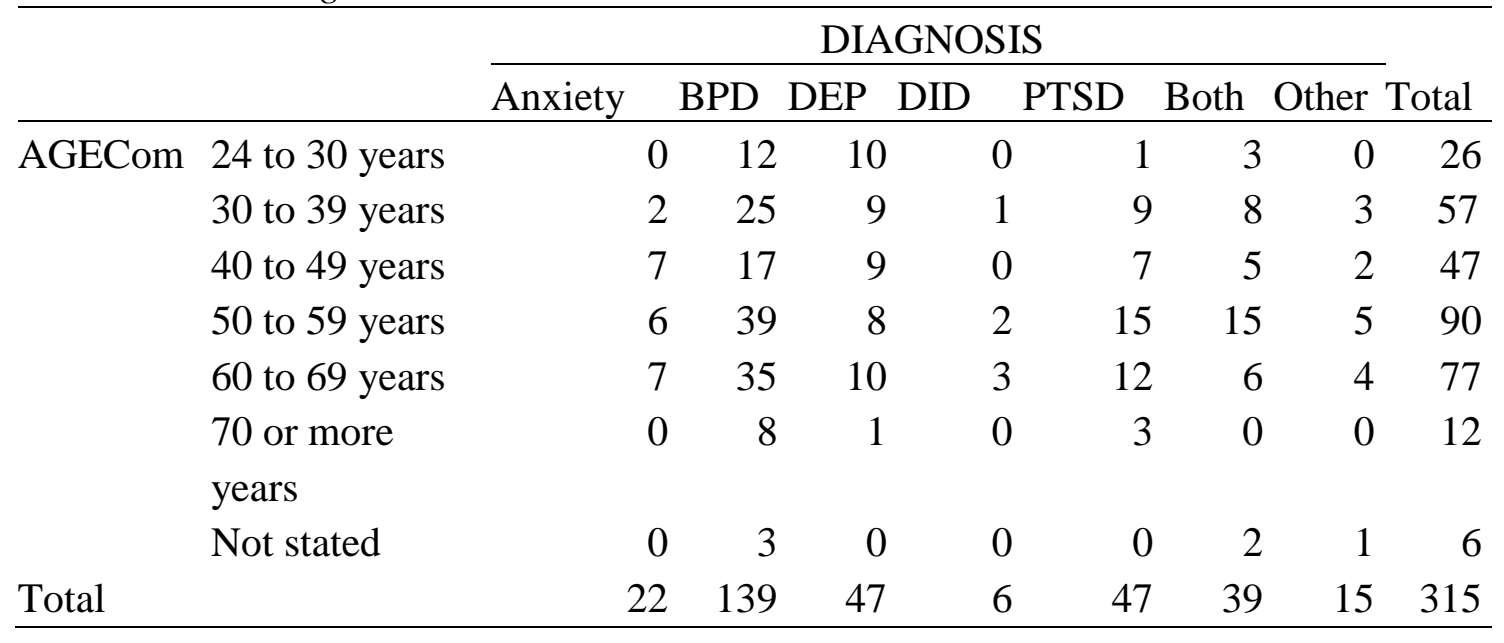

Table E10

Chi-Square Tests YRSPRACCom x DXNoDidOt

\begin{tabular}{|c|c|c|c|}
\hline & Value & $\mathrm{df}$ & $\begin{array}{l}\text { Asymp. Sig. } \\
\text { (2-sided) }\end{array}$ \\
\hline Pearson Chi-Square & 44.207 & 35 & .137 \\
\hline Likelihood Ratio & 44.634 & 35 & .128 \\
\hline Linear-by-Linear & 4.355 & 1 & .037 \\
\hline \multicolumn{4}{|l|}{ Association } \\
\hline $\mathrm{N}$ of Valid Cases & 325 & & \\
\hline
\end{tabular}


Table E11

YRSPRACCOM $^{a} \times$ TermnoNssi $^{b}$ Crosstabulation

\begin{tabular}{llrrrrr}
\hline & & \multicolumn{4}{c}{ TermnoNssi } & \\
\cline { 3 - 6 } & & & $\begin{array}{c}\text { Self } \\
\text { Missing }\end{array}$ & $\begin{array}{c}\text { Self } \\
\text { Hnjury }\end{array}$ & $\begin{array}{c}\text { Self } \\
\text { Mutilation }\end{array}$ & Total \\
\hline YRSPRACCo & less than 1 & 0 & 11 & 3 & 1 & 15 \\
& year & & & & & \\
& 1 to 5 years & 5 & 39 & 20 & 4 & 68 \\
& 6 to 10 years & 1 & 12 & 10 & 0 & 23 \\
& 11 to 15 years & 1 & 9 & 13 & 4 & 27 \\
& 16 to 20 years & 4 & 16 & 14 & 7 & 41 \\
& 21 to 30 years & 6 & 27 & 37 & 11 & 81 \\
& 31 or more & 4 & 20 & 15 & 16 & 55 \\
& No answer & 0 & 0 & 1 & 0 & 1 \\
& & 21 & 134 & 113 & 43 & 311 \\
\hline
\end{tabular}

Table E12

Chi-Square Tests YRSPRACCom x TermnoNssi

\begin{tabular}{|c|c|c|c|}
\hline & Value & df & $\begin{array}{c}\text { Asymp. Sig. } \\
\text { (2-sided) }\end{array}$ \\
\hline Pearson Chi-Square & $36.994^{\mathrm{a}}$ & 21 & .017 \\
\hline Likelihood Ratio & 39.692 & 21 & .008 \\
\hline Linear-by-Linear & 11.757 & 1 & .001 \\
\hline Association & & & \\
\hline $\mathrm{N}$ of Valid Cases & 311 & & \\
\hline
\end{tabular}

a. 13 cells $(40.6 \%)$ have expected count less than 5 . The minimum expected count is .07 . 
Table E13

Chi-Square TestsYRSPRACCom x DXNoDidOt

Asymp. Sig.

\begin{tabular}{rrrr} 
& Value & df & (2-sided) \\
\hline Pearson Chi-Square & $44.207^{\mathrm{a}}$ & 35 & .137
\end{tabular}

$\begin{array}{llll}\text { Likelihood Ratio } & 44.634 & 35 & .128\end{array}$

$\begin{array}{llll}\text { Linear-by-Linear } & 4.355 & 1 & .037\end{array}$

Association

$\mathrm{N}$ of Valid Cases

324

a. 26 cells $(54.2 \%)$ have expected count less than 5 . The minimum expected count is .07 . 